\title{
Speech and language impairments in behavioral variant frontotemporal dementia:
}

\section{A systematic review}

Amandine Geraudie, ${ }^{1,2}$ Petronilla Battista, ${ }^{1,3,4}$ Adolfo M. García, ${ }^{3,5,6,7}$, Isabel E. Allen, ${ }^{3,8}$ Zachary A. Miller, ${ }^{1}$ Maria Luisa Gorno-Tempini, ${ }^{1,3}$ Maxime Montembeault ${ }^{1 *}$

\footnotetext{
* Corresponding author: Maxime Montembeault, Ph.D., Memory and Aging Center, Department of Neurology, University of California San Francisco, 675 Nelson Rising Lane, Suite 190, San Francisco, CA, USA, 94158. Email: maxime.montembeault@gmail.com
} 
${ }^{1}$ Memory and Aging Center, Department of Neurology, University of California San Francisco, CA, USA

${ }^{2}$ Neurology Department, Toulouse University Hospital, Toulouse, France

${ }^{3}$ Global Brain Health Institute, University of California, San Francisco, USA

${ }^{4}$ Istituti Clinici Scientifici Maugeri IRCCS, Institute of Bari, Via Generale Nicola Bellomo, Bari, Italy

${ }^{5}$ Universidad de San Andrés, Buenos Aires, Argentina

${ }^{6}$ National Scientific and Technical Research Council (CONICET), Buenos Aires, Argentina

7 Departamento de Lingüística y Literatura, Facultad de Humanidades, Universidad de Santiago de Chile, Santiago, Chile

${ }^{8}$ Department of Epidemiology \& Biostatistics, University of California San Francisco, CA, USA 


\begin{abstract}
Although behavioral variant frontotemporal dementia (bvFTD) is classically defined by behavioral and socio-emotional changes, impairments often extend to other cognitive functions. These include early speech and language deficits related to the disease's core neural disruptions. Yet, their scope and clinical relevance remains poorly understood. This systematic review characterizes such disturbances in bvFTD, considering clinically, neuroanatomically, genetically, and neuropathologically defined subgroups. We included 181 experimental studies, with at least 5 bvFTD patients diagnosed using accepted criteria, comparing speech and language outcomes between bvFTD patients and healthy controls or between bvFTD subgroups. Results reveal extensive and heterogeneous deficits across cohorts, with (a) consistent lexico-semantic, orthographic, and prosodic impairments; (b) inconsistent deficits in motor speech and grammar; and (c) relative preservation of phonological skills. Also, preliminary findings suggest that the severity of speech and language deficits might be associated with global cognitive impairment, predominantly temporal or fronto-temporal atrophy and MAPT mutations (vs C9orf72). Although underrecognized, these impairments contribute to patient characterization and phenotyping, while potentially informing diagnosis and prognosis.
\end{abstract}

Keywords: behavioral variant frontotemporal dementia, speech, language, phonology, orthography, lexico-semantics, grammar, prosody, systematic review 
medRxiv preprint doi: https://doi.org/10.1101/2021.07.10.21260313; this version posted July 12, 2021. The copyright holder for this preprint

\section{Introduction}

The behavioral variant of frontotemporal dementia (bvFTD) is a neurodegenerative disorder characterized by a progressive decline in social cognitive functions and changes in personality and behavior (Neary et al., 1998; Rascovsky et al., 2011). Current diagnostic criteria include early behavioral disinhibition, apathy or inertia, loss of sympathy or empathy, stereotyped behaviour, hyperorality, dietary changes, deficits in executive functions and spared memory and visuo-spatial functions (Rascovsky et al., 2011). Yet, substantial deficits are being increasingly recognized in other domains. Crucially, these include speech and language deficits, which often emerge in early disease stages (Cheran et al., 2019) and affect daily functionality (Lima-Silva et al., 2015). To understand the scope and clinical relevance of these disruptions, we conducted the first systematic review of speech and language deficits in bvFTD, considering their relationship with clinical, neural, genetic, and neuropathological factors.

Beyond a brief mention of stereotypy of speech, current diagnostic criteria of bvFTD make no reference to speech and language. Yet, the article describing the criteria report specific speech and language deficits in as many $20 \%$ of patients (Rascovsky et al., 2011), in line with earlier characterizations highlighting altered speech output (aspontaneity or press of speech), stereotypies, echolalia, perseveration, and mutism (Neary et al., 1998). More recently, evidence from a large bvFTD sample (Saxon et al., 2017) shows that naming deficits are as frequent as hyperorality (a core diagnostic feature) in the sample informing Rascovsky's criteria (55\%) (Rascovsky et al., 2011). In bvFTD, speech and language symptoms extend to multiple language domains and go beyond executive dysfunction (Hardy et al., 2016). They can appear very early in the disease, even at pre-symptomatic stages (Cheran et al., 2019), and they worsen as disease progresses (Ash et al., 2019). They are related to damage in cerebral regions that are targeted in bvFTD as well as part of the speech and language brain networks (Hardy et al., 2016). They can also pose differential diagnosis challenges with language-predominant neurodegenerative diseases such as primary progressive aphasias (PPA) (Pozueta et al., 2019). Thus, the neglect of speech and language in bvFTD may hinder valuable opportunities for disease characterization and phenotyping, calling for comprehensive overviews of existing evidence.

Yet, no study has provided a comprehensive and systematic overview of speech and language in bvFTD. Although a few primary studies have focused on language symptoms in bvFTD, they most often include low sample sizes, given the low prevalence of this syndrome, or they only provide partial coverage of relevant language domains. Fortunately, multiple 
bvFTD reports also include language tests as part of their secondary outcome measures. A systematic review of all this evidence would provide a detailed account of speech and language in bvFTD, potentially revealing underexplored markers to complement diagnosis (especially in contexts lacking gold-standard pathological or genetic data), prognosis (as communication difficulties may influence behavioural changes (Harris et al., 2016)), and management (given that such difficulties increase caregiver burden (Savundranayagam et al., 2005).

The goal of this study is to systematically review the existing studies covering language functioning in bvFTD. First, we aim to determine the impaired and preserved language domains in bvFTD by reviewing studies comparing bvFTD patients to controls. Given the fact that we expect some heterogeneity in language outcomes in bvFTD patients, the second aim of this study is to investigate which bvFTD features are associated with more severe language impairments. To do so, we will review studies comparing patients' subgroups based on clinical (for example, according to severity of the global cognitive impairment), neural (for example, temporal vs. frontal atrophy), genetic (for example, no mutation, C9orf72, MAPT or GRN mutations), and neuropathological (for example, frontotemporal lobar degeneration tau [FTLD-tau] vs. FTLD-TDP) profiles. A better characterization of language profile in these patients may contribute to a more fine-grained phenotyping, differential diagnosis as well as prognosis in bvFTD patients.

\section{Methods}

This work was performed and reported following Preferred Reporting Items for Systematic Reviews and Meta-Analyses (PRISMA) guidelines (Page et al., 2021).

\subsection{Search strategy}

A systematic review of the literature was conducted on the following databases: PubMed, Embase, Web of Science, PsycINFO and Cochrane CENTRAL, with the help of a university librarian. In PubMed, the search was conducted with the following search terms: ("language disorders" (as a MeSH term), "Aphasia" (as a MeSH term), "language", "linguistic", "aphasia", "aphasic", "speech", "naming", "anomic", "anomia", "semantic", "semantics", "syntax", "syntactic", "prosody", "prosodic", "phonology", "phonological”, "discourse", "picture description", "fluency", "grammar", "agrammatism", "agrammatic", "writing”, "write”, “reading", "read”, “comprehension”, "repetition”, “dysarthria”, "spell”, "spelling", "communication", "word", "sentence", "verb", "verbal", "noun", "lexical", 
medRxiv preprint doi: https://doi.org/10.1101/2021.07.10.21260313; this version posted July 12, 2021. The copyright holder for this preprint

"lexicon”, "dyslexia", “dyslexic", "alexia", "alexic") AND ("bvFTD” or ("behavioral” or "behavioural") and ("frontotemporal lobar degeneration" (as a MeSH term) or "ftld") or (("behavioral" or "behavioural") and ("frontotemporal" or "fronto-temporal") and ("dementia" or "dementias" or "degeneration")) or (("behavioral" or "behavioural") and ("ftd")). The same terms were used for a generic search (without PubMed field tags) in other databases. The search was conducted on February $9^{\text {th }}$, 2020. Additionally, reference lists of identified papers were manually reviewed for additional relevant articles. Duplicates were removed and only published articles or articles in press were retained.

\subsection{Study selection}

Articles were selected by two independent raters (AG and MM) based on the following criteria: (i) article written in English; (ii) experimental study in humans (excluding reviews and animal studies); (iii) inclusion of at least five bvFTD patients (excluding FTDALS patients or general FTD group); (iv) bvFTD patients diagnosed with accepted international consensus criteria (Neary et al., 1998; Rascovsky et al., 2011) - in light of this criterion, articles published before 1998 have therefore been excluded; when the diagnostic approach was not clear, the corresponding author of the paper was contacted by email (in case of no response or unavailability of relevant information from the researchers, the study was excluded); (v) comparison group of interest (healthy controls or subgroups of bvFTD patients); (vi) report of the performance in a relevant speech or language domain for bvFTD patients alongside a statistical comparison between groups. We targeted the following speech and language domains: global language screening, motor speech (including motor speech examination and motor speech features extracted from connected speech), phonology (including phonological manipulation and repetition tests), orthography (including reading and writing tasks), lexico-semantics (including word retrieval, word comprehension, semantic knowledge and semantic features extracted from connected speech), grammar (including sentence comprehension and grammatical features extracted from connected speech), and prosody (including receptive and productive tasks). To determine inclusion, the two authors (AG, MM) separately reviewed first the titles and abstract and then the full-text papers. For studies in which there was a disagreement, consensus was reached through discussion between both authors. 
medRxiv preprint doi: https://doi.org/10.1101/2021.07.10.21260313; this version posted July 12, 2021. The copyright holder for this preprint

\subsection{Data extraction}

Our final selection comprised 181 papers (Figure 1), each of which was used to extract the following information: (i) bvFTD sample characteristics (sample size, mean age, mean disease duration, mean severity using Mini-Mental State Exam), (ii) sample size of the comparison group, (iii) language tests administered, (iv) results of statistical comparison for language measures, (v) participant's language, (vi) research or clinical center in which patients were recruited. Since the same patient cohort may have been used for multiple studies from a single research team, we flagged results on the exact same language measures from the same team and used a systematic approach to ensure exhaustivity and reduce population bias. First, we reported all studies (no matter the research center) in order to give a complete overview of the literature (Table 1). However, in the Results section and in Figure 2, if two or more studies from the same research center included the exact same language task, only the article with the largest sample of bvFTD patients was considered for interpretation.

\subsection{Study quality assessment}

The risk of bias in studies was assessed at the study level with an adapted version of the Newcastle Ottawa Scale (Wells et al., 2000), recommended for non-randomized studies, including case-control and cohort studies. We assessed each study for (i) sample representativeness, (ii) sample size, (iii) comparability between patients and controls, (iv) ascertainment of language symptoms, and (v) statistical quality (Supplementary material). For the interpretation of the total scores, ranging from 0 to 5 , studies were judged to be of low risk of bias ( $\geq 3$ points) or high risk of bias ( $<3$ points). Therefore, a higher score on this tool represents a lower risk of bias.

\section{Results}

\subsection{Impaired and preserved language domains in bvFTD}

From the 181 selected studies (Figure 1), 156 compared bvFTD to healthy control participants on at least one language measure (Table 1, Figure 2).

\subsubsection{Global language performance}

Language has been globally evaluated through measures from diverse batteries: the language subscale of the Addenbrooke Cognitive Examination Revised (ACE-R; including naming, comprehension, repetition, reading, and writing), the Aachen Aphasia Test (including detailed evaluation of spontaneous language, token tests, repetition, writing, naming and 
medRxiv preprint doi: https://doi.org/10.1101/2021.07.10.21260313; this version posted July 12, 2021. The copyright holder for this preprint

comprehension), the Language Aphasia Screening Test (LAST) (including picture naming, repetition, counting from 1 to 10, word-to-picture matching, and comprehension of instructions with three levels of complexity), the Sydney Language Battery (including naming, word-picture matching, picture-to-picture matching, and word repetition tasks), and the Consortium to Establish a Registry for Alzheimer's Disease (CERAD) language subtest (including verbal fluency and picture naming).

A global language impairment was found in bvFTD when using some global language batteries (language subscale of ACE-R: Lima-Silva et al., 2015; Oliver et al., 2015; Salimi et al., 2019, Aachen aphasia test: Van den Stock et al., 2015). However, other batteries failed to find any difference in bvFTD compared to controls (LAST: Johnen et al., 2018, the Sydney Language Battery: Hsieh et al., 2013 and the language subsection of CERAD: Semler et al., 2019). These mixed results may reflect differences in sample sizes between studies (Hsieh et al., 2013; Semler et al., 2019) or difference in the tasks included in these batteries (for example, LAST do not include reading and writing assessment but ACE-R language do).

\subsubsection{Motor speech}

Motor speech encompasses diverse mechanisms involved in planning, programming, controlling, coordinating, and executing speech production. Various aspects of this domain (e.g., voice sound, pronunciation, articulation, speech errors) can be assessed through highly controlled tasks or through connected speech.

\subsubsection{Motor speech examination}

Motor speech as assessed using controlled tasks seems relatively preserved in bvFTD. Vogel et al. extensively characterized motor speech signatures in 24 bvFTD using perceptual and acoustical analyses of tasks from the Progressive Aphasia Language Scale (saying the day of the week, sequential motion rate and alternating motion rate tasks (i.e., repeating /papa/ or /pataka/), pronouncing a sustained vowel). Objective and listener-based analysis showed that while motor speech is globally preserved, two-thirds of bvFTD showed more subtle motor speech changes (i.e., shorter phrases, longer pauses, strangled-strained voice and articulation difficulties, impaired diadochokinetic performance) (Vogel et al., 2017). Mandelli et al. also showed preserved verbal agility (Mandelli et al., 2016). 
medRxiv preprint doi: https://doi.org/10.1101/2021.07.10.21260313; this version posted July 12, 2021. The copyright holder for this preprint

\subsubsection{Motor speech through connected speech}

Despite partly contradictory evidence (Vogel et al., 2017), speech rate seems globally preserved in bvFTD (Ash et al., 2013; Gunawardena et al., 2010; Pressman et al., 2019; Wilson et al., 2010). Indeed, even in the infrequent reports showing decreased speech rate, this deficit disappears upon excluding long pauses (Ash et al., 2016). Consistently, compared with controls, bvFTD patients produce more frequent, variable, and extended silent pauses (Nevler et al., 2017; Vogel et al., 2017; Wilson et al., 2010), with no differences in the number of filled pauses and shorter speech segments (Nevler et al., 2017; Vogel et al., 2017). However, the rate of global speech errors (Ash et al., 2009, 2019; Gunawardena et al., 2010) and phonemic errors (Ash et al., 2013), as well as phonetic errors and distortions (Ash et al., 2013; Wilson et al., 2010) is similar between bvFTD patients and healthy persons.

\subsubsection{Phonology}

The term phonology refers to abstract categories capturing partial recurrent similarities between speech sounds. Phonology may be evaluated through sound manipulation or word/sentence repetition tasks.

\subsubsection{Phonological manipulation}

bvFTD patients showed preserved phonological abilities when assessed with minimal pairs discriminations of the PALPA3 (i.e. discriminating pairs of words that differ in a single phonemic consonant, for example, 'cut' and 'gut') (Hardy et al., 2016).

\subsubsection{Repetition tasks}

Repetition capacities are preserved for both words and sentences in bvFTD (Chen et al., 2018; Hardy et al., 2016; Mandelli et al., 2016; Viskontas et al., 2011; Vogel et al., 2017).

\subsubsection{Orthography}

Orthography refers to a system of conventions for reading or writing a language.

Reading appears impaired in bvFTD. Most studies used the National Adult Reading Test (NART), assessing irregular single word reading (Downey et al., 2015; Gregory et al., 2002; Snowden et al., 2008; Virani et al., 2013), and one study focused on non-word reading (Hardy et al., 2016). Decreased text-reading abilities have also been shown in bvFTD patients, with slower articulation rate, elevated number of pauses, and finally, longer and more variable pauses (Vogel et al., 2017; Yunusova et al., 2016). 
medRxiv preprint doi: https://doi.org/10.1101/2021.07.10.21260313; this version posted July 12, 2021. The copyright holder for this preprint

Writing, as investigated with the Graded difficulty Spelling Test (assessing spelling of orthographically ambiguous words which could plausibly be written in more than one way while retaining the same sound) is also impaired in bvFTD patients (Hardy et al., 2016).

\subsubsection{Lexico-semantics}

Lexico-semantics refers to the mapping of canonical conceptual information onto particular lexical units. This can be measured in both production and comprehension, with dedicated tasks tapping on sub-domains such as word retrieval, word comprehension, and semantic knowledge. Lexico-semantics can also be assessed more ecologically through connected speech tasks.

\subsubsection{Word retrieval}

Naming, as assessed using traditional tasks, is most frequently impaired in bvFTD patients. The most frequently used task was the Boston Naming Test (BNT), with 12 studies revealing impairments (Ash et al., 2016; Banks \& Weintraub, 2008; Couto et al., 2013; De Winter et al., 2016b; Fernandez-Duque \& Black, 2007; Lin et al., 2016; Peelle et al., 2008; Russo et al., 2014; Tan et al., 2015; Torralva et al., 2007; Whitwell et al., 2009; Wicklund et al., 2007) and six reporting preserved abilities (Chan et al., 2015; Gleichgerrcht et al., 2012; Kamminga et al., 2014; McKinnon et al., 2008; Rankin et al., 2007; Scherling et al., 2014). Overall, longer versions of the BNT (i.e., 30 or 60 items) seem more powerful to reveal deficits than shorter versions (i.e., 15 or 20 items), which provide mixed results. Using the DO-80 task, two studies showed impairment with the full-length version (Matuszewski et al., 2006; Piolino et al., 2007) but one study using the abbreviated version did not show any differences between the two groups (Rousseaux et al., 2010). Studies using the Graded Naming Test (GNT) provided mixed results, ranging from impaired (Downey et al., 2015; Gregory et al., 2002) to preserved (Snowden et al., 2008) performance.

Additional evidence suggests that naming deficits in bvFTD may be driven by specific lexical categories. Hardy et al. investigated verb naming and revealed a decreased performance bvFTD (Hardy et al., 2016). Indeed, action naming may be impaired despite preserved object naming abilities in bvFTD (Cotelli et al., 2006). As for famous face naming (Cotelli et al., 2006), results are mixed as some studies showed altered capacities (Clague et al., 2005; Kamminga et al., 2015) whereas others found no differences (Clague et al., 2005; Keane et al., 2002). Finally, studies using non-verbal stimuli also provided mixed findings: two studies of odor naming provided diverging results (Luzzi et al., 2007; Orasji et al., 2016), 
medRxiv preprint doi: https://doi.org/10.1101/2021.07.10.21260313; this version posted July 12, 2021. The copyright holder for this preprint

while studies of sound naming showed no difference in comparison with healthy controls (Chow et al., 2010; Lin et al., 2016).

\subsubsection{Word comprehension}

Word comprehension, as assessed using word-picture matching tasks, appears impaired in bvFTD (Chen et al., 2018; Cotelli et al., 2006; Downey et al., 2015; Rhee et al., 2001; Rogers et al., 2006; Sturm et al., 2018; Vignando et al., 2020; Vogel et al., 2017), although other studies did not show any difference between bvFTD and healthy controls (Irish et al., 2011; Luzzi et al., 2007; Miller et al., 2012; Stopford et al., 2012). Of note, these studies included fewer patients, and with shorter disease duration (Table 1). Patients with bvFTD were also impaired on a word definition task (Downey et al., 2015).

\subsubsection{Verbal semantic knowledge}

Verbal semantic processing through semantic associations (matching two semantically-linked words together) is most frequently impaired in bvFTD (Cousins et al., 2016; Rogers et al., 2006 vs. Cosentino et al., 2006 with only 12 patients in this study).

Semantic knowledge (as assessed through the categorical or attribute knowledge of objects or public events) is also decreased in bvFTD (Irish et al., 2016; Johnson et al., 2011; Matuszewski et al., 2006). Deficits have also been revealed through tasks tapping on analogy processing (Krawczyk et al., 2008; Morrison et al., 2004) as well as proverb or idiom comprehension (Luzzi et al., 2020; Reyes et al., 2018). Semantic categorization (defining which item belongs to a target category) is also impaired in bvFTD (Hughes et al., 2011; Koenig et al., 2006 vs. Grossman et al., 2004). As for synonyms matching task, results are more mixed: some studies show impaired performance (Fletcher et al., 2016) while others show preserved abilities (Hsieh et al., 2012). More specifically, Hardy et al. showed that performance is spared for abstract synonyms and impaired for concrete synonyms in these patients (Hardy et al., 2016). Emotional semantics is also impaired in bvFTD (Eckart et al., 2012; Hsieh et al., 2012). Finally, semantic difficulties in bvFTD also impact more global tasks like judging or understanding the organization of actions in scripts (for example, for 'going fishing': 'open can of worms / place worm on hook') (Cosentino et al., 2006; Farag et al., 2010). 
medRxiv preprint doi: https://doi.org/10.1101/2021.07.10.21260313; this version posted July 12, 2021. The copyright holder for this preprint

\subsubsection{Non-verbal semantic knowledge}

Although not a linguistic domain per se, non-verbal semantic knowledge is a critical domain to assess in parallel with verbal semantic knowledge. This allows disentangling the extent to which deficits in lexico-semantic tasks are driven by lexical (e.g. word category) vs. conceptual (e.g. semantic features) factors. Non-verbal semantic knowledge is most frequently impaired in bvFTD patients when assessed using pictorial semantic associations (matching two semantically associated pictures) (Ash et al., 2013; Gleichgerrcht et al., 2012; Gunawardena et al., 2010; Rogers et al., 2006; Tan et al., 2015; Torralva et al., 2007 vs. McKinnon et al., 2008; Orasji et al., 2016 with less than nine patients in each of these studies). Semantic knowledge of odours is also globally impaired in bvFTD (Luzzi et al., 2007; Magerova et al., 2014; Orasji et al., 2016 vs. Omar et al., 2013) without difference for flavors (Omar et al., 2013).

Studies on semantic knowledge for sounds provide mixed results: some showed impairments (Clark et al., 2017; Fletcher et al., 2015, 2016) while others revealed no difference compared to controls (Chow et al., 2010; Lin et al., 2016). Semantic knowledge for people (face-name matching tasks) are also mixed: one study revealed lower scores in bvFTD (De Winter et al., 2016b) while two studies failed to reveal any difference with controls (Clague et al., 2005; Keane et al., 2002).

\subsubsection{Lexico-semantics through connected speech}

Lexico-semantic abilities using connected speech provide mixed results in bvFTD. Word-level measures are comparable to healthy controls, while discourse-level measures are typically impaired.

In terms of word-level features, the use of lexical categories (nouns, pronouns, verbs, open-class words, closed-class words) does not differ between bvFTD and controls (Ash et al., 2009, 2013, 2016; Hardy et al., 2016; Wilson et al., 2010), except for quantifiers, which occur less commonly in bvFTD patients' discourse (Ash et al., 2016). Average lexical frequency of the words and nouns used is also comparable to healthy controls (Hardy et al., 2016; Wilson et al., 2010). Considering errors, results are mixed for semantic paraphasias and word-finding difficulties (Ash et al., 2006; Wilson et al., 2010: no difference vs. Rousseaux et al., 2010: more frequent).

In terms of discourse-level features, accuracy of the discourse (as judged through global organization, complexity or the ability to remain on topic) seems to be preserved when 
medRxiv preprint doi: https://doi.org/10.1101/2021.07.10.21260313; this version posted July 12, 2021. The copyright holder for this preprint

investigated with a global index (Gola et al., 2015; Mendez et al., 2014), but more finegrained examinations reveal impairments in accurately reporting events and precisely guiding communication (with insufficient or superfluous responses) (Ash et al., 2006; Healey et al., 2019; Healey et al., 2015). As for connectedness, even if measures of action or evaluation clauses and temporal organization revealed no difference (Gola et al., 2015), other studies revealed impairments in global connectedness, maintenance of a theme and discourse organization (Ash et al., 2006; Rousseaux et al., 2010).

\subsubsection{Grammar}

Grammar refers to the system of Sequencing of hierarchically organized morphosyntactic patterns, determining the well-formedness or ill-formedness of sentences and words. It underlies both sentence comprehension and production (although no study investigated sentence production in bvFTD). Grammatical features can also be extracted from connected speech.

\subsubsection{Sentence comprehension}

Overall, in bvFTD, sentence comprehension was most frequently preserved when using simple sentence comprehension tasks, but impaired when using more complex experimental sentence comprehension assessments.

Most studies on simple sentence comprehension employed sentence-picture matching tasks (selecting which of many pictures matches a given sentence). Four of them showed preserved abilities (Cotelli et al., 2007; Hardy et al., 2016; Johnson et al., 2011; Rosen et al., 2004) and two showed decreased scores (Charles et al., 2014; Mandelli et al., 2016). Other studies used instructions tasks (e.g., asking the patient to follow instructions that are variable in length and linguistic complexity such as 'Point to a square' or 'Put the small red square on the large blue circle'). Three showed preserved performance (Gleichgerrcht et al., 2012; Torralva et al., 2007; Vogel et al., 2017) and one showed impaired abilities (Giovagnoli et al., 2008). Finally, some studies assessed sentence comprehension using comprehension questions on sentences: two showed preserved abilities (Ash et al., 2009; Peelle et al., 2008) and one revealed difficulties with comparative questions (Smits et al., 2015).

Contrary to simple sentence comprehension tasks, those employing more complex materials have mainly revealed deficits, such as difficulties during a discourse task (Grossman et al., 2005; Luzzi et al., 2020; Rousseaux et al., 2010) or with ambiguous sentences (McMillan et al., 2013; Spotorno et al., 2015a). Other authors have found a partial sensitivity 
medRxiv preprint doi: https://doi.org/10.1101/2021.07.10.21260313; this version posted July 12, 2021. The copyright holder for this preprint

to syntactic violations (Murray et al., 2007; Peelle et al., 2007). For example, patients were impaired in grammatically judging an unknown verb used with correct or violated grammatical rules (Murray et al., 2007). They were also less sensitive to syntactic errors (as, for example, 'The book is being closely pick/picked by the group of curious students' or 'The friend is being reunion/met in the shopping mall entrance') (Peelle et al., 2007).

\subsubsection{Grammar through connected speech}

Connected speech analyses reveal preserved grammar in bvFTD patients (Ash et al., 2013, 2016, 2019; Gunawardena et al., 2010; Rousseaux et al., 2010; Vogel et al., 2017; Wilson et al., 2010). More precisely, patients do not significantly differ from controls in utterance length (Ash et al., 2013; Wilson et al., 2010), word and clause complexity (Ash et al., 2013, 2016, 2019; Gunawardena et al., 2010; Wilson et al., 2010), and correct and incorrect sentences (Ash et al., 2013; Rousseaux et al., 2010; Vogel et al., 2017; Wilson et al., 2010).

\subsubsection{Prosody}

Prosody is a supra-segmental feature of language using modulation of intonation, rhythm, and intensity to convey emotional or linguistic distinctions.

Receptive prosody appears impaired in bvFTD. The most frequently used tasks are emotion labelling tasks, in which the participant must listen to stimuli with distinct prosodic features and pick an emotional label (e.g., anger, sadness, happiness). Most studies revealed global impaired recognition of prosody using vocal signals or sentences (Keane et al., 2002; Shany-Ur et al., 2012; Snowden et al., 2008), although two studies did not find any significant difference in bvFTD patients (Omar et al., 2011; Rankin et al., 2009). Another study suggested that this impairment in bvFTD may depend on emotion type: impaired recognition of happiness, sadness, surprise, and anger but preserved recognition of fear and disgust (Keane et al., 2002).

Fewer studies have assessed prosody during speech production in bvFTD. These studies showed reduced stress (Vogel et al., 2017), mixed results for pitch modulation (altered in Nevler et al., 2017 but preserved in Pressman et al., 2019 and Vogel et al., 2017), and preserved intensity (Pressman et al., 2019). 
medRxiv preprint doi: https://doi.org/10.1101/2021.07.10.21260313; this version posted July 12, 2021. The copyright holder for this preprint

\subsection{Language profiles according to bvFTD subgroups}

From the 181 studies assessing language in bvFTD (Figure 1), 26 compared patient subgroups divided upon four criteria (Table 2): clinical, neural, genetic or neuropathological subgroups. Such comparisons aim to identify which features may be more associated with language impairments and potentially informing on the heterogeneity of language profiles across the bvFTD population.

\subsubsection{Comparisons between clinically defined bvFTD subgroups}

Few clinical factors influencing language profiles in bvFTD have been identified so far. First, bvFTD patients with impaired global cognitive performance had more severe deficits in picture naming (Manes et al., 2011; Roca et al., 2013), sentence comprehension (Torralva et al., 2009) and semantic knowledge (Roca et al., 2013). Furthermore, patients with poverty of speech had more pressure of speech, tangentiality (i.e. digressions, free associations of ideas), derailment, and clanging (associations of words based upon sounds) than those without this feature (Mendez et al., 2017). The level of confidence of the diagnosis (probable vs. possible bvFTD) provided conflicting results. While Kipps et al. found a difference in picture naming in patients with a diagnosis of probable bvFTD versus possible bvFTD (Kipps et al., 2009), Borroni et al. and Kramer et al. did not find any significant difference in the language profile of probable and possible bvFTD patients (Borroni et al., 2015; Kramer et al., 2018).

None of the other investigated clinical factors had an impact on language measures. Global language skills do not seem affected by the presence of absence of parkinsonism (Park et al., 2017). Naming abilities are not influenced by the presence or absence of memory deficits (Bertoux et al., 2014, 2016; Fernández-Matarrubia et al., 2017), moral judgment profiles (Gleichgerrcht et al., 2011) or a medical history of vascular disease (Torralva et al., 2015) or traumatic brain injury (Deutsch et al., 2015). Finally, sentence comprehension seems unaffected by age at onset (Ye et al., 2015) or profession (Massimo et al., 2019).

\subsubsection{Comparisons between neuroanatomically defined bvFTD subgroups}

First, a frontal dominant vs. temporo-limbic dominant atrophy pattern seems to impact sentence comprehension. Frontal predominant bvFTD show more difficulties in the Token task than temporo-limbic predominant bvFTD (Cerami et al., 2016). 
medRxiv preprint doi: https://doi.org/10.1101/2021.07.10.21260313; this version posted July 12, 2021. The copyright holder for this preprint

The laterality of atrophy, or right vs. left predominant atrophy, significantly affects naming abilities, with left-lateralized bvFTD patients showing lower performance than rightlateralized cases (Mendez \& Lim, 2004).

Finally, one study investigated differences between bvFTD subgroups based on their patterns of network degeneration (with a predominance in the semantic appraisal network (SAN), in the salience network (SN), subdivided in frontal (SN-F) and fronto-temporal (SNFT) predominant subgroups, or in the subcortical network (subcortical)). While affect naming did not differ between all the subgroups, picture naming was lower in the SAN bvFTD subgroup. The SN-FT bvFTD subgroup had the second lowest scores without significant difference with other groups. Sentence comprehension was lower in the SN-FT subgroup, differing significantly from SN-F and subcortical subgroups. The SAN bvFTD subgroup had the second lowest scores, without significant difference with other groups (Ranasinghe, 2016). Irregular words reading, repetition as well as verbal agility did not differ between all the subgroups (Ranasinghe et al., 2016).

\subsubsection{Comparisons between genetically defined bvFTD subgroups}

First, a global genetic origin (familial bvFTD vs. sporadic bvFTD) does not affect repetition and reading abilities (Heuer et al., 2020).

More specifically, relative to patients with C9orf72 expansions, those with MAPT mutations exhibit greater deficits in writing, object naming and in two different tasks of single word comprehension (Downey et al., 2014; Hardy et al., 2016). However, other studies reported that the MAPT mutations, in comparison to other genetic mutations (C9orf72 or $G R N$ ), does not influence performance in repetition, reading (Hardy et al., 2016; Heuer et al., 2020), single-word comprehension (Downey et al., 2014), semantic knowledge (Moore et al., 2020) or sentence comprehension (Hardy et al., 2016) disproportionately.

However, the presence of a C9orf72 or GRN expansion does not lead to more severe language impairments for any of the measures investigated, in comparison to other genetic mutations (Downey et al., 2014; Hardy et al., 2016; Heuer et al., 2020; Moore et al., 2020; Sha et al., 2012; Suhonen et al., 2017).

\subsubsection{Comparisons between neuropathologically defined bvFTD subgroups}

When comparing bvFTD linked to FTLD vs. AD pathologies, no difference was found in naming (Mendez \& Shapira, 2013; Perry et al., 2017) or word comprehension, but repetition scores were lower in AD than in FTLD patients (Perry et al., 2017). 
medRxiv preprint doi: https://doi.org/10.1101/2021.07.10.21260313; this version posted July 12, 2021. The copyright holder for this preprint

Considering major FTLD molecular class, no language difference was found between FTLD-tau, TDP and FUS (Perry et al., 2017) nor between tau-positive and tau-negative bvFTD patients (Mendez \& Shapira, 2013). However, Perry et al. also compared bvFTD linked to different FTLD subtypes: CBD, PSP, FTLD-TDP (type A, B, C, D or unclassified) and FUS, when sample size permitted. They found that patients with a FTLD-TDP type C pathology performed significantly lower in picture naming in comparison to PSP and FTLDTDP unclassified, but not CBD, FTLD-TDP type A or FTLD-TDP type B. Also, patients with a FTLD-TPD type B performed significantly lower in word comprehension, in comparison to FTLD-TDP unclassified (Perry et al., 2017).

\subsection{Study quality assessment}

Based on our assessment for the risk of bias 130 studies had a low risk of bias and 51 studies had a high risk of bias. Table S1 indicates, for each study, the risk of bias in each item assessed (e.g., representativeness, sample size, comparability, outcome, and statistics). The highest risk of bias was due to small sample size (i.e., less than 20 patients overall), to inadequate comparability of the healthy controls with the bvFTD (i.e., cases and controls were only partially matched on basic demographic variables), and to partial independent validation and/or description of patient selection criteria (Figure 3). Most studies employed validated neuropsychological tools to test speech and language outcomes, while studies without validated measurement tools mainly included experimental tasks and/or measures derived from spontaneous, narrative or connected speech.

\section{Discussion}

In this review, we investigated the scope of speech and language impairments in bvFTD, considering multiple domains (motor speech, phonology, orthography, lexicosemantics, grammar, and prosody) and modulating (clinical, neural, genetic, neuropathological) factors. Overall, we found that bvFTD patients present with extensive but heterogeneous deficits. These were more consistently reported in lexico-semantic, orthographic, and prosodic domains. Assessments of motor speech and grammar provided mixed results, with a slight majority of studies showing preserved performance. Finally, no study showed phonological impairments. Also, speech and language impairments were more pronounced in patients with (i) more severe global cognitive impairment, (ii) probable (as opposed to possible) bvFTD diagnosis, (iii) predominant frontotemporal atrophy (vs. frontal- 
medRxiv preprint doi: https://doi.org/10.1101/2021.07.10.21260313; this version posted July 12, 2021. The copyright holder for this preprint

or subcortical-predominant) or semantic appraisal network damage, and (iv) MAPT mutations (vs. C9orf72). The impact of underlying neuropathology remains underexplored. Overall, our study suggests that despite being under-recognized, speech and language impairments in bvFTD could afford sensitive biomarkers for both diagnosis and prognosis.

\subsection{Characterization of language in bvFTD}

Three language domains were found to be consistently impaired (more than $60 \%$ of reports) in bvFTD: lexico-semantics, orthography, and prosody. First, bvFTD are impaired in the lexico-semantic domains, more precisely in word retrieval, word comprehension and semantic knowledge. Of note, the semantic impairment in bvFTD patients did not appear to be restricted to verbal stimuli but also extended to non-verbal information. However, these lexico-semantic deficits are not always observed in connected speech studies, but fine-grained examinations revealed impairments at the discourse level (connectedness, accuracy, theme maintenance, etc.). In bvFTD patients, lexico-semantic impairments have been related to left anterior temporal lobe and left inferior frontal gyrus (Hardy et al., 2016), which are core regions of the semantic network (Lambon Ralph et al., 2017) and also atrophied in bvFTD patients (Bejanin et al., 2020). Interestingly, lexico-semantic difficulties may be more marked for actions (verbs) than for objects (nouns) in bvFTD (in naming: Cotelli et al., 2006; Hardy et al., 2016; word comprehension: Rhee et al., 2001, semantic knowledge: Bak \& Hodges, 2003). This may suggest a larger involvement of frontal lobe and more specifically motor regions (Birba et al., 2017; García et al., 2018), as well as more executive resources in verbs than nouns processing (Bak et al., 2001). Second, reading capacities are also altered in bvFTD patients, which has most frequently been shown for irregular words, but also for non-words and text. Reading irregular words is related to semantic abilities and involves the anterior temporal role (Wilson et al., 2009), a region targeted by neurodegeneration in bvFTD. Nonetheless, more fine-grained studies involving reading different types of words are needed in bvFTD, as well as more studies of writing abilities. Third, prosody recognition was impaired in most reports. Previous studies showed that this function depends on medial and orbitofrontal regions and on anterior temporal poles which are core regions of neurodegeneration (Pichon \& Kell, 2013; Schirmer \& Kotz, 2006). bvFTD patients also have impaired expressive prosody, which has been linked to left inferior frontal, anterior cingulate, insula, left fusiform and right inferior frontal gyri (Nevler et al., 2017), regions also atrophied in bvFTD and involved in social and behavioral disorders (Massimo et al., 2019). These results highlight the relevance of prosodic markers in bvFTD, especially given the 
medRxiv preprint doi: https://doi.org/10.1101/2021.07.10.21260313; this version posted July 12, 2021. The copyright holder for this preprint

relationship of prosody with socio-emotional behavior, a core impairment in bvFTD (Rascovsky et al., 2011).

Two language domains showed mixed results in bvFTD, with a slight majority of studies showing preserved performance: motor speech and grammar. Motor speech is globally preserved, even if subtle changes appears when more detailly investigated, related to inferior frontal gyrus, insula and right precentral gyrus (Vogel et al., 2017). These regions have been linked to various motor speech aspects in healthy participants: left anterior insula for articulation, SMA and pre-SMA for initiation and execution of speech (Price, 2010). Grammar appears to be globally preserved when assessed with simple comprehension tasks or in its production during connected speech, but more altered when assessed with complex tasks. This might be due to increased executive demands. In a task-based fMRI study of grammar processing, decreased activation in the dorsal inferior frontal cortex has been found in bvFTD patients in comparison to healthy controls (Cooke et al., 2003). Previous studies in healthy controls have also highlighted the role of left frontal regions in grammar (Cooke et al., 2002; Grossman et al., 2002; McMillan et al., 2013).

One language domain showed consistently preserved performance in bvFTD: phonology. This was observed in studies assessing phonology with both phonological manipulation and repetition of words and sentences. These results are in line with the implication of posterior temporo-parietal regions in this language domains, more posterior than the atrophied regions in bvFTD (Forkel et al., 2020).

\subsection{The heterogeneity of language impairments in bvFTD}

We have also identified factors that are associated with more speech and language impairments in bvFTD patients. Unsurprisingly, a more severe global cognitive impairment leads to more alterations in speech and language in bvFTD patients, which highlight the role of speech and language tasks as additional tools that are sensitive to disease progression and severity. The level of certainty of diagnosis (possible versus probable) also affects the severity of language impairments. This may be related to the fact that within individuals with a diagnosis of possible bvFTD, some may not progress to more severe stages of the disease ("bvFTD phenocopy”) (Hornberger et al., 2009). Consistent with our findings, a previous study also found that there was a higher prevalence of stereotypy of speech in bvFTD progressors, versus non-progressors (Hornberger et al., 2009).

The neurodegeneration pattern may also impact language capacities. A leftpredominant pattern of atrophy (vs right-predominant) is associated with more severe naming 
medRxiv preprint doi: https://doi.org/10.1101/2021.07.10.21260313; this version posted July 12, 2021. The copyright holder for this preprint

impairments, consistently with the role of the left hemisphere in speech and language (Mendez \& Lim, 2004). This pattern is also observed in other neurodegenerative diseases such as left-predominant svPPA patients who show more severe naming impairments than right-predominant svPPA patients (Binney et al., 2016). Frontal (vs. temporo-limbic) structural alterations as well as altered fronto-temporal connectivity were associated with more significant sentence comprehension difficulties. This is consistent with the predominant role of the left frontal regions in syntax processing (Cerami et al., 2016; Schell et al., 2017) even if temporal lobes are also involved in this process (Lukic et al., 2021). A more semantic appraisal network predominant pattern alters naming capacities more importantly (Ranasinghe et al., 2016), which is consistent with the role of bilateral anterior temporal lobes in semantic processing (Lambon Ralph et al., 2017).

Furthermore, our review suggests that the presence of a MAPT mutations impact language, more specifically lexico-semantics (naming, single-word comprehension) and writing, more significantly than C9orf72. In that specific study, writing was assessed with the Graded Spelling Test, in which all words are orthographically ambiguous, in the sense that they can plausibly be written in multiple ways, while retaining the sound of the target item (Hardy et al., 2016). Therefore, this task also includes a semantic component. The more severe lexico-semantic impairment in MAPT vs $C 9$ orf72 bvFTD patients may be related to a greater involvement of anterior temporal lobe, a region highly implicated in lexico-semantics, in bvFTD patients with MAPT mutations than with C9orf72 expansion (Josephs et al., 2007; Mahoney et al., 2012). There was no significant difference when investigating other speech and language domains, nor when including GRN mutations in the comparison. Overall, these preliminary results are surprising, given that outside of a diagnosis of bvFTD, GRN mutations are the most frequently associated with a speech and language predominant diagnosis of PPA (Saracino et al., 2021). More studies on genetic cases of bvFTD are needed to confirm the differential speech and language profiles.

As for the effect of underlying neuropathology, it remains to be determined due to the low number of studies. Nonetheless, a few differences have been reported. Underlying AD pathology may alter repetition more than FTLD pathology (Perry et al., 2017), in line with the posterior predominance of $\mathrm{AD}$ (Braak \& Braak, 1991) and the involvement of posterior temporo-parietal regions in repetition (Forkel et al., 2020). FTLD-TDP type C seems to lead to more naming difficulties in comparison to PSP and FTLD-TDP unclassified, but not CBD, FTLD-TDP type A or FTLD-TDP type B. This is consistent with the implication of FTLDTDP type $\mathrm{C}$ in a large majority of svPPA cases and in the left anterior temporal lobe, a core 
medRxiv preprint doi: https://doi.org/10.1101/2021.07.10.21260313; this version posted July 12, 2021. The copyright holder for this preprint

region for naming (Borghesani et al., 2020). Finally, FTLD-TDP type B seems related to more comprehension difficulties in comparison to FTLD-TDP unclassified, consistent with anterior temporal atrophy described in cases of patients with language disturbances related to FTLD-TDP type B (Lee et al., 2020).

In conclusion, the heterogeneity of speech and language symptoms in bvFTD patients is concordant with previous studies assessing the impact of clinical, neuroanatomical, genetic and neuropathological features on such symptoms. In the first aim of this systematic review, we delineated a relatively clear speech and language profile in bvFTD. Nonetheless, the evidence is still too limited to allow clear conclusions for the second aim. Future prospective studies investigating the impact of these features on speech and language symptoms in bvFTD patients will be essential to manage the clinical complexities of this disease at the singlepatient level.

\subsection{Beyond the characterization of patients: Speech and language measures to improve bvFTD phenotyping and to track disease progression in bvFTD}

The language characterization of bvFTD is needed for a better understanding of the bvFTD syndrome, but it may also be useful for its differential diagnosis from other neurodegenerative disease, especially PPA and AD. The profile of speech and language imapirments in bvFTD reported in this review, namely an impairment in lexico-semantics and orthography, with preserved phonological and relatively intact motor speech and grammar, resembles the most to the one described in svPPA. Nonetheless, when compared to svPPA, bvFTD patients show better performance in most lexico-semantic tasks, but do not differ in phonology, reading, motor speech and grammar (Ash et al., 2013; Harciarek \& Kertesz, 2008; Hardy et al., 2016; Wilson et al., 2010). Furthermore, when compared to lvPPA, bvFTD patients are less impaired in phonology (repetition), naming and syntactic comprehension but have more fluency disruptions in their discourse (Ash et al., 2013; Smits et al., 2015; Wilson et al., 2010). When compared to nfvPPA, bvFTD patients have better performances on tasks involving motor speech, grammar or verb naming, but did not differ in other language domains such as lexico-semantics (Ash et al., 2013; Hardy et al., 2016; Wilson et al., 2010).

Although most studies show that language in bvFTD do not differ from AD (Blair et al., 2007; Diehl et al., 2005; Harciarek \& Kertesz, 2008; Smits et al., 2015; Wilson et al., 2010), it was reported that semantic and motor speech abilities are more impaired in bvFTD than in AD (Blair et al., 2007). Finally, other studies have also shown that speech and language can be helpful in the differential diagnosis of bvFTD versus ALS/FTD (Saxon et al., 
medRxiv preprint doi: https://doi.org/10.1101/2021.07.10.21260313; this version posted July 12, 2021. The copyright holder for this preprint

2017), CBS and PSP (Cotelli et al., 2006), DLB and vascular dementia (Smits et al., 2015).

Thus, a detailed language investigation seems to allow distinctions between bvFTD and other neurodegenerative disorders.

Although only a few studies have assessed speech and language longitudinally in bvFTD, it is of great interest to know which domains could track disease progression. Global language performances seem to decrease with time (Blair et al., 2007; Schubert et al., 2016). A connected speech study also suggests that syntactic complexity and speech rate declines with time in bvFTD (Ash et al., 2019). As for naming, results are mixed (no change with time in (Ash et al., 2019; Binney et al., 2017; Cousins et al., 2018 vs. decrease in Hardy et al., 2016; Mahoney et al., 2014; Wicklund et al., 2007). This decline may be faster than in AD patients but slower than in PPA patients (Wicklund et al., 2007). Finally, other studies have showed that speech rate (Ash, 2019), reading performance (Irish et al., 2012), word comprehension and semantic abilities (Hardy et al., 2016; Cousins et al., 2018) do not change with time. Overall, these studies suggest that with the advancement of the disease, some speech and language impairments might become more severe in bvFTD patients. More studies are needed to understand the potential of speech and language markers in tracking bvFTD progression.

\subsection{Current gaps and future directions}

This systematic review also highlights some limitations which could guide future research in this field.

The first set of limitations concerns the samples included in the reviewed studies. Our review reveals that $80 \%$ of the included studies involved less than bvFTD 30 patients (Figure 3), which may lead to a lack of power to detect subtle language impairments. Furthermore, during the selection process, many studies (163) have been excluded because they did not include a comparison group of healthy controls. Finally, most of the articles included came from North America, Western Europe or Australia and included English-speaking participants (Table 1). Therefore, the results of this review may not be generalizable to other underrepresented populations, languages, and cultures. Together, these limitations call for studies involving a greater number of bvFTD patients and compared to a matched group of healthy participants. Multi-center studies should also be led worldwide, including currently underrepresented regions such as Africa, Asia, Eastern Europe or South America.

The second set of limitations is related to the speech and language assessments. Although a large number of studies were included in the present review, most of them 
investigated language as a secondary outcome measure using quick assessment tools. Therefore, the results were rarely interpreted or discussed in the original papers. Also, some domains such as motor speech, phonology and prosody have been scarcely studied until now (Figure 2), although some of them show potential as clinical markers of bvFTD. Furthermore, the assessment tools used in the literature are highly heterogeneous across studies, making it impossible to use meta-analytic statistical approaches. Because a complete speech and language assessment can be lengthy, connected speech approaches are gaining in popularity because of their high cost-effectiveness. Indeed, these approaches are quick, they allow for an assessment of multiple speech and language subdomains simultaneously and they are becoming more automated. Previous studies have shown their utility in PPA to distinguish the 3 subtypes and have studied neural correlates of connected speech components (Wilson et al., 2010a). Once further validated, they will be highly helpful in the characterization of bvFTD patients. In our review, we showed that connected speech seem to be sensitive to impairments in most speech and language domains, except for grammar.

Finally, more studies investigating the heterogeneity of speech and language symptoms in bvFTD, by comparing bvFTD subgroups, are needed to confirm the preliminary conclusions proposed in this review.

\subsection{Conclusion}

Through this review, our aim was to investigate language impairments in bvFTD syndrome, yet mostly characterized by behavioral and personality changes. Our review shed light on both extensive and heterogeneous speech and language alterations in bvFTD patients, more consistent in lexico-semantic, orthography and prosody domains. It also highlights that a globally altered cognitive status, a frontotemporal predominant atrophy and the presence of a $M A P T$ mutation may be key features for language impairments. A better acknowledgement of these language and speech difficulties may help a better characterization of bvFTD and it may be helpful for both differential diagnosis and follow-up. 


\section{Acknowledgements}

We thank Dr. Evans Whitaker from the UCSF Health Sciences Library for his help with the literature search strategy.

AG received an internship grant from the French Society of Neurology.

AMG is supported by CONICET; ANID, FONDECYT Regular [grant numbers 1210176 and 1210195]; Programa Interdisciplinario de Investigación Experimental en Comunicación y Cognición (PIIECC), Facultad de Humanidades, USACH.

MM is supported by postdoctoral funding from Canadian Institutes of Health Research (CIHR) and Fonds Québécois de Recherche en Santé (FRQS).

\section{Declaration of interest : None}

Funding : This research did not receive any specific grant from funding agencies in the public, commercial, or not-for-profit sectors. 
medRxiv preprint doi: https://doi.org/10.1101/2021.07.10.21260313; this version posted July 12, 2021. The copyright holder for this preprint

(which was not certified by peer review) is the author/funder, who has granted medRxiv a license to display the preprint in perpetuity. It is made available under a CC-BY-NC-ND 4.0 International license .

\section{References}

Agosta, F., Galantucci, S., Magnani, G., Marcone, A., Martinelli, D., Antonietta Volontè, M., Riva, N., Iannaccone, S., Ferraro, P. M., Caso, F., Chiò, A., Comi, G., Falini, A., \& Filippi, M. (2015). MRI signatures of the frontotemporal lobar degeneration continuum. Human Brain Mapping, 36(7), 2602 $\square 2614$. https://doi.org/10.1002/hbm.22794

Ash, S., Moore, P., Antani, S., McCawley, G., Work, M., \& Grossman, M. (2006). Trying to tell a tale $\square$ : Discourse impairments in progressive aphasia and frontotemporal dementia. Neurology, 66(9), $1405 \square 1413$. https://doi.org/10.1212/01.wnl.0000210435.72614.38

Ash, S., Moore, P., Vesely, L., Gunawardena, D., McMillan, C., Anderson, C., Avants, B., \& Grossman, M. (2009). Non-Fluent Speech in Frontotemporal Lobar Degeneration. Journal of Neurolinguistics, 22(4), $370 \square 383$. https://doi.org/10.1016/j.jneuroling.2008.12.001

Ash, S., Evans, E., O’Shea, J., Powers, J., Boller, A., Weinberg, D., Haley, J., McMillan, C., Irwin, D. J., Rascovsky, K., \& Grossman, M. (2013). Differentiating primary progressive aphasias in a brief sample of connected speech. Neurology, 81(4), 329 $\square 336$. https://doi.org/10.1212/WNL.0b013e31829c5d0e

Ash, S., Ternes, K., Bisbing, T., Min, N. E., Moran, E., York, C., McMillan, C. T., Irwin, D. J., \& Grossman, M. (2016). Dissociation of quantifiers and object nouns in speech in focal neurodegenerative disease. Neuropsychologia, 89, 141 $\square$ 152. https://doi.org/10.1016/j.neuropsychologia.2016.06.013

Ash, S., Nevler, N., Phillips, J., Irwin, D. J., McMillan, C. T., Rascovsky, K., \& Grossman, M. (2019). A longitudinal study of speech production in primary progressive aphasia and behavioral variant frontotemporal dementia. Brain and Language, 194, 46 $\square$ 57. https://doi.org/10.1016/j.bandl.2019.04.006

Bak, T. H., O’Donovan, D. G., Xuereb, J. H., Boniface, S., \& Hodges, J. R. (2001). Selective impairment of verb processing associated with pathological changes in Brodmann areas 44 and 45 in the motor neurone disease-dementia-aphasia syndrome. Brain: A Journal of Neurology, 124(Pt 1), 103 $\square$ 120. https://doi.org/10.1093/brain/124.1.103

Bak, T. H., \& Hodges, J. R. (2003). Kissing and dancing-A test to distinguish the lexical and conceptual contributions to noun/verb and action/object dissociation. Preliminary results in patients with frontotemporal dementia. Journal of Neurolinguistics, 16(2), 169 $\square 181$. https://doi.org/10.1016/S0911-6044(02)00011-8

Banks, S., \& Weintraub, S. (2008). Self-awareness and self-monitoring of cognitive and behavioral deficits in behavioral variant frontotemporal dementia, primary progressive aphasia and probable Alzheimer's disease. Brain and Cognition, 67(1), 58 $\square 68$. https://doi.org/10.1016/j.bandc.2007.11.004

Bejanin, A., Tammewar, G., Marx, G., Cobigo, Y., Iaccarino, L., Kornak, J., Staffaroni, A. M., Dickerson, B. C., Boeve, B. F., Knopman, D. S., Gorno-Tempini, M., Miller, B. L., Jagust, W. J., Boxer, A. L., Rosen, H. J., \& Rabinovici, G. D. (2020).

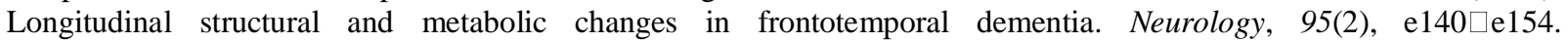
https://doi.org/10.1212/WNL.0000000000009760

Bertoux, M., de Souza, L. C., Corlier, F., Lamari, F., Bottlaender, M., Dubois, B., \& Sarazin, M. (2014). Two distinct amnesic

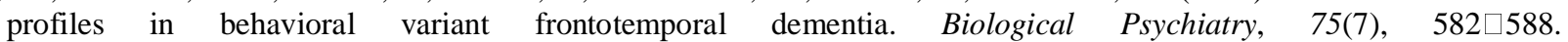
https://doi.org/10.1016/j.biopsych.2013.08.017

Bertoux, M., de Souza, L. C., O’Callaghan, C., Greve, A., Sarazin, M., Dubois, B., \& Hornberger, M. (2016). Social Cognition Deficits $\square$ : The Key to Discriminate Behavioral Variant Frontotemporal Dementia from Alzheimer's Disease Regardless of Amnesia? Journal of Alzheimer's Disease: JAD, 49(4), 1065ロ1074. https://doi.org/10.3233/JAD-150686

Binney, R. J., Henry, M. L., Babiak, M., Pressman, P. S., Santos-Santos, M. A., Narvid, J., Mandelli, M. L., Strain, P. J., Miller, B. L., Rankin, K. P., Rosen, H. J., \& Gorno-Tempini, M. L. (2016). Reading words and other people $\square$ : A comparison of exception word, familiar face and affect processing in the left and right temporal variants of primary progressive aphasia. Cortex; a Journal Devoted to the Study of the Nervous System and Behavior, 82, $147 \square 163$. https://doi.org/10.1016/j.cortex.2016.05.014

Binney, R. J., Pankov, A., Marx, G., He, X., McKenna, F., Staffaroni, A. M., Kornak, J., Attygalle, S., Boxer, A. L., Schuff, N., Gorno-Tempini, M.-L., Weiner, M. W., Kramer, J. H., Miller, B. L., \& Rosen, H. J. (2017). Data-driven regions of interest for longitudinal change in three variants of frontotemporal lobar degeneration. Brain and Behavior, 7(4), e00675. https://doi.org/10.1002/brb3.675

Birba, A., García-Cordero, I., Kozono, G., Legaz, A., Ibáñez, A., Sedeño, L., \& García, A. M. (2017). Losing ground $\square$ : Frontostriatal atrophy disrupts language embodiment in Parkinson's and Huntington's disease. Neuroscience and Biobehavioral Reviews, 80, 673 $\square 687$. https://doi.org/10.1016/j.neubiorev.2017.07.011

Blair, M., Marczinski, C. A., Davis-Faroque, N., \& Kertesz, A. (2007). A longitudinal study of language decline in Alzheimer's disease and frontotemporal dementia. Journal of the International Neuropsychological Society: JINS, 13(2), $237 \square 245$. https://doi.org/10.1017/S1355617707070269

Borghesani, V., Battistella, G., Mandelli, M. L., Welch, A., Weis, E., Younes, K., Neuhaus, J., Grinberg, L. T., Seeley, W. M., Spina, S., Miller, B., Miller, Z., \& Gorno-Tempini, M. L. (2020). Regional and hemispheric susceptibility of the temporal lobe to FTLD-TDP type C pathology. NeuroImage. Clinical, 28, 102369. https://doi.org/10.1016/j.nicl.2020.102369

Borroni, B., Cosseddu, M., Pilotto, A., Premi, E., Archetti, S., Gasparotti, R., Cappa, S., \& Padovani, A. (2015). Early stage of behavioral variant frontotemporal dementia $\square$ : Clinical and neuroimaging correlates. Neurobiology of Aging, 36(11), 3108 $\square 3115$. https://doi.org/10.1016/j.neurobiolaging.2015.07.019

Braak, H., \& Braak, E. (1991). Neuropathological stageing of Alzheimer-related changes. Acta Neuropathologica, 82(4), 239 $\square 259$. https://doi.org/10.1007/BF00308809

Brambati, S. M., Myers, D., Wilson, A., Rankin, K. P., Allison, S. C., Rosen, H. J., Miller, B. L., \& Gorno-Tempini, M. L. (2006). The Anatomy of Category-specific Object Naming in Neurodegenerative Diseases. Journal of Cognitive Neuroscience, 18(10), 1644 $\square$ 1653. https://doi.org/10.1162/jocn.2006.18.10.1644 
medRxiv preprint doi: https://doi.org/10.1101/2021.07.10.21260313; this version posted July 12, 2021. The copyright holder for this preprint

(which was not certified by peer review) is the author/funder, who has granted medRxiv a license to display the preprint in perpetuity. It is made available under a CC-BY-NC-ND 4.0 International license .

Cerami, C., Dodich, A., Lettieri, G., Iannaccone, S., Magnani, G., Marcone, A., Gianolli, L., Cappa, S. F., \& Perani, D. (2016). Different FDG-PET metabolic patterns at single-subject level in the behavioral variant of fronto-temporal dementia. Cortex; a Journal Devoted to the Study of the Nervous System and Behavior, 83, $101 \square 112$. https://doi.org/10.1016/j.cortex.2016.07.008

Chan, H.-M., Stolwyk, R., Neath, J., Kelso, W., Walterfang, M., Mocellin, R., Pantelis, C., \& Velakoulis, D. (2015). Neurocognitive similarities between severe chronic schizophrenia and behavioural variant frontotemporal dementia. Psychiatry Research, 225(3), 658 $\square 666$. https://doi.org/10.1016/j.psychres.2014.11.029

Charles, D., Olm, C., Powers, J., Ash, S., Irwin, D. J., McMillan, C. T., Rascovsky, K., \& Grossman, M. (2014). Grammatical comprehension deficits in non-fluent/agrammatic primary progressive aphasia. Journal of Neurology, Neurosurgery, and Psychiatry, 85(3), 249 $\square 256$. https://doi.org/10.1136/jnnp-2013-305749

Chen, Y., Kumfor, F., Landin-Romero, R., Irish, M., Hodges, J. R., \& Piguet, O. (2018). Cerebellar atrophy and its contribution to cognition in frontotemporal dementias. Annals of Neurology, 84(1), 98 $\square$ 109. https://doi.org/10.1002/ana.25271

Cheran, G., Wu, L., Lee, S., Manoochehri, M., Cines, S., Fallon, E., Lynch, T., Heidebrink, J., Paulson, H., Goldman, J., Huey, E., \& Cosentino, S. (2019). Cognitive Indicators of Preclinical Behavioral Variant Frontotemporal Dementia in MAPT Carriers. Journal of the International Neuropsychological Society: JINS, 25(2), $184 \square 194$. https://doi.org/10.1017/S1355617718001005

Chiong, W., Wilson, S. M., D’Esposito, M., Kayser, A. S., Grossman, S. N., Poorzand, P., Seeley, W. W., Miller, B. L., \& Rankin, K. P. (2013). The salience network causally influences default mode network activity during moral reasoning. Brain, 136(6), 1929 $\square$ 1941. https://doi.org/10.1093/brain/awt066

Chow, M. L., Brambati, S. M., Gorno-Tempini, M. L., Miller, B. L., \& Johnson, J. K. (2010). Sound naming in neurodegenerative disease. Brain and Cognition, 72(3), 423ロ429. https://doi.org/10.1016/j.bandc.2009.12.003

Clague, F., Dudas, R. B., Thompson, S. A., Graham, K. S., \& Hodges, J. R. (2005). Multidimensional measures of person knowledge and spatial associative learning $\square$ : Can these be applied to the differentiation of Alzheimer's disease from frontotemporal and vascular dementia? Neuropsychologia, 43(9), 1338卬1350. https://doi.org/10.1016/j.neuropsychologia.2004.11.023

Clark, C. N., Nicholas, J. M., Henley, S. M. D., Downey, L. E., Woollacott, I. O., Golden, H. L., Fletcher, P. D., Mummery, C. J., Schott, J. M., Rohrer, J. D., Crutch, S. J., \& Warren, J. D. (2015). Humour processing in frontotemporal lobar degeneration $\square: \quad$ A behavioural and neuroanatomical analysis. Cortex, 69, $47 \square 59$. https://doi.org/10.1016/j.cortex.2015.03.024

Clark, C. N., Nicholas, J. M., Gordon, E., Golden, H. L., Cohen, M. H., Woodward, F. J., Macpherson, K., Slattery, C. F., Mummery, C. J., Schott, J. M., Rohrer, J. D., \& Warren, J. D. (2016). Altered Sense of Humor in Dementia. Journal of Alzheimer's Disease, 49(1), 111 $\square 119$. https://doi.org/10.3233/JAD-150413

Clark, C. N., Nicholas, J. M., Agustus, J. L., Hardy, C. J. D., Russell, L. L., Brotherhood, E. V., Dick, K. M., Marshall, C. R., Mummery, C. J., Rohrer, J. D., \& Warren, J. D. (2017). Auditory conflict and congruence in frontotemporal dementia. Neuropsychologia, 104, 144 $\square$ 156. https://doi.org/10.1016/j.neuropsychologia.2017.08.009

Clark, C. N., Golden, H. L., McCallion, O., Nicholas, J. M., Cohen, M. H., Slattery, C. F., Paterson, R. W., Fletcher, P. D., Mummery, C. J., Rohrer, J. D., Crutch, S. J., \& Warren, J. D. (2018). Music models aberrant rule decoding and reward valuation in dementia. Social Cognitive and Affective Neuroscience, 13(2), $192 \square 202$. https://doi.org/10.1093/scan/nsx 140

Cohen, M. H., Carton, A. M., Hardy, C. J., Golden, H. L., Clark, C. N., Fletcher, P. D., Jaisin, K., Marshall, C. R., Henley, S. M. D., Rohrer, J. D., Crutch, S. J., \& Warren, J. D. (2016). Processing emotion from abstract art in frontotemporal lobar degeneration. Neuropsychologia, 81, 245 $\square 254$. https://doi.org/10.1016/j.neuropsychologia.2015.12.031

Cooke, A., Zurif, E. B., DeVita, C., Alsop, D., Koenig, P., Detre, J., Gee, J., Pinãngo, M., Balogh, J., \& Grossman, M. (2002). Neural basis for sentence comprehension $\square$ : Grammatical and short-term memory components. Human Brain Mapping, 15(2), 80 $\square 94$. https://doi.org/10.1002/hbm.10006

Cooke, A., DeVita, C., Gee, J., Alsop, D., Detre, J., Chen, W., \& Grossman, M. (2003). Neural basis for sentence comprehension deficits in frontotemporal dementia. Brain and Language, 85(2), 211 $\square 221$. https://doi.org/10.1016/S0093934X(02)00562-X

Cosentino, S., Chute, D., Libon, D., Moore, P., \& Grossman, M. (2006). How does the brain support script comprehension? A study of executive processes and semantic knowledge in dementia. Neuropsychology, 20(3), $307 \square 318$. https://doi.org/10.1037/0894-4105.20.3.307

Cotelli, M., Borroni, B., Manenti, R., Alberici, A., Calabria, M., Agosti, C., Arévalo, A., Ginex, V., Ortelli, P., Binetti, G., Zanetti, O., Padovani, A., \& Cappa, S. F. (2006). Action and object naming in frontotemporal dementia, progressive supranuclear palsy, and corticobasal degeneration. Neuropsychology, 20(5), 558 $\square 565$. https://doi.org/10.1037/0894-4105.20.5.558

Cotelli, M., Borroni, B., Manenti, R., Ginex, V., Calabria, M., Moro, A., Alberici, A., Zanetti, M., Zanetti, O., Cappa, S. F., \& Padovani, A. (2007). Universal grammar in the frontotemporal dementia spectrum $\square$ : Evidence of a selective disorder in the corticobasal degeneration syndrome. Neuropsychologia, 45(13), 3015 $\square 3023$. https://doi.org/10.1016/j.neuropsychologia.2007.05.012

Cousins, K. A. Q., York, C., Bauer, L., \& Grossman, M. (2016). Cognitive and anatomic double dissociation in the representation of concrete and abstract words in semantic variant and behavioral variant frontotemporal degeneration. Neuropsychologia, 84, 244\251. https://doi.org/10.1016/j.neuropsychologia.2016.02.025

Couto, B., Manes, F., Montañés, P., Matallana, D., Reyes, P., Velasquez, M., Yoris, A., Baez, S., \& Ibáñez, A. (2013). Structural neuroimaging of social cognition in progressive non-fluent aphasia and behavioral variant of frontotemporal dementia. Frontiers in Human Neuroscience, 7, 467. https://doi.org/10.3389/fnhum.2013.00467 
medRxiv preprint doi: https://doi.org/10.1101/2021.07.10.21260313; this version posted July 12, 2021. The copyright holder for this preprint

(which was not certified by peer review) is the author/funder, who has granted medRxiv a license to display the preprint in perpetuity. It is made available under a CC-BY-NC-ND 4.0 International license .

De Winter, F.-L., Van den Stock, J., de Gelder, B., Peeters, R., Jastorff, J., Sunaert, S., Vanduffel, W., Vandenberghe, R., \& Vandenbulcke, M. (2016a). Amygdala atrophy affects emotion-related activity in face-responsive regions in frontotemporal degeneration. Cortex, 82, 179 $\square 191$. https://doi.org/10.1016/j.cortex.2016.06.001

De Winter, F.-L., Timmers, D., de Gelder, B., Van Orshoven, M., Vieren, M., Bouckaert, M., Cypers, G., Caekebeke, J., Van de Vliet, L., Goffin, K., Van Laere, K., Sunaert, S., Vandenberghe, R., Vandenbulcke, M., \& Van den Stock, J. (2016b). Face shape and face identity processing in behavioral variant fronto-temporal dementia $\square$ : A specific deficit for familiarity and name recognition of famous faces. NeuroImage: Clinical, $11, \quad 368 \square 377$. https://doi.org/10.1016/j.nicl.2016.03.001

Dermody, N., Hornberger, M., Piguet, O., Hodges, J. R., \& Irish, M. (2016a). Prospective Memory Impairments in Alzheimer's Disease and Behavioral Variant Frontotemporal Dementia $\square$ : Clinical and Neural Correlates. Journal of Alzheimer's

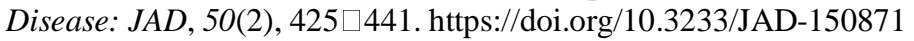

Dermody, N., Wong, S., Ahmed, R., Piguet, O., Hodges, J. R., \& Irish, M. (2016b). Uncovering the Neural Bases of Cognitive and Affective Empathy Deficits in Alzheimer's Disease and the Behavioral-Variant of Frontotemporal Dementia. Journal of Alzheimer's Disease: JAD, 53(3), 801 $\square 816$. https://doi.org/10.3233/JAD-160175

Deutsch, M. B., Mendez, M. F., \& Teng, E. (2015). Interactions between Traumatic Brain Injury and Frontotemporal

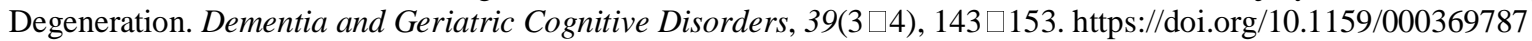

Diehl, J., Monsch, A. U., Aebi, C., Wagenpfeil, S., Krapp, S., Grimmer, T., Seeley, W., Förstl, H., \& Kurz, A. (2005). Frontotemporal dementia, semantic dementia, and Alzheimer's disease $\square$ : The contribution of standard neuropsychological tests to differential diagnosis. Journal of Geriatric Psychiatry and Neurology, 18(1), $39 \square 44$. https://doi.org/10.1177/0891988704272309

Downey, L. E., Blezat, A., Nicholas, J., Omar, R., Golden, H. L., Mahoney, C. J., Crutch, S. J., \& Warren, J. D. (2013). Mentalising music in frontotemporal dementia. Cortex, 49(7), 1844 $\square 1855$. https://doi.org/10.1016/j.cortex.2012.09.011

Downey, L. E., Fletcher, P. D., Golden, H. L., Mahoney, C. J., Agustus, J. L., Schott, J. M., Rohrer, J. D., Beck, J., Mead, S., Rossor, M. N., Crutch, S. J., \& Warren, J. D. (2014). Altered body schema processing in frontotemporal dementia with C9ORF72 mutations. Journal of Neurology, Neurosurgery, and Psychiatry, 85(9), $1016 \square 1023$. https://doi.org/10.1136/jnnp-2013-306995

Downey, L. E., Mahoney, C. J., Buckley, A. H., Golden, H. L., Henley, S. M., Schmitz, N., Schott, J. M., Simpson, I. J., Ourselin, S., Fox, N. C., Crutch, S. J., \& Warren, J. D. (2015). White matter tract signatures of impaired social cognition in frontotemporal lobar degeneration. NeuroImage. Clinical, 8, 640 $\square 651$. https://doi.org/10.1016/j.nicl.2015.06.005

Eckart, J. A., Sturm, V. E., Miller, B. L., \& Levenson, R. W. (2012). Diminished disgust reactivity in behavioral variant frontotemporal dementia. Neuropsychologia, 50(5), 786 $\square 790$. https://doi.org/10.1016/j.neuropsychologia.2012.01.012

Farag, C., Troiani, V., Bonner, M., Powers, C., Avants, B., Gee, J., \& Grossman, M. (2010). Hierarchical Organization of Scripts $\square$ : Converging Evidence from fMRI and Frontotemporal Degeneration. Cerebral Cortex, $20(10), 2453 \square 2463$. https://doi.org/10.1093/cercor/bhp313

Fernandez-Duque, D., \& Black, S. (2007). Metacognitive judgment and denial of deficit $\square$ : Evidence from frontotemporal dementia. Judgment and Decision Making, 2, 359 7370.

Fernández-Matarrubia, M., Matías-Guiu, J. A., Cabrera-Martín, M. N., Moreno-Ramos, T., Valles-Salgado, M., Carreras, J. L., \& Matías-Guiu, J. (2017). Episodic Memory Dysfunction in Behavioral Variant Frontotemporal Dementia $\square$ : A Clinical And FDG-PET Study. Journal of Alzheimer's Disease: JAD, 57(4), 1251 $\square$ 1264. https://doi.org/10.3233/JAD-160874

Filippi, M., Agosta, F., Scola, E., Canu, E., Magnani, G., Marcone, A., Valsasina, P., Caso, F., Copetti, M., Comi, G., Cappa, S. F., \& Falini, A. (2013). Functional network connectivity in the behavioral variant of frontotemporal dementia. Cortex, 49(9), 2389 $\square 2401$. https://doi.org/10.1016/j.cortex.2012.09.017

Filippi, M., Basaia, S., Canu, E., Imperiale, F., Meani, A., Caso, F., Magnani, G., Falautano, M., Comi, G., Falini, A., \& Agosta, F. (2017). Brain network connectivity differs in early-onset neurodegenerative dementia. Neurology, 89(17), $1764 \square 1772$. https://doi.org/10.1212/WNL.0000000000004577

Fletcher, P. D., Nicholas, J. M., Shakespeare, T. J., Downey, L. E., Golden, H. L., Agustus, J. L., Clark, C. N., Mummery, C. J., Schott, J. M., Crutch, S. J., \& Warren, J. D. (2015). Dementias show differential physiological responses to salient sounds. Frontiers in Behavioral Neuroscience, 9. https://doi.org/10.3389/fnbeh.2015.00073

Fletcher, P. D., Nicholas, J. M., Downey, L. E., Golden, H. L., Clark, C. N., Pires, C., Agustus, J. L., Mummery, C. J., Schott, J. M., Rohrer, J. D., Crutch, S. J., \& Warren, J. D. (2016). A physiological signature of sound meaning in dementia. Cortex, 77, 13ロ23. https://doi.org/10.1016/j.cortex.2016.01.007

Forkel, S. J., Rogalski, E., Drossinos Sancho, N., D’Anna, L., Luque Laguna, P., Sridhar, J., Dell'Acqua, F., Weintraub, S., Thompson, C., Mesulam, M.-M., \& Catani, M. (2020). Anatomical evidence of an indirect pathway for word repetition. Neurology, 94(6), e594ロ 6 606. https://doi.org/10.1212/WNL.0000000000008746

Frings, L., Dressel, K., Abel, S., Saur, D., Kümmerer, D., Mader, I., Weiller, C., \& Hüll, M. (2010). Reduced Precuneus Deactivation during Object Naming in Patients with Mild Cognitive Impairment, Alzheimer's Disease, and Frontotemporal Lobar Degeneration. Dementia and Geriatric Cognitive Disorders, 30(4), $334 \square 343$. https://doi.org/10.1159/000320991

Galton, C. J., Gomez-Anson, B., Antoun, N., Scheltens, P., Patterson, K., Graves, M., Sahakian, B. J., \& Hodges, J. R. (2001). Temporal lobe rating scale $\square$ : Application to Alzheimer's disease and frontotemporal dementia. Journal of Neurology, Neurosurgery \& Psychiatry, 70(2), 165 $\square$ 173. https://doi.org/10.1136/jnnp.70.2.165

García, A. M., Bocanegra, Y., Herrera, E., Moreno, L., Carmona, J., Baena, A., Lopera, F., Pineda, D., Melloni, M., Legaz, A., Muñoz, E., Sedeño, L., Baez, S., \& Ibáñez, A. (2018). Parkinson's disease compromises the appraisal of action meanings evoked by naturalistic texts. Cortex; a Journal Devoted to the Study of the Nervous System and Behavior, $100,111 \square 126$. https://doi.org/10.1016/j.cortex.2017.07.003 
medRxiv preprint doi: https://doi.org/10.1101/2021.07.10.21260313; this version posted July 12, 2021. The copyright holder for this preprint

(which was not certified by peer review) is the author/funder, who has granted medRxiv a license to display the preprint in perpetuity. It is made available under a CC-BY-NC-ND 4.0 International license .

Giovagnoli, A. R., Erbetta, A., Reati, F., \& Bugiani, O. (2008). Differential neuropsychological patterns of frontal variant frontotemporal dementia and Alzheimer's disease in a study of diagnostic concordance. Neuropsychologia, 46(5), 1495 $\square 1504$. https://doi.org/10.1016/j.neuropsychologia.2007.12.023

Giovagnoli, A. R., Bell, B., Erbetta, A., Paterlini, C., \& Bugiani, O. (2019). Analyzing theory of mind impairment in patients with behavioral variant frontotemporal dementia. Neurological Sciences, 40(9), 1893ロ1900. https://doi.org/10.1007/s10072019-03911-6

Gleichgerrcht, E., Torralva, T., Roca, M., Pose, M., \& Manes, F. (2011). The role of social cognition in moral judgment in

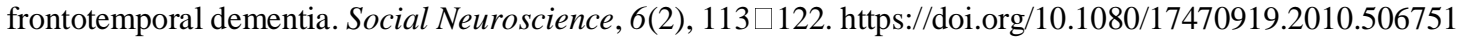

Gleichgerrcht, E., Torralva, T., Roca, M., Szenkman, D., Ibanez, A., Richly, P., Pose, M., \& Manes, F. (2012). Decision Making Cognition in Primary Progressive Aphasia. Behavioural Neurology, 25(1), 45ロ52. https://doi.org/10.3233/BEN-20120352

Gola, K. A., Thorne, A., Veldhuisen, L. D., Felix, C. M., Hankinson, S., Pham, J., Shany-Ur, T., Schauer, G. P., Stanley, C. M., Glenn, S., Miller, B. L., \& Rankin, K. P. (2015). Neural substrates of spontaneous narrative production in focal neurodegenerative disease. Neuropsychologia, 79, 158 $\square$ 171. https://doi.org/10.1016/j.neuropsychologia.2015.10.022

Gregory, C., Lough, S., Stone, V., Erzinclioglu, S., Martin, L., Baron $\square$ Cohen, S., \& Hodges, J. R. (2002). Theory of mind in patients with frontal variant frontotemporal dementia and Alzheimer's disease $\square$ : Theoretical and practical implications. Brain, 125(4), 752 $\square 764$. https://doi.org/10.1093/brain/awf079

Grossman, M., Cooke, A., DeVita, C., Alsop, D., Detre, J., Chen, W., \& Gee, J. (2002). Age-related changes in working memory during sentence comprehension $\square$ : An fMRI study. NeuroImage, $15(2), \quad 302 \square 317$. https://doi.org/10.1006/nimg.2001.0971

Grossman, M., McMillan, C., Moore, P., Ding, L., Glosser, G., Work, M., \& Gee, J. (2004). What's in a name $\square$ : Voxel $\square$ based morphometric analyses of MRI and naming difficulty in Alzheimer's disease, frontotemporal dementia and corticobasal degeneration. Brain, 127(3), 628 $\square 649$. https://doi.org/10.1093/brain/awh075

Grossman, M., Rhee, J., \& Moore, P. (2005). Sentence Processing in Frontotemporal Dementia. Cortex, 41(6), $764 \square 777$. https://doi.org/10.1016/S0010-9452(08)70295-8

Gunawardena, D., Ash, S., McMillan, C., Avants, B., Gee, J., \& Grossman, M. (2010). Why are patients with progressive nonfluent aphasia nonfluent? Neurology, 75(7), 588ロ594. https://doi.org/10.1212/WNL.0b013e3181ed9c7d

Harciarek, M., \& Kertesz, A. (2008). The prevalence of misidentification syndromes in neurodegenerative diseases. Alzheimer Disease and Associated Disorders, 22(2), 163ロ169. https://doi.org/10.1097/WAD.0b013e3181641341

Hardy, C. J. D., Buckley, A. H., Downey, L. E., Lehmann, M., Zimmerer, V. C., Varley, R. A., Crutch, S. J., Rohrer, J. D., Warrington, E. K., \& Warren, J. D. (2016). The Language Profile of Behavioral Variant Frontotemporal Dementia.

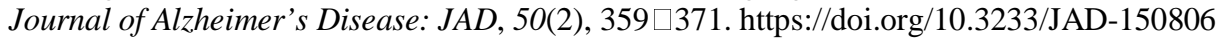

Harris, J. M., Jones, M., Gall, C., Richardson, A. M. T., Neary, D., du Plessis, D., Pal, P., Mann, D. M. A., Snowden, J. S., \& Thompson, J. C. (2016). Co-Occurrence of Language and Behavioural Change in Frontotemporal Lobar Degeneration. Dementia and Geriatric Cognitive Disorders Extra, 6(2), 205ロ213. https://doi.org/10.1159/000444848

Healey, M. L., McMillan, C. T., Golob, S., Spotorno, N., Rascovsky, K., Irwin, D. J., Clark, R., \& Grossman, M. (2015). Getting on the same page $\square$ : The neural basis for social coordination deficits in behavioral variant frontotemporal degeneration. Neuropsychologia, 69, 56 $\square 66$. https://doi.org/10.1016/j.neuropsychologia.2015.01.028

Healey, M., Spotorno, N., Olm, C., Irwin, D. J., \& Grossman, M. (2019). Cognitive and Neuroanatomic Accounts of Referential Communication in Focal Dementia. ENeuro, 6(5). https://doi.org/10.1523/ENEURO.0488-18.2019

Henley, S. M. D., Downey, L. E., Nicholas, J. M., Kinnunen, K. M., Golden, H. L., Buckley, A., Mahoney, C. J., \& Crutch, S. J. (2014). Degradation of cognitive timing mechanisms in behavioural variant frontotemporal dementia. Neuropsychologia,

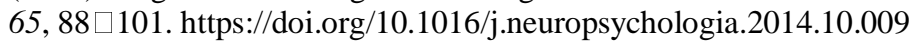

Heuer, H. W., Wang, P., Rascovsky, K., Wolf, A., Appleby, B., Bove, J., Bordelon, Y., Brannelly, P., Brushaber, D. E., Caso, C., Coppola, G., Dickerson, B., Dickinson, S., Domoto-Reilly, K., Faber, K., Ferrall, J., Fields, J., Fishman, A., Fong, J., ... ARTFL and LEFFTDS consortia. (2020). Comparison of sporadic and familial behavioral variant frontotemporal dementia (FTD) in a North American cohort. Alzheimer's \& Dementia: The Journal of the Alzheimer's Association, 16(1), 60ロ70. https://doi.org/10.1002/alz.12046

Hoefer, M., Allison, S. C., Schauer, G. F., Neuhaus, J. M., Hall, J., Dang, J. N., Weiner, M. W., Miller, B. L., \& Rosen, H. J.

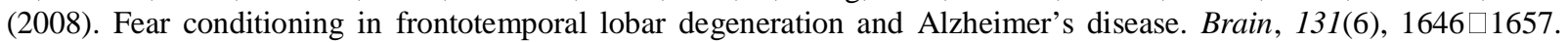
https://doi.org/10.1093/brain/awn082

Hornberger, M., Shelley, B. P., Kipps, C. M., Piguet, O., \& Hodges, J. R. (2009). Can progressive and non-progressive behavioural variant frontotemporal dementia be distinguished at presentation? Journal of Neurology, Neurosurgery, and Psychiatry, 80(6), 591ロ593. https://doi.org/10.1136/jnnp.2008.163873

Hou, C. E., Miller, B. L., \& Kramer, J. H. (2005). Patterns of autobiographical memory loss in dementia. International Journal of Geriatric Psychiatry, 20(9), 809ロ815. https://doi.org/10.1002/gps.1361

Hsieh, S., Foxe, D., Leslie, F., Savage, S., Piguet, O., \& Hodges, J. R. (2012). Grief and joy $\square$ : Emotion word comprehension in the dementias. Neuropsychology, 26(5), 624 $\square 630$. https://doi.org/10.1037/a0029326

Hsieh, S., Schubert, S., Hoon, C., Mioshi, E., \& Hodges, J. R. (2013). Validation of the Addenbrooke's Cognitive Examination III

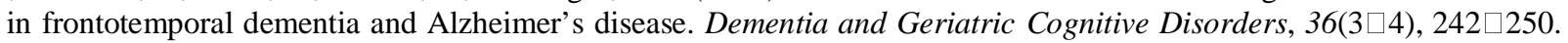
https://doi.org/10.1159/000351671

Hua, A. Y., Sible, I. J., Perry, D. C., Rankin, K. P., Kramer, J. H., Miller, B. L., Rosen, H. J., \& Sturm, V. E. (2018). Enhanced Positive Emotional Reactivity Undermines Empathy in Behavioral Variant Frontotemporal Dementia. Frontiers in Neurology, 9. https://doi.org/10.3389/fneur.2018.00402 
medRxiv preprint doi: https://doi.org/10.1101/2021.07.10.21260313; this version posted July 12, 2021. The copyright holder for this preprint

(which was not certified by peer review) is the author/funder, who has granted medRxiv a license to display the preprint in perpetuity. It is made available under a CC-BY-NC-ND 4.0 International license .

Hughes, L. E., Nestor, P. J., Hodges, J. R., \& Rowe, J. B. (2011). Magnetoencephalography of frontotemporal dementia $\square$ : Spatiotemporally localized changes during semantic decisions. Brain: A Journal of Neurology, 134(Pt 9), $2513 \square 2522$. https://doi.org/10.1093/brain/awr196

Hutchings, R., Hodges, J. R., Piguet, O., \& Kumfor, F. (2015). Why Should I Care? Dimensions of\&nbsp;Socio-Emotional Cognition in\&nbsp;Younger-Onset Dementia. Journal of Alzheimer's Disease, 48(1), $135 \square 147$. https://doi.org/10.3233/JAD-150245

Hutchings, R., Palermo, R., Bruggemann, J., Hodges, J. R., Piguet, O., \& Kumfor, F. (2018). Looking but not seeing $\square$ : Increased eye fixations in behavioural-variant frontotemporal dementia. Cortex, 103, $71 \square 81$. https://doi.org/10.1016/j.cortex.2018.02.011

Irish, M., Hornberger, M., Lah, S., Miller, L., Pengas, G., Nestor, P. J., Hodges, J. R., \& Piguet, O. (2011). Profiles of recent autobiographical memory retrieval in semantic dementia, behavioural-variant frontotemporal dementia, and Alzheimer's disease. Neuropsychologia, 49(9), 2694ロ2702. https://doi.org/10.1016/j.neuropsychologia.2011.05.017

Irish, M., Graham, A., Graham, K. S., Hodges, J. R., \& Hornberger, M. (2012). Differential impairment of source memory in progressive versus non-progressive behavioral variant frontotemporal dementia. Archives of Clinical Neuropsychology: The Official Journal of the National Academy of Neuropsychologists, 27(3), 338ロ347. https://doi.org/10.1093/arclin/acs033

Irish, M., Hodges, J. R., \& Piguet, O. (2013). Episodic future thinking is impaired in the behavioural variant of frontotemporal dementia. Cortex, 49(9), 2377 $\square 2388$. https://doi.org/10.1016/j.cortex.2013.03.002

Irish, M., Hornberger, M., El Wahsh, S., Lam, B. Y. K., Lah, S., Miller, L., Hsieh, S., Hodges, J. R., \& Piguet, O. (2014a). Grey and white matter correlates of recent and remote autobiographical memory retrieval-Insights from the dementias. PloS One, 9(11), e113081. https://doi.org/10.1371/journal.pone.0113081

Irish, M., Hodges, J. R., \& Piguet, O. (2014b). Right anterior temporal lobe dysfunction underlies theory of mind impairments in semantic dementia. Brain, 137(4), 1241 $\square$ 1253. https://doi.org/10.1093/brain/awu003

Irish, M., Eyre, N., Dermody, N., O'Callaghan, C., Hodges, J. R., Hornberger, M., \& Piguet, O. (2016). Neural Substrates of Semantic Prospection-Evidence from the Dementias. Frontiers in Behavioral Neuroscience, 10, 96. https://doi.org/10.3389/fnbeh.2016.00096

Jastorff, J., De Winter, F.-L., Van den Stock, J., Vandenberghe, R., Giese, M. A., \& Vandenbulcke, M. (2016). Functional dissociation between anterior temporal lobe and inferior frontal gyrus in the processing of dynamic body expressions $\square$ : Insights from behavioral variant frontotemporal dementia. Human Brain Mapping, 37(12), $4472 \square 4486$. https://doi.org/10.1002/hbm.23322

Jenner, C., Reali, G., Puopolo, M., \& Silveri, M. C. (2006). Can Cognitive and Behavioural Disorders Differentiate Frontal Variant-Frontotemporal Dementia From Alzheimer's Disease at Early Stages? Behavioural Neurology, 17(2), 89ロ95. https://doi.org/10.1155/2006/812760

Johnen, A., Frommeyer, J., Modes, F., Wiendl, H., Duning, T., \& Lohmann, H. (2016a). Dementia Apraxia Test (DATE) $\square$ : A Brief Tool to Differentiate Behavioral Variant Frontotemporal Dementia from Alzheimer's Dementia Based on Apraxia Profiles. Journal of Alzheimer's Disease, 49(3), 593ロ605. https://doi.org/10.3233/JAD-150447

Johnen, A., Brandstetter, L., Kärgel, C., Wiendl, H., Lohmann, H., \& Duning, T. (2016b). Shared neural correlates of limb apraxia in early stages of Alzheimer's dementia and behavioural variant frontotemporal dementia. Cortex, 84, $1 \square 14$. https://doi.org/10.1016/j.cortex.2016.08.009

Johnen, A., Reul, S., Wiendl, H., Meuth, S. G., \& Duning, T. (2018). Apraxia profiles—A single cognitive marker to discriminate all variants of frontotemporal lobar degeneration and Alzheimer's disease. Alzheimer's \& Dementia: Diagnosis, Assessment \& Disease Monitoring, 10(1), 363ロ 371. https://doi.org/10.1016/j.dadm.2018.04.002

Johnson, J. K., Chang, C.-C., Brambati, S. M., Migliaccio, R., Gorno-Tempini, M. L., Miller, B. L., \& Janata, P. (2011). Music Recognition in Frontotemporal Lobar Degeneration and Alzheimer Disease. Cognitive and Behavioral Neurology, 24(2), 74ロ84. https://doi.org/10.1097/WNN.0b013e31821de326

Josephs, K. A., Ahmed, Z., Katsuse, O., Parisi, J. F., Boeve, B. F., Knopman, D. S., Petersen, R. C., Davies, P., Duara, R., GraffRadford, N. R., Uitti, R. J., Rademakers, R., Adamson, J., Baker, M., Hutton, M. L., \& Dickson, D. W. (2007). Neuropathologic features of frontotemporal lobar degeneration with ubiquitin-positive inclusions with progranulin gene (PGRN) mutations. Journal of Neuropathology and Experimental Neurology, 66(2), 142ロ151. https://doi.org/10.1097/nen.0b013e31803020cf

Kamminga, J., Kumfor, F., Burrell, J. R., Piguet, O., Hodges, J. R., \& Irish, M. (2015). Differentiating between right-lateralised semantic dementia and behavioural-variant frontotemporal dementia $\square$ : An examination of clinical characteristics and

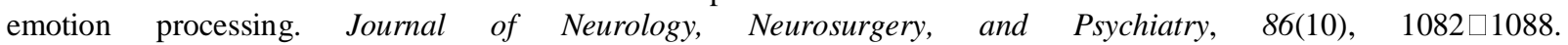
https://doi.org/10.1136/jnnp-2014-309120

Kamminga, J., O'Callaghan, C., Hodges, J. R., \& Irish, M. (2014). Differential Prospective Memory Profiles in Frontotemporal Dementia Syndromes. Journal of Alzheimer's Disease, 38(3), 669 $\square 679$. https://doi.org/10.3233/JAD-131118

Kaq, C., S, A., Ca, O., \& M, G. (2018). Longitudinal Changes in Semantic Concreteness in Semantic Variant Primary Progressive Aphasia (svPPA). ENeuro, 5(6). https://doi.org/10.1523/ENEURO.0197-18.2018

Keane, J., Calder, A. J., Hodges, J. R., \& Young, A. W. (2002). Face and emotion processing in frontal variant frontotemporal dementia. Neuropsychologia, 40(6), 655ロ665. https://doi.org/10.1016/S0028-3932(01)00156-7

Kipps, C. M., Hodges, J. R., Fryer, T. D., \& Nestor, P. J. (2009). Combined magnetic resonance imaging and positron emission tomography brain imaging in behavioural variant frontotemporal degeneration $\square$ : Refining the clinical phenotype. Brain: A Journal of Neurology, 132(Pt 9), 2566ロ2578. https://doi.org/10.1093/brain/awp077

Koenig, P., Smith, E. E., \& Grossman, M. (2006). Semantic categorisation of novel objects in frontotemporal dementia. Cognitive Neuropsychology, 23(4), 541 $\square 562$. https://doi.org/10.1080/02643290542000094 
medRxiv preprint doi: https://doi.org/10.1101/2021.07.10.21260313; this version posted July 12, 2021. The copyright holder for this preprint

(which was not certified by peer review) is the author/funder, who has granted medRxiv a license to display the preprint in perpetuity. It is made available under a CC-BY-NC-ND 4.0 International license .

Kramer, J. H., Jurik, J., Sha, S. J., Rankin, K. P., Rosen, H. J., Johnson, J. K., \& Miller, B. L. (2003). Distinctive Neuropsychological Patterns in Frontotemporal Dementia, Semantic Dementia, And Alzheimer Disease. Cognitive and Behavioral Neurology, 16(4), $211 \square 218$.

Krämer, J., Lueg, G., Schiffler, P., Vrachimis, A., Weckesser, M., Wenning, C., Pawlowski, M., Johnen, A., Teuber, A., Wersching, H., Meuth, S. G., \& Duning, T. (2018). Diagnostic Value of Diffusion Tensor Imaging and Positron Emission Tomography in Early Stages of Frontotemporal Dementia. Journal of Alzheimer's Disease: JAD, 63(1), 239 $\square 253$. https://doi.org/10.3233/JAD-170224

Krawczyk, D. C., Morrison, R. G., Viskontas, I., Holyoak, K. J., Chow, T. W., Mendez, M. F., Miller, B. L., \& Knowlton, B. J. (2008). Distraction during relational reasoning $\square$ : The role of prefrontal cortex in interference control. Neuropsychologia, 46(7), 2020 $\square$ 2032. https://doi.org/10.1016/j.neuropsychologia.2008.02.001

Kumfor, F., Honan, C., McDonald, S., Hazelton, J. L., Hodges, J. R., \& Piguet, O. (2017). Assessing the «social brain » in dementia $\square$ : Applying TASIT-S. Cortex; a Journal Devoted to the Study of the Nervous System and Behavior, 93, 166 $\square$ 177. https://doi.org/10.1016/j.cortex.2017.05.022

Kumfor, F., Irish, M., Hodges, J. R., \& Piguet, O. (2013a). Discrete Neural Correlates for the Recognition of Negative Emotions $\square$ : Insights from Frontotemporal Dementia. PloS One, 8(6), e67457. https://doi.org/10.1371/journal.pone.0067457

Kumfor, F., Irish, M., Hodges, J. R., \& Piguet, O. (2013b). The orbitofrontal cortex is involved in emotional enhancement of memory $\square$ : Evidence from the dementias. Brain, 136(10), 2992 $\square 3003$. https://doi.org/10.1093/brain/awt185

Kumfor, F., Irish, M., Hodges, J. R., \& Piguet, O. (2014). Frontal and temporal lobe contributions to emotional enhancement of memory in behavioral-variant frontotemporal dementia and Alzheimer's disease. Frontiers in Behavioral Neuroscience, 8, 225. https://doi.org/10.3389/fnbeh.2014.00225

Kumfor, F., Hutchings, R., Irish, M., Hodges, J. R., Rhodes, G., Palermo, R., \& Piguet, O. (2015). Do I know you? Examining face and object memory in frontotemporal dementia. Neuropsychologia, $71, \quad 101 \square 111$. https://doi.org/10.1016/j.neuropsychologia.2015.03.020

Kumfor, F., Teo, D., Miller, L., Lah, S., Mioshi, E., Hodges, J. R., Piguet, O., \& Irish, M. (2016). Examining the Relationship Between Autobiographical Memory Impairment and Carer Burden in Dementia Syndromes. Journal of Alzheimer's Disease, 51(1), 237 $\square 248$. https://doi.org/10.3233/JAD-150740

Laisney, M., Matuszewski, V., Mézenge, F., Belliard, S., de la Sayette, V., Eustache, F., \& Desgranges, B. (2009). The underlying mechanisms of verbal fluency deficit in frontotemporal dementia and semantic dementia. Journal of Neurology, 256(7), 1083. https://doi.org/10.1007/s00415-009-5073-y

Lambon Ralph, M. A., Jefferies, E., Patterson, K., \& Rogers, T. T. (2017). The neural and computational bases of semantic cognition. Nature Reviews Neuroscience, $18(1), 42 \square 55$. https://doi.org/10.1038/nrn.2016.150

Lee, D. J., Bigio, E. H., Rogalski, E. J., \& Mesulam, M.-M. (2020). Speech and Language Presentations of FTLD-TDP Type B Neuropathology. Journal of Neuropathology and Experimental Neurology, 79(3), $277 \square 283$. https://doi.org/10.1093/jnen/nlz132

Lima-Silva, T. B., Bahia, V. S., Carvalho, V. A., Guimarães, H. C., Caramelli, P., Balthazar, M. L. F., Damasceno, B., Bottino, C. M. de C., Brucki, S. M. D., Nitrini, R., \& Yassuda, M. S. (2015). Direct and indirect assessments of activities of daily living in behavioral variant frontotemporal dementia and Alzheimer disease. Journal of Geriatric Psychiatry and Neurology, 28(1), 19ロ26. https://doi.org/10.1177/0891988714541874

Lin, P.-H., Chen, H.-H., Chen, N.-C., Chang, W.-N., Huang, C.-W., Chang, Y.-T., Hsu, S.-W., Hsu, C.-W., \& Chang, C.-C. (2016). Anatomical Correlates of Non-Verbal Perception in Dementia Patients. Frontiers in Aging Neuroscience, 8, 207. https://doi.org/10.3389/fnagi.2016.00207

Lukic, S., Thompson, C. K., Barbieri, E., Chiappetta, B., Bonakdarpour, B., Kiran, S., Rapp, B., Parrish, T. B., \& Caplan, D. (2021). Common and distinct neural substrates of sentence production and comprehension. NeuroImage, $224,117374$. https://doi.org/10.1016/j.neuroimage.2020.117374

Luzzi, S., Snowden, J. S., Neary, D., Coccia, M., Provinciali, L., \& Lambon Ralph, M. A. (2007). Distinct patterns of olfactory impairment in Alzheimer's disease, semantic dementia, frontotemporal dementia, and corticobasal degeneration. Neuropsychologia, 45(8), 1823 $\square$ 1831. https://doi.org/10.1016/j.neuropsychologia.2006.12.008

Luzzi, S., Baldinelli, S., Ranaldi, V., Fiori, C., Plutino, A., Fringuelli, F. M., Silvestrini, M., Baggio, G., \& Reverberi, C. (2020). The neural bases of discourse semantic and pragmatic deficits in patients with frontotemporal dementia and Alzheimer's disease. Cortex; a Journal Devoted to the Study of the Nervous System and Behavior, 128, $174 \square 191$. https://doi.org/10.1016/j.cortex.2020.03.012

Magerova, H., Vyhnalek, M., Laczo, J., Andel, R., Rektorova, I., Kadlecova, A., Bojar, M., \& Hort, J. (2014). Odor identification in frontotemporal lobar degeneration subtypes. American Journal of Alzheimer's Disease and Other Dementias, 29(8), 762 $\square 768$. https://doi.org/10.1177/1533317514539033

Mahoney, C. J., Beck, J., Rohrer, J. D., Lashley, T., Mok, K., Shakespeare, T., Yeatman, T., Warrington, E. K., Schott, J. M., Fox, N. C., Rossor, M. N., Hardy, J., Collinge, J., Revesz, T., Mead, S., \& Warren, J. D. (2012). Frontotemporal dementia with the C9ORF72 hexanucleotide repeat expansion $\square$ : Clinical, neuroanatomical and neuropathological features. Brain: A Journal of Neurology, 135(Pt 3), 736 $\square 750$. https://doi.org/10.1093/brain/awr361

Mahoney, C. J., Ridgway, G. R., Malone, I. B., Downey, L. E., Beck, J., Kinnunen, K. M., Schmitz, N., Golden, H. L., Rohrer, J. D., Schott, J. M., Rossor, M. N., Ourselin, S., Mead, S., Fox, N. C., \& Warren, J. D. (2014). Profiles of white matter tract

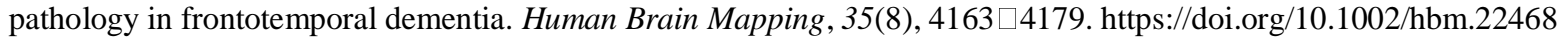

Mahoney, C. J., Simpson, I. J. A., Nicholas, J. M., Fletcher, P. D., Downey, L. E., Golden, H. L., Clark, C. N., Schmitz, N., Rohrer, J. D., Schott, J. M., Zhang, H., Ourselin, S., Warren, J. D., \& Fox, N. C. (2015). Longitudinal diffusion tensor imaging in frontotemporal dementia. Annals of Neurology, 77(1), 33 $\square 46$. https://doi.org/10.1002/ana.24296 
medRxiv preprint doi: https://doi.org/10.1101/2021.07.10.21260313; this version posted July 12, 2021. The copyright holder for this preprint

(which was not certified by peer review) is the author/funder, who has granted medRxiv a license to display the preprint in perpetuity. It is made available under a CC-BY-NC-ND 4.0 International license .

Mandelli, M. L., Vitali, P., Santos, M., Henry, M., Gola, K., Rosenberg, L., Dronkers, N., Miller, B., Seeley, W. W., \& GornoTempini, M. L. (2016). Two insular regions are differentially involved in behavioral variant FTD and nonfluent/agrammatic variant PPA. Cortex; a Journal Devoted to the Study of the Nervous System and Behavior, 74, 149 $\square 157$. https://doi.org/10.1016/j.cortex.2015.10.012

Manes, F., Torralva, T., Ibáñez, A., Roca, M., Bekinschtein, T., \& Gleichgerrcht, E. (2011). Decision-making in frontotemporal dementia $\square$ : Clinical, theoretical and legal implications. Dementia and Geriatric Cognitive Disorders, 32(1), $11 \square 17$. https://doi.org/10.1159/000329912

Manuel, A. L., Foxe, D., Bradshaw, N., Cordato, N. J., Hodges, J. R., Burrell, J. R., \& Piguet, O. (2019). Sustained attention

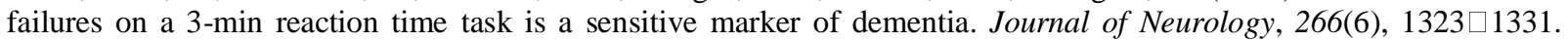
https://doi.org/10.1007/s00415-019-09261-9

Marshall, C. R., Hardy, C. J. D., Russell, L. L., Clark, C. N., Dick, K. M., Brotherhood, E. V., Bond, R. L., Mummery, C. J., Schott, J. M., Rohrer, J. D., Kilner, J. M., \& Warren, J. D. (2017). Impaired Interoceptive Accuracy in Semantic Variant Primary Progressive Aphasia. Frontiers in Neurology, 8, 610. https://doi.org/10.3389/fneur.2017.00610

Marshall, C. R., Hardy, C. J. D., Allen, M., Russell, L. L., Clark, C. N., Bond, R. L., Dick, K. M., Brotherhood, E. V., Rohrer, J. D., Kilner, J. M., \& Warren, J. D. (2018a). Cardiac responses to viewing facial emotion differentiate frontotemporal dementias. Annals of Clinical and Translational Neurology, 5(6), 687ロ696. https://doi.org/10.1002/acn3.563

Marshall, C. R., Hardy, C. J. D., Russell, L. L., Clark, C. N., Bond, R. L., Dick, K. M., Brotherhood, E. V., Mummery, C. J., Schott, J. M., Rohrer, J. D., Kilner, J. M., \& Warren, J. D. (2018b). Motor signatures of emotional reactivity in frontotemporal dementia. Scientific Reports, 8(1), 1030. https://doi.org/10.1038/s41598-018-19528-2

Marshall, C. R., Hardy, C. J. D., Russell, L. L., Bond, R. L., Sivasathiaseelan, H., Greaves, C., Moore, K. M., Agustus, J. L., van Leeuwen, J. E. P., Wastling, S. J., Rohrer, J. D., Kilner, J. M., \& Warren, J. D. (2019). The functional neuroanatomy of emotion processing in frontotemporal dementias. Brain: A Journal of Neurology, 142(9), 2873ロ 2887. https://doi.org/10.1093/brain/awz204

Massimo, L., Xie, S. X., Rennert, L., Fick, D. M., Halpin, A., Placek, K., Williams, A., Rascovsky, K., Irwin, D. J., Grossman, M., \& McMillan, C. T. (2019). Occupational attainment influences longitudinal decline in behavioral variant frontotemporal degeneration. Brain Imaging and Behavior, 13(1), 293ॅ301. https://doi.org/10.1007/s1 1682-018-9852-x

Matuszewski, V., Piolino, P., de la Sayette, V., Lalevée, C., Pélerin, A., Dupuy, B., Viader, F., Eustache, F., \& Desgranges, B. (2006). Retrieval mechanisms for autobiographical memories $\square$ : Insights from the frontal variant of frontotemporal dementia. Neuropsychologia, 44(12), 2386 $\square 2397$. https://doi.org/10.1016/j.neuropsychologia.2006.04.031

McKinnon, M. C., Nica, E. I., Sengdy, P., Kovacevic, N., Moscovitch, M., Freedman, M., Miller, B. L., Black, S. E., \& Levine, B. (2008). Autobiographical Memory and Patterns of Brain Atrophy in Fronto-temporal Lobar Degeneration. Journal of Cognitive Neuroscience, 20(10), 1839 $\square 1853$. https://doi.org/10.1162/jocn.2008.20126

McMillan, C. T., Coleman, D., Clark, R., Liang, T.-W., Gross, R. G., \& Grossman, M. (2013). Converging evidence for the processing costs associated with ambiguous quantifier comprehension. Frontiers in Psychology, 4, 153. https://doi.org/10.3389/fpsyg.2013.00153

Mendez, M. F., \& Shapira, J. S. (2013). Hypersexual behavior in frontotemporal dementia $\square$ : A comparison with early-onset

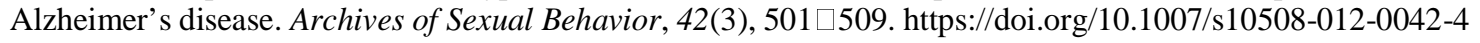

Mendez, M. F., \& Lim, G. T. H. (2004). Alterations of the sense of «humanness » in right hemisphere predominant frontotemporal dementia patients. Cognitive and Behavioral Neurology: Official Journal of the Society for Behavioral and Cognitive Neurology, 17(3), 133ロ138. https://doi.org/10.1097/01.wnn.0000136593.21532.16

Mendez, M. F., Fong, S. S., Shapira, J. S., Jimenez, E. E., Kaiser, N. C., Kremen, S. A., \& Tsai, P.-H. (2014). Observation of Social Behavior in Frontotemporal Dementia. American Journal of Alzheimer's Disease \& Other Dementiasr, 29(3), 215 $\square 221$. https://doi.org/10.1177/1533317513517035

Mendez, M. F., Carr, A. R., \& Paholpak, P. (2017). Psychotic-Like Speech in Frontotemporal Dementia. The Journal of Neuropsychiatry and Clinical Neurosciences, 29(2), 183ロ185. https://doi.org/10.1176/appi.neuropsych.16030058

Mesulam, M.-M., Rogalski, E. J., Wieneke, C., Hurley, R. S., Geula, C., Bigio, E. H., Thompson, C. K., \& Weintraub, S. (2014). Primary progressive aphasia and the evolving neurology of the language network. Nature Reviews. Neurology, 10(10), 554־569. https://doi.org/10.1038/nrneurol.2014.159

Miller, L. A., Hsieh, S., Lah, S., Savage, S., Hodges, J. R., \& Piguet, O. (2012). One Size Does Not Fit All $\square$ : Face Emotion Processing Impairments in Semantic Dementia, Behavioural-Variant Frontotemporal Dementia and Alzheimer's Disease Are Mediated by Distinct Cognitive Deficits. Behavioural Neurology, 25(1), 53ロ60. https://doi.org/10.3233/BEN-20120349

Moore, K., Convery, R., Bocchetta, M., Neason, M., Cash, D. M., Greaves, C., Russell, L. L., Clarke, M. T. M., Peakman, G., van Swieten, J., Jiskoot, L., Moreno, F., Barandiaran, M., Sanchez-Valle, R., Borroni, B., Laforce, R., Doré, M.-C., Masellis, M., Tartaglia, M. C., ... Genetic FTD Initiative, GENFI*. (2020). A modified Camel and Cactus Test detects presymptomatic semantic impairment in genetic frontotemporal dementia within the GENFI cohort. Applied Neuropsychology. Adult, 1 $\square 8$. https://doi.org/10.1080/23279095.2020.1716357

Morrison, R. G., Krawczyk, D. C., Holyoak, K. J., Hummel, J. E., Chow, T. W., Miller, B. L., \& Knowlton, B. J. (2004). A neurocomputational model of analogical reasoning and its breakdown in frontotemporal lobar degeneration. Journal of Cognitive Neuroscience, 16(2), 260 271 . https://doi.org/10.1162/089892904322984553

Murray, R., Koenig, P., Antani, S., McCawley, G., \& Grossman, M. (2007). Lexical acquisition in progressive aphasia and frontotemporal dementia. Cognitive Neuropsychology, 24(1), 48ロ69. https://doi.org/10.1080/02643290600890657

Neary, D., Snowden, J. S., Gustafson, L., Passant, U., Stuss, D., Black, S., Freedman, M., Kertesz, A., Robert, P. H., Albert, M., Boone, K., Miller, B. L., Cummings, J., \& Benson, D. F. (1998). Frontotemporal lobar degeneration $\square$ : A consensus on clinical diagnostic criteria. Neurology, 51(6), 1546 $\square$ 1554. https://doi.org/10.1212/wnl.51.6.1546 
medRxiv preprint doi: https://doi.org/10.1101/2021.07.10.21260313; this version posted July 12, 2021. The copyright holder for this preprint

(which was not certified by peer review) is the author/funder, who has granted medRxiv a license to display the preprint in perpetuity. It is made available under a CC-BY-NC-ND 4.0 International license .

Nevler, N., Ash, S., Jester, C., Irwin, D. J., Liberman, M., \& Grossman, M. (2017). Automatic measurement of prosody in behavioral variant FTD. Neurology, 89(7), 650ロ656. https://doi.org/10.1212/WNL.0000000000004236

Oliver, L. D., Mitchell, D. G. V., Dziobek, I., MacKinley, J., Coleman, K., Rankin, K. P., \& Finger, E. C. (2015). Parsing cognitive and emotional empathy deficits for negative and positive stimuli in frontotemporal dementia. Neuropsychologia, 67, 14ロ26. https://doi.org/10.1016/j.neuropsychologia.2014.11.022

Omar, R., Henley, S. M. D., Bartlett, J. W., Hailstone, J. C., Gordon, E., Sauter, D. A., Frost, C., Scott, S. K., \& Warren, J. D. (2011). The structural neuroanatomy of music emotion recognition $\square$ : Evidence from frontotemporal lobar degeneration. NeuroImage, 56(3), 1814 $\square$ 1821. https://doi.org/10.1016/j.neuroimage.2011.03.002

Omar, R., Mahoney, C. J., Buckley, A. H., \& Warren, J. D. (2013). Flavour identification in frontotemporal lobar degeneration. Journal of Neurology, Neurosurgery, and Psychiatry, 84(1), 88ロ93. https://doi.org/10.1136/jnnp-2012-303853

Orasji, S. S. S., Mulder, J. L., de Bruijn, S. F. T. M., \& Wirtz, P. W. (2016). Olfactory dysfunction in behavioral variant frontotemporal dementia. Clinical Neurology and Neurosurgery, 141, 106ロ110. https://doi.org/10.1016/j.clineuro.2016.01.003

Page, M. J., McKenzie, J. E., Bossuyt, P. M., Boutron, I., Hoffmann, T. C., Mulrow, C. D., Shamseer, L., Tetzlaff, J. M., Akl, E. A., Brennan, S. E., Chou, R., Glanville, J., Grimshaw, J. M., Hróbjartsson, A., Lalu, M. M., Li, T., Loder, E. W., MayoWilson, E., McDonald, S., ... Moher, D. (2021). The PRISMA 2020 statement $\square$ : An updated guideline for reporting systematic reviews. $B M J, 372, \mathrm{n} 71$. https://doi.org/10.1136/bmj.n71

Park, H. K., Park, K. H., Yoon, B., Lee, J.-H., Choi, S. H., Joung, J. H., Yoon, S. J., Kim, B. C., Kim, S. H., Kim, E.-J., Na, D. L., \& Park, K. W. (2017). Clinical characteristics of parkinsonism in frontotemporal dementia according to subtypes. Journal of the Neurological Sciences, 372, 51 $\square 56$. https://doi.org/10.1016/j.jns.2016.11.033

Peelle, J. E., Cooke, A., Moore, P., Vesely, L., \& Grossman, M. (2007). Syntactic and thematic components of sentence processing in progressive nonfluent aphasia and nonaphasic frontotemporal dementia. Journal of Neurolinguistics, 20(6),

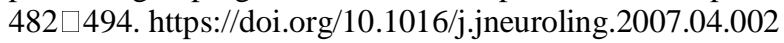

Peelle, J. E., Troiani, V., Gee, J., Moore, P., McMillan, C., Vesely, L., \& Grossman, M. (2008). Sentence comprehension and voxel-based morphometry in progressive nonfluent aphasia, semantic dementia, and nonaphasic frontotemporal

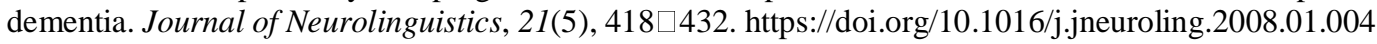

Perry, D. C., Brown, J. A., Possin, K. L., Datta, S., Trujillo, A., Radke, A., Karydas, A., Kornak, J., Sias, A. C., Rabinovici, G. D., Gorno-Tempini, M. L., Boxer, A. L., De May, M., Rankin, K. P., Sturm, V. E., Lee, S. E., Matthews, B. R., Kao, A. W., Vossel, K. A., ... Seeley, W. W. (2017). Clinicopathological correlations in behavioural variant frontotemporal dementia. Brain: A Journal of Neurology, 140(12), 3329ロ3345. https://doi.org/10.1093/brain/awx254

Perry, R. J., \& Hodges, J. R. (2000). Differentiating frontal and temporal variant frontotemporal dementia from Alzheimer's disease. Neurology, 54(12), 2277ロ2284. https://doi.org/10.1212/WNL.54.12.2277

Pichon, S., \& Kell, C. A. (2013). Affective and sensorimotor components of emotional prosody generation. The Journal of Neuroscience: The Official Journal of the Society for Neuroscience, 33(4), 1640ロ1650. https://doi.org/10.1523/JNEUROSCI.3530-12.2013

Piolino, P., Chételat, G., Matuszewski, V., Landeau, B., Mézenge, F., Viader, F., de la Sayette, V., Eustache, F., \& Desgranges, B. (2007). In search of autobiographical memories $\square$ : A PET study in the frontal variant of frontotemporal dementia. Neuropsychologia, 45(12), 2730 $\square 2743$. https://doi.org/10.1016/j.neuropsychologia.2007.04.013

Pozueta, A., Lage, C., García-Martínez, M., Kazimierczak, M., Bravo, M., López-García, S., Riancho, J., González-Suarez, A., Vázquez-Higuera, J. L., de Arcocha-Torres, M., Banzo, I., Jiménez-Bonilla, J., Berciano, J., Rodríguez-Rodríguez, E., \& Sánchez-Juan, P. (2019). Cognitive and Behavioral Profiles of Left and Right Semantic Dementia $\square$ : Differential Diagnosis with Behavioral Variant Frontotemporal Dementia and Alzheimer's Disease. Journal of Alzheimer's Disease: $J A D, 72(4), 1129 \square 1144$. https://doi.org/10.3233/JAD-190877

Pressman, P. S., Ross, E. D., Cohen, K. B., Chen, K.-H., Miller, B. L., Hunter, L. E., Gorno-Tempini, M. L., \& Levenson, R. W. (2019). Interpersonal prosodic correlation in frontotemporal dementia. Annals of Clinical and Translational Neurology,

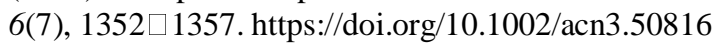

Price, C. J. (2010). The anatomy of language $\square$ : A review of 100 fMRI studies published in 2009. Annals of the New York Academy of Sciences, 1191, 62 $\square 88$. https://doi.org/10.1111/j.1749-6632.2010.05444.x

Ranasinghe, K. G., Rankin, K. P., Pressman, P. S., Perry, D. C., Lobach, I. V., Seeley, W. W., Coppola, G., Karydas, A. M., Grinberg, L. T., Shany-Ur, T., Lee, S. E., Rabinovici, G. D., Rosen, H. J., Gorno-Tempini, M. L., Boxer, A. L., Miller, Z. A., Chiong, W., DeMay, M., Kramer, J. H., ... Miller, B. L. (2016). Distinct Subtypes of Behavioral Variant

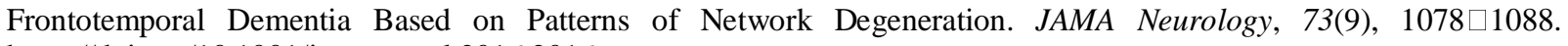
https://doi.org/10.1001/jamaneurol.2016.2016

Rankin, K. P., Liu, A. A., Howard, S., Slama, H., Hou, C. E., Shuster, K., \& Miller, B. L. (2007). A Case-controlled Study of Altered Visual Art Production in Alzheimer's and FTLD. Cognitive and Behavioral Neurology, 20(1), $48 \square 61$. https://doi.org/10.1097/WNN.0b013e31803141dd

Rankin, K. P., Salazar, A., Gorno-Tempini, M. L., Sollberger, M., Wilson, S. M., Pavlic, D., Stanley, C. M., Glenn, S., Weiner, M. W., \& Miller, B. L. (2009). Detecting sarcasm from paralinguistic cues $\square$ : Anatomic and cognitive correlates in neurodegenerative disease. NeuroImage, 47(4), 2005 $\square 2015$. https://doi.org/10.1016/j.neuroimage.2009.05.077

Rascovsky, K., Hodges, J. R., Knopman, D., Mendez, M. F., Kramer, J. H., Neuhaus, J., van Swieten, J. C., Seelaar, H., Dopper, E. G. P., Onyike, C. U., Hillis, A. E., Josephs, K. A., Boeve, B. F., Kertesz, A., Seeley, W. W., Rankin, K. P., Johnson, J. K., Gorno-Tempini, M.-L., Rosen, H., ... Miller, B. L. (2011). Sensitivity of revised diagnostic criteria for the behavioural variant of frontotemporal dementia. Brain: A Journal of Neurology, 134(Pt 9), $2456 \square 2477$. https://doi.org/10.1093/brain/awr179

Reyes, P., Ortega-Merchan, M. P., Rueda, A., Uriza, F., Santamaria-García, H., Rojas-Serrano, N., Rodriguez-Santos, J., VelascoLeon, M. C., Rodriguez-Parra, J. D., Mora-Diaz, D. E., \& Matallana, D. (2018). Functional Connectivity Changes in 
medRxiv preprint doi: https://doi.org/10.1101/2021.07.10.21260313; this version posted July 12, 2021. The copyright holder for this preprint (which was not certified by peer review) is the author/funder, who has granted medRxiv a license to display the preprint in perpetuity. It is made available under a CC-BY-NC-ND 4.0 International license .

Behavioral, Semantic, and Nonfluent Variants of Frontotemporal Dementia. Behavioural Neurology, 2018, 9684129. https://doi.org/10.1155/2018/9684129

Reyes, P. A., Rueda, A. D. P., Uriza, F., \& Matallana, D. L. (2019). Networks Disrupted in Linguistic Variants of Frontotemporal Dementia. Frontiers in Neurology, 10, 903. https://doi.org/10.3389/fneur.2019.00903

Rhee, J., Antiquena, P., \& Grossman, M. (2001). Verb Comprehension in Frontotemporal Degeneration $\square$ : The Role of Grammatical, Semantic and Executive Components. Neurocase, 7(2), 173ロ184. https://doi.org/10.1093/neucas/7.2.173

Roca, M., Manes, F., Gleichgerrcht, E., Watson, P., Ibáñez, A., Thompson, R., Torralva, T., \& Duncan, J. (2013). Intelligence and executive functions in frontotemporal dementia. Neuropsychologia, 51 (4), $725 \square 730$. https://doi.org/10.1016/j.neuropsychologia.2013.01.008

Rogers, T. T., Ivanoiu, A., Patterson, K., \& Hodges, J. R. (2006). Semantic memory in Alzheimer's disease and the

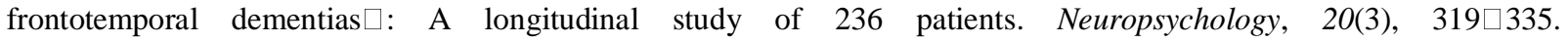
https://doi.org/10.1037/0894-4105.20.3.319

Rosen, H. J., Gorno-Tempini, M. L., Goldman, W. P., Perry, R. J., Schuff, N., Weiner, M., Feiwell, R., Kramer, J. H., \& Miller, B. L. (2002). Patterns of brain atrophy in frontotemporal dementia and semantic dementia. Neurology, 58(2), $198 \square 208$. https://doi.org/10.1212/WNL.58.2.198

Rosen, H. J., Pace-Savitsky, K., Perry, R. J., Kramer, J. H., Miller, B. L., \& Levenson, R. W. (2004). Recognition of Emotion in the Frontal and Temporal Variants of Frontotemporal Dementia. Dementia and Geriatric Cognitive Disorders, 17(4), 277ロ281. https://doi.org/10.1159/000077154

Rosen, H. J., Alcantar, O., Zakrzewski, J., Shimamura, A. P., Neuhaus, J., \& Miller, B. L. (2014). Metacognition in the behavioral

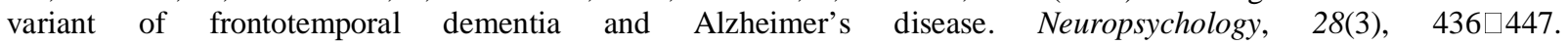
https://doi.org/10.1037/neu0000012

Rousseaux, M., Sève, A., Vallet, M., Pasquier, F., \& Mackowiak-Cordoliani, M. A. (2010). An analysis of communication in

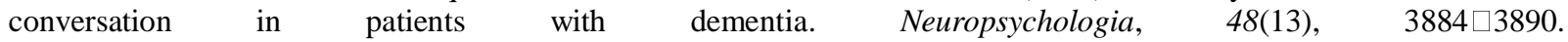
https://doi.org/10.1016/j.neuropsychologia.2010.09.026

Russo, G., Russo, M. J., Buyatti, D., Chrem, P., Bagnati, P., Fernández Suarez, M., Campos, J., Cohen, G., Amengual, A., Allegri, R. F., \& Knopman, D. S. (2014). Utility of the Spanish version of the FTLD-modified CDR in the diagnosis and staging

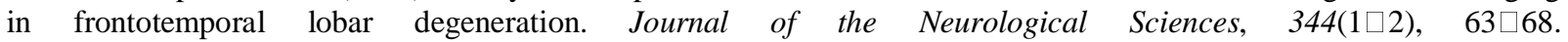
https://doi.org/10.1016/j.jns.2014.06.024

Salimi, S., Irish, M., Foxe, D., Hodges, J. R., Piguet, O., \& Burrell, J. R. (2019). Visuospatial dysfunction in Alzheimer's disease and behavioural variant frontotemporal dementia. Journal of the Neurological Sciences, 402, 74ロ80. https://doi.org/10.1016/j.jns.2019.04.019

Santamaría-García, H., Baez, S., Reyes, P., Santamaría-García, J. A., Santacruz-Escudero, J. M., Matallana, D., Arévalo, A., Sigman, M., García, A. M., \& Ibáñez, A. (2017). A lesion model of envy and Schadenfreude $\square$ : Legal, deservingness and moral dimensions as revealed by neurodegeneration. Brain: A Journal of Neurology, 140(12), 3357ロ 3377. https://doi.org/10.1093/brain/awx269

Saracino, D., Ferrieux, S., Noguès-Lassiaille, M., Houot, M., Funkiewiez, A., Sellami, L., Deramecourt, V., Pasquier, F., Couratier, P., Pariente, J., Géraudie, A., Epelbaum, S., Wallon, D., Hannequin, D., Martinaud, O., Clot, F., Camuzat, A., Bottani, S., Rinaldi, D., ... Ftd/Ftd-Als, on behalf of the F. R. N. on. (2021). Primary Progressive Aphasia Associated With GRN Mutations $\square$ : New Insights Into the Nonamyloid Logopenic Variant. Neurology, 97(1), e88ロe102. https://doi.org/10.1212/WNL.0000000000012174

Savundranayagam, M. Y., Hummert, M. L., \& Montgomery, R. J. V. (2005). Investigating the effects of communication problems on caregiver burden. The Journals of Gerontology. Series B, Psychological Sciences and Social Sciences, 60(1), S48-55. https://doi.org/10.1093/geronb/60.1.s48

Saxon, J. A., Thompson, J. C., Jones, M., Harris, J. M., Richardson, A. M., Langheinrich, T., Neary, D., Mann, D. M., \& Snowden, J. S. (2017). Examining the language and behavioural profile in FTD and ALS-FTD. Journal of Neurology, Neurosurgery, and Psychiatry, 88(8), 675ロ680. https://doi.org/10.1136/jnnp-2017-315667

Schell, M., Zaccarella, E., \& Friederici, A. D. (2017). Differential cortical contribution of syntax and semantics $\square$ : An fMRI study on two-word phrasal processing. Cortex; a Journal Devoted to the Study of the Nervous System and Behavior, 96, 105 $\square 120$. https://doi.org/10.1016/j.cortex.2017.09.002

Scherling, C. S., Hall, T., Berisha, F., Klepac, K., Karydas, A., Coppola, G., Kramer, J. H., Rabinovici, G., Ahlijanian, M., Miller, B. L., Seeley, W., Grinberg, L. T., Rosen, H., Meredith, J., \& Boxer, A. L. (2014). Cerebrospinal fluid neurofilament concentration reflects disease severity in frontotemporal degeneration. Annals of Neurology, 75(1), 116 126. https://doi.org/10.1002/ana.24052

Scherling, C. S., Zakrzewski, J., Datta, S., Levenson, R. W., Shimamura, A. P., Sturm, V. E., Miller, B. L., \& Rosen, H. J. (2017). Mistakes, Too Few to Mention? Impaired Self-conscious Emotional Processing of Errors in the Behavioral Variant of Frontotemporal Dementia. Frontiers in Behavioral Neuroscience, 11, 189. https://doi.org/10.3389/fnbeh.2017.00189

Schirmer, A., \& Kotz, S. A. (2006). Beyond the right hemisphere $\square$ : Brain mechanisms mediating vocal emotional processing. Trends in Cognitive Sciences, 10(1), 24ロ30. https://doi.org/10.1016/j.tics.2005.11.009

Schubert, S., Leyton, C. E., Hodges, J. R., \& Piguet, O. (2016). Longitudinal Memory Profiles in Behavioral-Variant

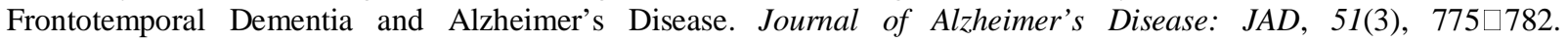
https://doi.org/10.3233/JAD-150802

Semler, E., Petersdorff, L., Anderl-Straub, S., Böhm, S., Lulé, D., Fangerau, H., Ludolph, A. C., Otto, M., \& Uttner, I. (2019). Moral judgment in patients with behavioral variant of frontotemporal dementia and amyotrophic lateral sclerosis $\square$ : No impairment of the moral position, but rather its execution. Amyotrophic Lateral Sclerosis and Frontotemporal Degeneration, $20(1 \square 2), 12 \square 18$. https://doi.org/10.1080/21678421.2018.1534972 
medRxiv preprint doi: https://doi.org/10.1101/2021.07.10.21260313; this version posted July 12, 2021. The copyright holder for this preprint

(which was not certified by peer review) is the author/funder, who has granted medRxiv a license to display the preprint in perpetuity. It is made available under a CC-BY-NC-ND 4.0 International license .

Sha, S. J., Takada, L. T., Rankin, K. P., Yokoyama, J. S., Rutherford, N. J., Fong, J. C., Khan, B., Karydas, A., Baker, M. C., DeJesus-Hernandez, M., Pribadi, M., Coppola, G., Geschwind, D. H., Rademakers, R., Lee, S. E., Seeley, W., Miller, B. L., \& Boxer, A. L. (2012). Frontotemporal dementia due to C9ORF72 mutations $\square$ : Clinical and imaging features. Neurology, 79(10), 1002 $\square$ 1011. https://doi.org/10.1212/WNL.0b013e318268452e

Shany-Ur, T., Poorzand, P., Grossman, S. N., Growdon, M. E., Jang, J. Y., Ketelle, R. S., Miller, B. L., \& Rankin, K. P. (2012). Comprehension of insincere communication in neurodegenerative disease $\square$ : Lies, sarcasm, and theory of mind. Cortex, 48(10), 1329 $\square 1341$. https://doi.org/10.1016/j.cortex.2011.08.003

Smits, L. L., Harten, A. C. van, Pijnenburg, Y. a. L., Koedam, E. L. G. E., Bouwman, F. H., Sistermans, N., Reuling, I. E. W., Prins, N. D., Lemstra, A. W., Scheltens, P., \& Flier, W. M. van der. (2015). Trajectories of cognitive decline in different types of dementia. Psychological Medicine, 45(5), 1051 $\square$ 1059. https://doi.org/10.1017/S0033291714002153

Snowden, J. S., Austin, N. A., Sembi, S., Thompson, J. C., Craufurd, D., \& Neary, D. (2008). Emotion recognition in Huntington's disease and frontotemporal dementia. Neuropsychologia, 46(11), $2638 \square 2649$. https://doi.org/10.1016/j.neuropsychologia.2008.04.018

Spotorno, N., Healey, M., McMillan, C. T., Rascovsky, K., Irwin, D. J., Clark, R., \& Grossman, M. (2015). Processing ambiguity in a linguistic context $\square$ : Decision-making difficulties in non-aphasic patients with behavioral variant frontotemporal degeneration. Frontiers in Human Neuroscience, 9, 583. https://doi.org/10.3389/fnhum.2015.00583

Spotorno, N., McMillan, C. T., Rascovsky, K., Irwin, D. J., Clark, R., \& Grossman, M. (2015). Beyond words $\square$ : Pragmatic inference in behavioral variant of frontotemporal degeneration. Neuropsychologia, $75, \quad 556 \square 564$. https://doi.org/10.1016/j.neuropsychologia.2015.07.002

Stock, J. V. den, Stam, D., Winter, F.-L. D., Mantini, D., Szmrecsanyi, B., Laere, K. V., Vandenberghe, R., \& Vandenbulcke, M. (2017). Moral processing deficit in behavioral variant frontotemporal dementia is associated with facial emotion recognition and brain changes in default mode and salience network areas. Brain and Behavior, 7(12), e00843. https://doi.org/10.1002/brb3.843

Stopford, C. L., Thompson, J. C., Neary, D., Richardson, A. M. T., \& Snowden, J. S. (2012). Working memory, attention, and executive function in Alzheimer's disease and frontotemporal dementia. Cortex, 48(4), $429 \square 446$. https://doi.org/10.1016/j.cortex.2010.12.002

Sturm, V. E., Sible, I. J., Datta, S., Hua, A. Y., Perry, D. C., Kramer, J. H., Miller, B. L., Seeley, W. W., \& Rosen, H. J. (2018). Resting parasympathetic dysfunction predicts prosocial helping deficits in behavioral variant frontotemporal dementia. Cortex, 109, 141 $\square 155$. https://doi.org/10.1016/j.cortex.2018.09.006

Suhonen, N.-M., Haanpää, R. M., Korhonen, V., Jokelainen, J., Pitkäniemi, A., Heikkinen, A.-L., Krüger, J., Hartikainen, P., Helisalmi, S., Hiltunen, M., Hänninen, T., \& Remes, A. M. (2017). Neuropsychological Profile in the C9ORF72 Associated Behavioral Variant Frontotemporal Dementia. Journal of Alzheimer's Disease: JAD, $58(2), 479 \square 489$. https://doi.org/10.3233/JAD-161142

Tan, R. H., Devenney, E., Kiernan, M. C., Halliday, G. M., Hodges, J. R., \& Hornberger, M. (2015). Terra incognita-cerebellar contributions to neuropsychiatric and cognitive dysfunction in behavioral variant frontotemporal dementia. Frontiers in Aging Neuroscience, 7, 121. https://doi.org/10.3389/fnagi.2015.00121

Torralva, T., Kipps, C. M., Hodges, J. R., Clark, L., Bekinschtein, T., Roca, M., Calcagno, M. L., \& Manes, F. (2007). The relationship between affective decision-making and theory of mind in the frontal variant of fronto-temporal dementia. Neuropsychologia, 45(2), 342 $\square 349$. https://doi.org/10.1016/j.neuropsychologia.2006.05.031

Torralva, T., Roca, M., Gleichgerrcht, E., Bekinschtein, T., \& Manes, F. (2009). A neuropsychological battery to detect specific executive and social cognitive impairments in early frontotemporal dementia. Brain: A Journal of Neurology, 132(Pt 5), 1299 $\square$ 1309. https://doi.org/10.1093/brain/awp041

Torralva, T., Sposato, L. A., Riccio, P. M., Gleichgerrcht, E., Roca, M., Toledo, J. B., Trojanowski, J. Q., Kukull, W. A., Manes, F., \& Hachinski, V. (2015). Role of brain infarcts in behavioral variant frontotemporal dementia $\square$ : Clinicopathological characterization in the National Alzheimer's Coordinating Center database. Neurobiology of Aging, 36(10), $2861 \square 2868$. https://doi.org/10.1016/j.neurobiolaging.2015.06.026

Van den Stock, J., De Winter, F.-L., de Gelder, B., Rangarajan, J. R., Cypers, G., Maes, F., Sunaert, S., Goffin, K., Vandenberghe, R., \& Vandenbulcke, M. (2015). Impaired recognition of body expressions in the behavioral variant of frontotemporal dementia. Neuropsychologia, 75, 496 $\square 504$. https://doi.org/10.1016/j.neuropsychologia.2015.06.035

Van den Stock, J., De Winter, F.-L., Stam, D., Van de Vliet, L., Huang, Y.-A., Dries, E., Van Assche, L., Emsell, L., Bouckaert, F., \& Vandenbulcke, M. (2019). Reduced tendency to attribute mental states to abstract shapes in behavioral variant frontotemporal dementia links with cerebellar structural integrity. NeuroImage. Clinical, 22, 101770. https://doi.org/10.1016/j.nicl.2019.101770

Vignando, M., Rumiati, R. I., Manganotti, P., Cattaruzza, T., \& Aiello, M. (2020). Establishing links between abnormal eating behaviours and semantic deficits in dementia. Journal of Neuropsychology, 14(3), $431 \square 448$. https://doi.org/10.1111/jnp.12195

Virani, K., Jesso, S., Kertesz, A., Mitchell, D., \& Finger, E. (2013). Functional neural correlates of emotional expression processing deficits in behavioural variant frontotemporal dementia. Journal of Psychiatry \& Neuroscience: JPN, 38(3), 174 $\square$ 182. https://doi.org/10.1503/jpn.120008

Viskontas, I. V., Boxer, A. L., Fesenko, J., Matlin, A., Heuer, H. W., Mirsky, J., \& Miller, B. L. (2011). Visual search patterns in semantic dementia show paradoxical facilitation of binding processes. Neuropsychologia, $49(3), 468 \square 478$. https://doi.org/10.1016/j.neuropsychologia.2010.12.039

Vogel, A. P., Poole, M. L., Pemberton, H., Caverlé, M. W. J., Boonstra, F. M. C., Low, E., Darby, D., \& Brodtmann, A. (2017). Motor speech signature of behavioral variant frontotemporal dementia $\square$ : Refining the phenotype. Neurology, 89(8), 837 $\square 844$. https://doi.org/10.1212/WNL.0000000000004248 
medRxiv preprint doi: https://doi.org/10.1101/2021.07.10.21260313; this version posted July 12, 2021. The copyright holder for this preprint

(which was not certified by peer review) is the author/funder, who has granted medRxiv a license to display the preprint in perpetuity. It is made available under a CC-BY-NC-ND 4.0 International license .

Wells, G. A., Shea, B., O’Connell, D. A., Peterson, J., Welch, V., Losos, M., \& Tugwell, P. (2000). The Newcastle-Ottawa Scale (NOS) for assessing the quality of nonrandomised studies in meta-analyses. http://www.ohri.ca/programs/clinical_epidemiology/oxford.asp

Whitwell, J. L., Przybelski, S. A., Weigand, S. D., Ivnik, R. J., Vemuri, P., Gunter, J. L., Senjem, M. L., Shiung, M. M., Boeve, B. F., Knopman, D. S., Parisi, J. E., Dickson, D. W., Petersen, R. C., Jack, C. R., \& Josephs, K. A. (2009). Distinct anatomical subtypes of the behavioural variant of frontotemporal dementia $\square$ : A cluster analysis study. Brain: A Journal of Neurology, 132(Pt 11), 2932 $\square 2946$. https://doi.org/10.1093/brain/awp232

Wicklund, A. H., Johnson, N., \& Weintraub, S. (2004). Preservation of Reasoning in Primary Progressive Aphasia $\square$ : Further Differentiation from Alzheimer's Disease and the Behavioral Presentation of Frontotemporal Dementia. Journal of Clinical and Experimental Neuropsychology, 26(3), 347—355. https://doi.org/10.1080/13803390490510077

Wicklund, A. H., Rademaker, A., Johnson, N., Weitner, B. B., \& Weintraub, S. (2007). Rate of Cognitive Change Measured by Neuropsychologic Test Performance in 3 Distinct Dementia Syndromes. Alzheimer Disease \& Associated Disorders, 21(4), S70. https://doi.org/10.1097/WAD.0b013e31815bf8a5

Wilson, N.-A., Ramanan, S., Roquet, D., Goldberg, Z.-L., Hodges, J. R., Piguet, O., \& Irish, M. (2020). Scene construction impairments in frontotemporal dementia $\square$ : Evidence for a primary hippocampal contribution. Neuropsychologia, 137, 107327. https://doi.org/10.1016/j.neuropsychologia.2019.107327

Wilson, S. M., Brambati, S. M., Henry, R. G., Handwerker, D. A., Agosta, F., Miller, B. L., Wilkins, D. P., Ogar, J. M., \& GornoTempini, M. L. (2009). The neural basis of surface dyslexia in semantic dementia. Brain: A Journal of Neurology, 132(Pt 1), 71 $\square$ 86. https://doi.org/10.1093/brain/awn300

Wilson, S. M., Henry, M. L., Besbris, M., Ogar, J. M., Dronkers, N. F., Jarrold, W., Miller, B. L., \& Gorno-Tempini, M. L. (2010a). Connected speech production in three variants of primary progressive aphasia. Brain: A Journal of Neurology, 133(Pt 7), 2069 $\square$ 2088. https://doi.org/10.1093/brain/awq129

Wilson, S. M., Henry, M. L., Besbris, M., Ogar, J. M., Dronkers, N. F., Jarrold, W., Miller, B. L., \& Gorno-Tempini, M. L. (2010b). Connected speech production in three variants of primary progressive aphasia. Brain, 133(7), $2069 \square 2088$. https://doi.org/10.1093/brain/awq129

Wilson, S. M., DeMarco, A. T., Henry, M. L., Gesierich, B., Babiak, M., Mandelli, M. L., Miller, B. L., \& Gorno-Tempini, M. L. (2014). What role does the anterior temporal lobe play in sentence-level processing? Neural correlates of syntactic processing in semantic variant primary progressive aphasia. Journal of Cognitive Neuroscience, $26(5), 970 \square 985$. https://doi.org/10.1162/jocn_a_00550

Ye, B. S., Choi, S. H., Han, S.-H., Kim, S., Yang, D.-W., Park, K. H., Han, H. J., Youn, Y. C., Choi, B.-O., Kim, S. H., Woo, S., Na, D. L., \& Kim, E.-J. (2015). Clinical and Neuropsychological Comparisons of Early-Onset Versus Late-Onset Frontotemporal Dementia $\square$ : A CREDOS-FTD Study. Journal of Alzheimer's Disease: JAD, 45(2), $599 \square 608$. https://doi.org/10.3233/JAD-141044

Yunusova, Y., Graham, N. L., Shellikeri, S., Phuong, K., Kulkarni, M., Rochon, E., Tang-Wai, D. F., Chow, T. W., Black, S. E., Zinman, L. H., \& Green, J. R. (2016). Profiling Speech and Pausing in Amyotrophic Lateral Sclerosis (ALS) and Frontotemporal Dementia (FTD). PLOS ONE, 11(1), e0147573. https://doi.org/10.1371/journal.pone.0147573

Zhou, J., Greicius, M. D., Gennatas, E. D., Growdon, M. E., Jang, J. Y., Rabinovici, G. D., Kramer, J. H., Weiner, M., Miller, B. L., \& Seeley, W. W. (2010). Divergent network connectivity changes in behavioural variant frontotemporal dementia and Alzheimer's disease. Brain, 133(5), 1352 $\square$ 1367. https://doi.org/10.1093/brain/awq075 
medRxiv preprint doi: https://doi.org/10.1101/2021.07.10.21260313; this version posted July 12, 2021. The copyright holder for this preprint (which was not certified by peer review) is the author/funder, who has granted medRxiv a license to display the preprint in perpetuity.

It is made available under a CC-BY-NC-ND 4.0 International license.

\section{Figures}

Figure 1: PRISMA Flowchart of literature search.

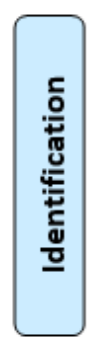

Records identified through database searching ( $n=6014)$
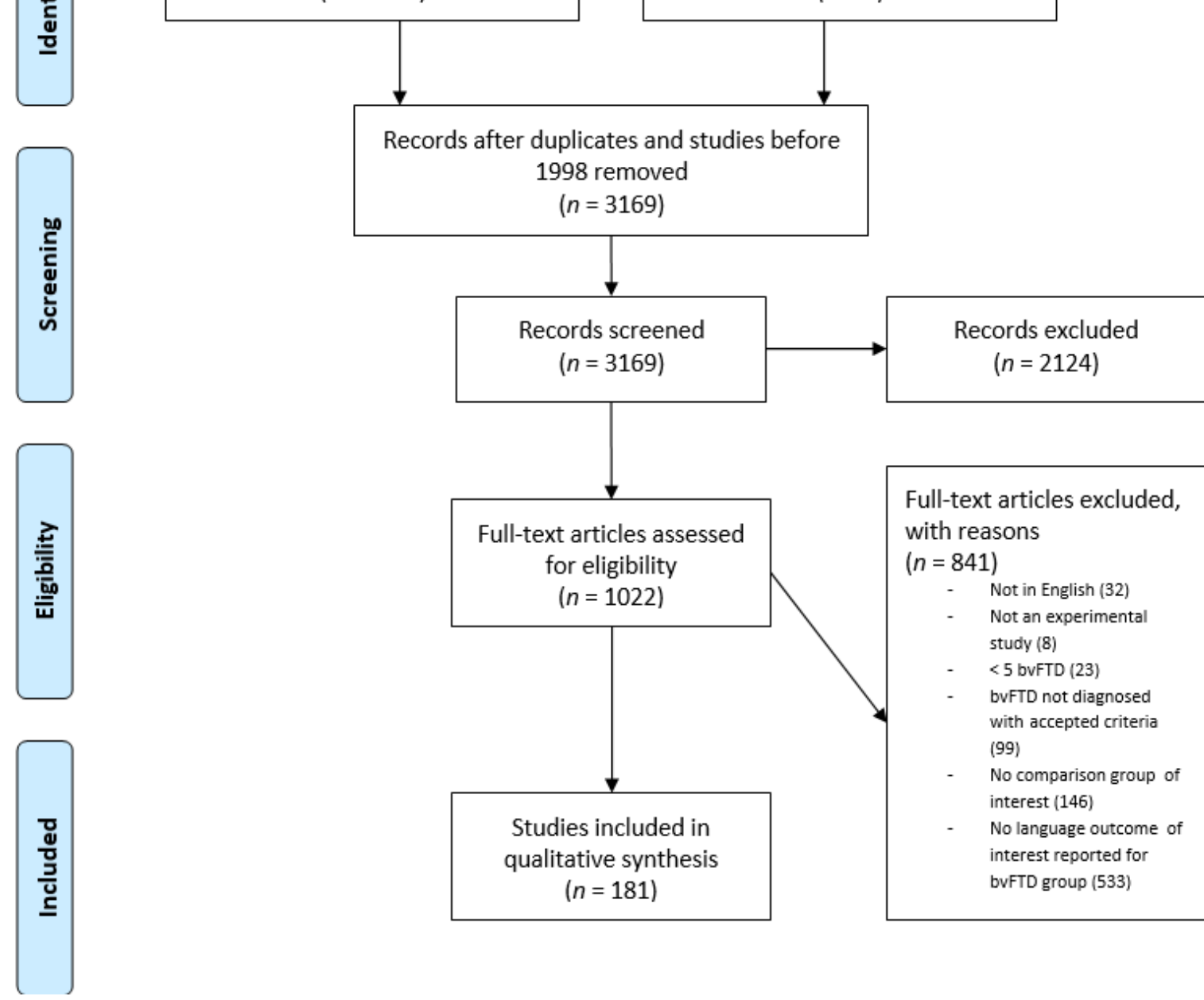
medRxiv preprint doi: https://doi.org/10.1101/2021.07.10.21260313; this version posted July 12, 2021. The copyright holder for this preprint (which was not certified by peer review) is the author/funder, who has granted medRxiv a license to display the preprint in perpetuity.

It is made available under a CC-BY-NC-ND 4.0 International license .

Figure 2: Summary of impaired and preserved language domains in bvFTD, in comparison to healthy controls. For each language subdomains, the number of studies in which the subdomain was altered (red bars) or spared (green bars) is indicated.

\begin{tabular}{|c|c|c|c|}
\hline & Impaired & & No difference \\
\hline Global & 4 & 3 & \\
\hline \multicolumn{4}{|l|}{ Motor speech } \\
\hline - Motor speech & 1 & 1 & \\
\hline - Connected speech & 3 & 7 & \\
\hline \multicolumn{4}{|l|}{ Phonology } \\
\hline - Phonological manipulation & 0 & 1 & \\
\hline - Repetition & 0 & 5 & \\
\hline \multicolumn{4}{|l|}{ Orthography } \\
\hline - Reading & 7 & 0 & \\
\hline - Writing & 1 & 0 & \\
\hline \multicolumn{4}{|l|}{ Lexico-semantic } \\
\hline - Word retrieval & 31 & 18 & \\
\hline - Word comprehension & 8 & 4 & \\
\hline - Semantic knowledge & 28 & 7 & \\
\hline - Connected speech & 6 & 9 & \\
\hline \multicolumn{4}{|l|}{ Grammar/syntax } \\
\hline - Sentence comprehension & 12 & 10 & \\
\hline - Connected speech & 0 & 8 & \\
\hline \multicolumn{4}{|l|}{ Prosody } \\
\hline - Receptive & 3 & 2 & \\
\hline - Productive & 2 & 1 & \\
\hline
\end{tabular}


medRxiv preprint doi: https://doi.org/10.1101/2021.07.10.21260313; this version posted July 12, 2021. The copyright holder for this preprint (which was not certified by peer review) is the author/funder, who has granted medRxiv a license to display the preprint in perpetuity.

It is made available under a CC-BY-NC-ND 4.0 International license .

Figure 3: Risk of bias assessment

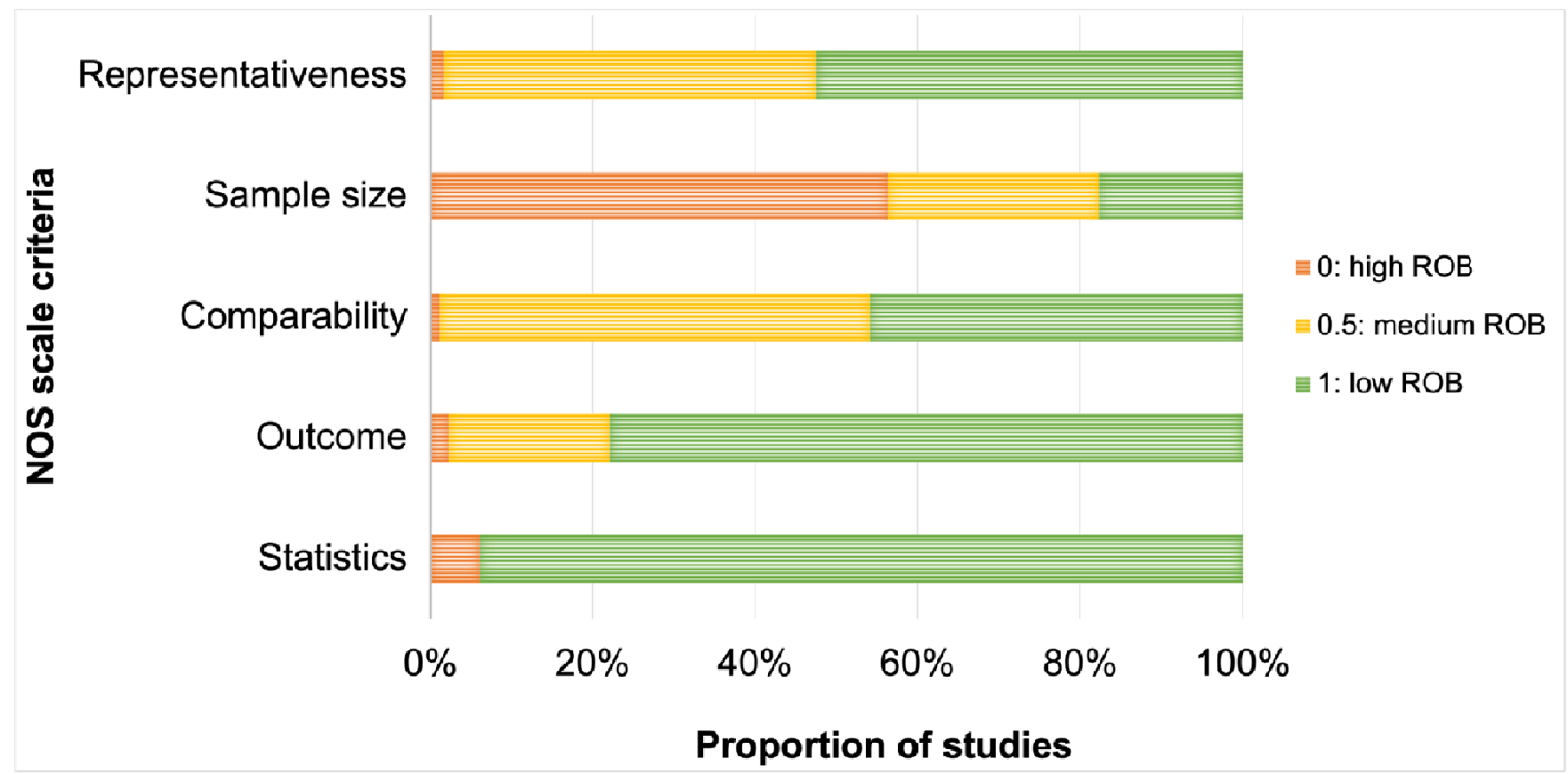


Tables

Table 1. Summary of all included studies comparing bvFTD patients with healthy controls on at least one language measure (Arrow pointing down signifies decreased performance in bvFTD versus healthy controls; Equal sign signifies no significant difference versus healthy controls; Both arrow pointing down and equal sign signifies mixed results; Asterisk signifies that article was not described in the text since another study from the same group and same language measure had a larger sample size).

\begin{tabular}{|c|c|c|c|c|c|c|c|c|c|c|c|c|c|c|}
\hline Authors, year & $\mathrm{HC}(\mathrm{n})$ & bvFTD (n) & Criteria & Language & Age (yo) & MMSE : m (sd) & Symptoms (y) & Global & Motor speech & Phonology & Orthography & Semantic/lexical & Grammar/syntax & Prosody \\
\hline Agosta et al., 2015 & 25 & 14 & 2011 & Italian & $61.6(8.2)$ & - & $3.2(2.2)$ & & & & & & $\downarrow^{*}$ & \\
\hline Ash et al., 2006 & 10 & 12 & 1998 & English & $64.8(13.1)$ & $25.0(6.8)$ & $4.5(1.5)$ & & $\downarrow^{*}$ & & & $=$ & & \\
\hline Ash et al., 2009 & 10 & 12 & 1998 & English & $64.8(13.2)$ & $25.3(6.5)$ & $4.1(1.6)$ & & $\downarrow^{*}=$ & & & & $=$ & \\
\hline Ash et al., 2013 & 12 & 17 & 2011 & English & $64.1(9.1)$ & $26.3(2.7)$ & $5.5(3.8)$ & & $=$ & & & $\downarrow$ & & \\
\hline Ash et al., 2016 & 27 & 54 & 2011 & English & $63.7(8.9)$ & $23.2(6.0)$ & $4.2(2.0)$ & & $=$ & & & $\downarrow$ & & \\
\hline Ash et al., 2019 & 26 & 14 & 2011 & English & $67.1(9.9)$ & $26.7(2.6)$ & $4.1(3.1)$ & & $\downarrow^{*}=$ & & & $\downarrow^{*}$ & & \\
\hline Banks \& Weintraub, 2008 & 15 & 11 & 1998 & English & $63.8(6.3)$ & $24.5(4.2)$ & $5.6(3.3)$ & & & & & $\downarrow$ & & \\
\hline Brambati et al., 2006 & 35 & 27 & 1998 & English & $59.9(6.1)$ & $25.5(3.8)$ & - & & & & & $=$ & & \\
\hline Chan et al., 2015 & 18 & 12 & 1998 & English & $52.5(10.4)$ & - & $3.3(2.1)$ & & & & & $=$ & & \\
\hline Charles et al., 2014 & 12 & 27 & 2011 & English & $62.0(7.1)$ & $25.6(3.9)$ & - & & & & & & $\downarrow$ & \\
\hline Chen et al., 2018 & 35 & 45 & 2011 & English & $60.9(8.0)$ & - & $3.3(1.9)$ & & & $=$ & & $\downarrow$ & & \\
\hline Chiong et al., 2013 & 16 & 10 & 2011 & English & $61.2(6.5)$ & $28.3(1.4)$ & - & & & $\downarrow^{*}$ & & $\downarrow^{*}$ & & \\
\hline Chow et al., 2010 & 10 & 9 & 1998 & English & $59.2(6.4)$ & $27.3(2.0)$ & - & & & & & $=$ & & \\
\hline Clague et al., $2005 \exp 1$ & 41 & 11 & 1998 & English & $60.3(6.9)$ & $27.1(2.0)$ & - & & & & & $\downarrow=$ & & \\
\hline Clague et al., $2005 \exp 2$ & 23 & 11 & 1998 & English & $61.3(5.3)$ & $28.1(2)$ & - & & & & & $=$ & & \\
\hline Clark et al., 2015 & 21 & 22 & 2011 & English & $67(7.7)$ & $25(3.5)$ & $9(5.4)$ & & & & $\downarrow^{*}$ & $\downarrow^{*}$ & & \\
\hline Clark et al., 2016 & 21 & 15 & 2011 & English & $65(7.3)$ & $25(4)$ & $6.3(3.4)$ & & & & $=*$ & $\downarrow^{*}=*$ & & \\
\hline Clark et al., 2017 & 20 & 19 & 2011 & English & $64(7.2)$ & $24.3(4.5)$ & $8.1(6.3)$ & & & & $\downarrow^{*}$ & $\downarrow^{*} \downarrow$ & & \\
\hline Clark et al., 2018 & 22 & 11 & 2011 & English & $65.8(7.6)$ & $25(3.8)$ & $9.8(5.5)$ & & & & $\downarrow^{*}$ & $\downarrow^{*}$ & & \\
\hline Cohen et al., 2016 & 29 & 11 & 2011 & English & $68(8.6)$ & $25.1(2.8)$ & $8.5(5.3)$ & & & & & $\downarrow^{*}=*$ & & \\
\hline Cooke et al., 2003 & 11 & 5 & 1998 & English & $64.4(13.1)$ & $24.4(4.3)$ & - & & & & & & $\downarrow$ & \\
\hline Cosentino et al., 2006 & 15 & 12 & 1998 & English & $67.4(11.7)$ & $22.6(6.4)$ & $6.0(3.1)$ & & & & & $=$ & & \\
\hline Cotelli et al., 2006 & 10 & 16 & 1998 & Italian & $64.8(9.1)$ & $20.3(6.1)$ & - & & & & & $\downarrow$ & & \\
\hline Cotelli et al., 2007 & 10 & 9 & 1998 & Italian & $65.8(8.7)$ & $25.6(1.6)$ & $7.8(3.8)$ & & & & & & $=$ & \\
\hline
\end{tabular}




\begin{tabular}{|c|c|c|c|c|c|c|c|c|c|c|c|c|c|}
\hline Cousins et al., 2016 & 18 & 18 & 2011 & English & $63.9(7.4)$ & $23.6(5.7)$ & $4.9(3.2)$ & & & & & $\downarrow$ & \\
\hline Couto et al., 2013 & 18 & 22 & 2011 & Spanish & $69.8(7.3)$ & $21.7(8.2)$ & - & & & & & $\downarrow$ & \\
\hline Dermody et al., 2016a & 12 & 12 & 2011 & English & $63.2(5.9)$ & - & $5.1(2.7)$ & & & & & $\downarrow^{*}=*$ & \\
\hline Dermody et al., 2016b & 22 & 24 & 2011 & English & $63.0(8.0)$ & - & $3.5(2.4)$ & & & & & $\downarrow^{*}$ & \\
\hline De Winter et al., 2016a & 20 & 19 & 2011 & Dutch & $67.4(8.6)$ & $26.3(2.1)$ & $2.4(1.5)$ & & & & & $\downarrow^{*}$ & $\downarrow^{*}$ \\
\hline De Winter et al., 2016b & 20 & 23 & 2011 & Dutch & $64.5(9.8)$ & $26.7(1.5)$ & - & & & & & $\downarrow$ & $\downarrow$ \\
\hline Downey et al., 2013 & 20 & 20 & 2011 & English & $64(9.3)$ & - & $5.5(5.4)$ & & & & $\downarrow^{*}$ & $\downarrow^{*}$ & \\
\hline Downey et al., 2015 & 37 & 29 & 2011 & English & $64(7.1)$ & - & $7.8(5.3)$ & & & & $\downarrow$ & $\downarrow$ & \\
\hline Eckart et al., 2012 & 25 & 21 & 1998 & English & $55.8(5.6)$ & $25.5(5.5)$ & - & & & & & $\downarrow$ & \\
\hline Farag et al., 2010 & 13 & 10 & 1998 & English & $69.8(9.6)$ & $25.2(3.4)$ & - & & & & & $\downarrow$ & \\
\hline Fernandez-Duque \& Black, 2007 & 14 & 10 & 1998 & French & $61.0(7.5)$ & $26(1.7)$ & - & & & & & $\downarrow$ & $\downarrow$ \\
\hline Filippi et al., 2013 & 30 & 12 & 2011 & Italian & $59(8)$ & $23.3(6.2)$ & $11(4)$ & & & & & & $\downarrow^{*}$ \\
\hline Filippi et al., 2017 & 32 & 38 & 2011 & Italian & $63.8(7.3)$ & $22.7(15.8)$ & $9.6(3.6)$ & & & & & & $\downarrow^{*}$ \\
\hline Fletcher et al., 2015 & 26 & 16 & 2011 & English & 66 & 24.1 & $8.3(6.2)$ & & & & & $\downarrow$ & \\
\hline Fletcher et al., 2016 & 20 & 13 & 2011 & English & 65.2 & - & 7.5 & & & & & $\downarrow$ & \\
\hline Frings et al., 2010 & 16 & 6 & 1998 & German & $63.8(9.4)$ & $26.1(1.9)$ & $2.7(0.9)$ & & & & & $\downarrow$ & \\
\hline Galton et al., 2001 & 18 & 13 & 1998 & English & $58(7.8)$ & $25.6(4.0)$ & $4.5(2.4)$ & & & & & $=*$ & \\
\hline Giovagnoli et al., 2008 & 91 & 40 & 1998 & Italian & $61.1(10.7)$ & - & $3.2(2.0)$ & & & & & & $\downarrow$ \\
\hline Giovagnoli et al., 2019 & 14 & 14 & 2011 & Italian & $56.8(14.9)$ & - & $2.7(1.6)$ & & & & & & $\downarrow^{*}$ \\
\hline Gleichgerrcht et al., 2012 & 14 & 35 & 1998 & Spanish & $68.5(7.3)$ & $26.8(4.9)$ & - & & & & & $\downarrow=$ & $=$ \\
\hline Gola et al., 2015 & 12 & 15 & 2011 & English & $61.5(8.3)$ & $24.5(5)$ & - & & & & & $=$ & \\
\hline Gregory et al., 2002 & 16 & 19 & 1998 & English & $57.1(5.1)$ & $28.7(1.0)$ & - & & & & $\downarrow$ & $\downarrow=*$ & \\
\hline Grossman et al., 2004 & 25 & 14 & 1998 & English & $63.1(12.2)$ & $18.0(6.5)$ & $3.5(2.8)$ & & & & & $\downarrow^{*}=$ & \\
\hline Grossman et al., 2005 & 17 & 8 & 1998 & English & $62.0(7.5)$ & $21.3(6.2)$ & - & & & & & & $\downarrow=*$ \\
\hline Gunawardena et al., 2010 & 13 & 12 & 1998 & English & $63.7(12.2)$ & $24.5(6.9)$ & $3.8(1.4)$ & & $=$ & & & $=* \downarrow$ & \\
\hline Hardy et al., 2016 & 24 & 24 & 2011 & English & $64.6(7.7)$ & $24.0(5.7)$ & $7.8(5.2)$ & & & $=$ & $\downarrow$ & $\downarrow=$ & \\
\hline Healey et al., 2015 & 14 & 12 & 2011 & English & $65.3(1.7)$ & $25.8(1.1)$ & - & & & & & & \\
\hline Healey et al., 2019 & 20 & 20 & 2011 & English & $64.7(9.1)$ & - & $4.5(3.2)$ & & & & & & \\
\hline Henley et al., 2014 & 31 & 20 & 2011 & English & $63.6(9.6)$ & - & - & & & & & $\downarrow^{*}$ & \\
\hline Hoefer et al., 2008 & 25 & 15 & 1998 & English & $62.3(8.7)$ & $20.3(9.6)$ & - & & & & & $\downarrow^{*}$ & \\
\hline Hou et al., 2005 & 8 & 11 & 1998 & English & $62.2(11.5)$ & 24.6 & - & & & & & $=*$ & \\
\hline Hsieh et al., 2012 & 15 & 8 & 2011 & English & $62.9(6.8)$ & - & - & & & & & $\downarrow=$ & \\
\hline Hsieh et al., 2013 & 25 & 12 & 2011 & English & $63.9(8.4)$ & - & $5.3(2.6)$ & $\downarrow^{*}=$ & & & & & \\
\hline Hua et al., 2018 & 25 & 26 & 2011 & English & $63.5(7.7)$ & $23.6(4.2)$ & - & & & & & $=*$ & \\
\hline
\end{tabular}




\begin{tabular}{|c|c|c|c|c|c|c|c|c|c|c|c|c|}
\hline Hughes et al., 2011 & 16 & 12 & 1998 & English & 59.8 & 23.3 & 4.1 & & & $\downarrow$ & & \\
\hline Hutchings et al., 2015 & 17 & 16 & 2011 & English & $64.1(10.3)$ & - & $5.1(5.4)$ & & & $=*$ & & \\
\hline Hutchings et al., 2018 & 21 & 20 & 2011 & English & $62.2(7.4)$ & - & $4.6(2.6)$ & $\downarrow *$ & & & & \\
\hline Irish et al., 2011 & 19 & 15 & 2011 & English & $61.6(7.4)$ & $26.0(2.8)$ & $3.2(2.2)$ & & & $\downarrow=$ & & \\
\hline Irish et al., 2013 & 10 & 10 & 2011 & English & $62.8(7.7)$ & - & $4.8(2.7)$ & & & $=*$ & & \\
\hline Irish et al., 2014a & 14 & 11 & 2011 & English & $62.4(7.3)$ & - & $3.7(2.5)$ & & & $=*$ & & \\
\hline Irish et al., 2014b & 14 & 10 & 2011 & English & $63.6(7.3)$ & - & $5.0(2.6)$ & & & $\downarrow^{*}$ & & \\
\hline Irish et al., 2016 & 20 & 15 & 2011 & English & $63.5(7.7)$ & - & $3.8(2.6)$ & & & $\downarrow^{*}$ & & \\
\hline Jastorff et al., 2016 & 19 & 14 & 2011 & Dutch & $67.2(8.4)$ & $26.6(1.5)$ & - & & & $\downarrow^{*}$ & $\downarrow^{*}$ & \\
\hline Jenner et al., 2006 & 22 & 24 & 1998 & Italian & $73.4(8.5)$ & $23.7(3.0)$ & - & & & $\downarrow$ & & \\
\hline Johnen et al., 2016a & 35 & 24 & 2011 & German & $64.9(8.0)$ & $24.7(5.0)$ & $2.7(1.8)$ & $\downarrow^{*}$ & & & & \\
\hline Johnen et al., 2016b & 34 & 18 & 2011 & German & $65.7(8.4)$ & $23.9(5.5)$ & $2.6(1.5)$ & $\downarrow^{*}$ & & & & \\
\hline Johnen et al., 2018 & 34 & 31 & 2011 & German & $64(8)$ & $28(18)$ & $2.3(1.5)$ & $=$ & & & & \\
\hline Johnson et al., 2011 & 17 & 11 & 1998 & English & $59.8(6.5)$ & $26.3(3.4)$ & - & & & $\downarrow=*$ & $\downarrow$ & \\
\hline Kamminga et al., 2014 & 11 & 8 & 2011 & English & $64.1(2.5)$ & - & $4.6(2.3)$ & & & $=$ & & \\
\hline Kamminga et al., 2015 & 20 & 19 & 2011 & English & $60.5(8.5)$ & - & $4.3(2.8)$ & & & $\downarrow=*$ & & \\
\hline Keane et al., 2002 & 12 & 6 & 1998 & English & $58.7(4.8)$ & $27.3(2.5)$ & $4.0(2.6)$ & & & $=$ & & $\downarrow$ \\
\hline Koenig et al., 2006 & 20 & 6 & 1998 & English & $66.5(10.6)$ & $22.8(4.3)$ & $3.4(0.5)$ & & & $\downarrow$ & & \\
\hline Kramer et al., 2003 & 25 & 21 & 1998 & English & $63.0(11.9)$ & $24.3(4.0)$ & - & & & $=*$ & & \\
\hline Krawczyk et al., 2008 & 10 & 10 & 1998 & English & 61 & 25.9 & 9 & & & $\downarrow$ & & \\
\hline Kumfor et al., 2013a & 27 & 18 & 2011 & English & $63.8(8.2)$ & - & $5.4(2.3)$ & & & $\downarrow^{*}$ & & \\
\hline Kumfor et al., 2013b & 15 & 11 & 2011 & English & $66.7(9.8)$ & - & $6.1(3.5)$ & & & $=*$ & & \\
\hline Kumfor et al., 2014 & 12 & 12 & 2011 & English & $66.5(9.4)$ & - & $5.8(3.1)$ & & & $=*$ & & \\
\hline Kumfor et al., 2015 & 11 & 13 & 2011 & English & $62.5(9.4)$ & - & $5.5(3.8)$ & & & $\downarrow^{*}$ & & \\
\hline Kumfor et al., 2016 & 16 & 13 & 2011 & English & $60.2(8.7)$ & - & $4.3(2.6)$ & & $=*$ & $\downarrow^{*}=*$ & & \\
\hline Kumfor et al., 2017 & 25 & 25 & 2011 & English & $65.0(8.6)$ & - & $4.3(2.3)$ & & & $\downarrow^{*}$ & & \\
\hline Hutchings et al., 2018 & 20 & 19 & 2011 & English & $62.7(8.7)$ & - & $6.4(3.2)$ & & & $\downarrow *$ & & \\
\hline Laisney et al., 2009 & 18 & 18 & 1998 & French & $67.2(7.9)$ & $24.9(3.0)$ & $2.7(1.6)$ & & & $=*$ & & \\
\hline Lima-Silva et al., 2015 & 34 & 20 & 1998 & Portuguese & $67.1(6.6)$ & $23.5(4.3)$ & - & $\downarrow$ & & & & \\
\hline Lin et al., 2016 & 15 & 15 & 1998 & Mandarin & $62.1(6.7)$ & $23.3(4.8)$ & - & & & $\downarrow=$ & & \\
\hline Luzzi et al., 2007 & 20 & 11 & 1998 & Italian & $64(7)$ & $24(6)$ & $4(2)$ & & & $\downarrow=$ & & \\
\hline Luzzi et al., 2020 & 32 & 24 & 1998 & Italian & $64.6(8.7)$ & $23.3(2.6)$ & - & & & $\downarrow$ & $\downarrow$ & \\
\hline Magerova et al., 2014 & 15 & 9 & 1998 & Czech & $63.1(9.2)$ & $24.1(4.8)$ & - & & & $\downarrow$ & & \\
\hline Mahoney et al., 2014 & 18 & 23 & 2011 & English & $63.8(10.0)$ & $25.3(4.2)$ & $6.7(5.1)$ & & & $\downarrow^{*}$ & & \\
\hline
\end{tabular}




\begin{tabular}{|c|c|c|c|c|c|c|c|c|c|c|c|c|c|c|}
\hline Mahoney et al., 2015 & 20 & 27 & 2011 & English & $62.5(9.0)$ & $24.2(5.9)$ & $6.5(4.9)$ & & & & & $\downarrow^{*}$ & & \\
\hline Mandelli et al., 2016 & 34 & 23 & 2011 & English & $62.9(6.5)$ & $26.6(3.5)$ & - & & $=$ & $=$ & & $=*$ & & \\
\hline Manuel et al., 2019 & 25 & 35 & 2011 & English & $61.4(8.7)$ & - & $5.6(3.9)$ & & & & & $\downarrow^{*}$ & & \\
\hline Marshall et al., 2017 & 19 & 16 & 2011 & English & $65.8(7.3)$ & $24.6(4.5)$ & $7.6(4.7)$ & & & & & $\downarrow^{*}$ & & \\
\hline Marshall et al., 2018a & 19 & 10 & 2011 & English & $67(6.3)$ & $24.1(4.9)$ & $8.2(5.3)$ & & & & & $\downarrow^{*}$ & & \\
\hline Marshall et al., 2018b & 21 & 13 & 2011 & English & $66.2(6.3)$ & $24.5(4.6)$ & $7.7(6.0)$ & & & & & $\downarrow^{*}$ & & \\
\hline Marshall et al., 2019 & 22 & 17 & 2011 & English & $68.6(6.8)$ & $23.7(4.8)$ & $7.2(6.3)$ & & & & & $\downarrow^{*}$ & & \\
\hline Matuszewski et al., 2006 & 21 & 20 & 1998 & French & $67.9(9.1)$ & $24.3(4.0)$ & - & & & & & $\downarrow$ & & \\
\hline McKinnon et al., 2008 & 16 & 8 & 1998 & English & $59(6.0)$ & $25.9(3.3)$ & $3.0[2-10]$ & & & & & $=$ & & \\
\hline McMillan et al., 2013 & 16 & 16 & 2011 & English & $64.3(2.0)$ & $24.7(1.2)$ & - & & & & & & $\downarrow$ & \\
\hline Mendez et al., 2014 & 20 & 10 & 2011 & English & $59.2(6.9)$ & $25.4(3.2)$ & $2.3(2.1)$ & & & & & $\downarrow$ & & \\
\hline Miller et al., 2012 & 36 & 17 & 1998 & English & $61(7.8)$ & $27.7(1.3)$ & $3.7(2.4)$ & & & & & $=$ & & \\
\hline Morrison et al., 2004 & 8 & 7 & 1998 & English & 64.7 & 25.7 & - & & & & & $\downarrow$ & & \\
\hline Murray et al., 2007 & 17 & 8 & 1998 & English & $63.8(14.8)$ & $28(1.7)$ & - & & & & & & $\downarrow$ & \\
\hline Nevler et al., 2017 & 17 & 32 & 2011 & English & $63(8.5)$ & $24.4(4.5)$ & $4(3.1)$ & & $\downarrow$ & & & & & $\downarrow$ \\
\hline Oliver et al., 2015 & 22 & 23 & 2011 & French & $64.7(8.5)$ & $22.0(5.1)$ & $6.0(3.4)$ & $\downarrow$ & & & & & & \\
\hline Omar et al., 2011 & 21 & 16 & 1998 & English & $64.7(8.0)$ & $26.9(3.9)$ & $6.9(4.1)$ & & & & & & & $=$ \\
\hline Omar et al., 2013 & 17 & 12 & 1998 & English & $66.1(7.6)$ & $23.5(6.0)$ & - & & & & $\downarrow^{*}$ & $=*=$ & & \\
\hline Orasji et al., 2016 & 11 & 9 & 1998 & Dutch & $73.1(10.3)$ & $25(3)$ & - & & & & & $\downarrow=$ & & \\
\hline Peelle et al., 2007 & 20 & 7 & 1998 & English & $60(10.4)$ & $24(5.1)$ & - & & & & & & $=$ & \\
\hline Peelle et al., 2008 & 29 & 32 & 1998 & English & $65.5(13.0)$ & $21.7(5.4)$ & $3.5(2.8)$ & & $=$ & & & $\downarrow$ & & \\
\hline Perry \& Hodges, 2000 & 10 & 10 & 1998 & English & $59.4(7.6)$ & $26.7(1.6)$ & - & & & & & $=*$ & & \\
\hline Piolino et al., 2007 & 21 & 13 & 1998 & English & $67.2(7.9)$ & $24.8(4)$ & - & & & & & $\downarrow$ & & \\
\hline Pressman et al., 2019 & 170 & 29 & 2011 & English & $60.9(8.8)$ & $25.1(4.8)$ & - & & $=$ & & & & & $=$ \\
\hline Rankin et al., 2007 & 15 & 9 & 1998 & English & $57.0(6.0)$ & $23.1(6.1)$ & - & & & & & $=$ & & \\
\hline Rankin et al., 2009 & 13 & 20 & 1998 & English & $60.0(8.1)$ & $24.6(5.7)$ & - & & & & & & & $=$ \\
\hline Reyes et al., 2018 & 32 & 50 & 2011 & Spanish & $65.9(8.1)$ & $22.5(6.5)$ & $7.3(5.6)$ & & & & & $\downarrow$ & & \\
\hline Reyes et al., 2019 & 33 & 26 & 2011 & Spanish & $64.4(5.7)$ & - & $6.2(5.1)$ & & & & & $=$ & & \\
\hline Rhee et al., 2001 & 10 & 10 & 1998 & English & $65.2(7.4)$ & $24.4(3.0)$ & - & & & & & $\downarrow$ & & \\
\hline Rogers et al., 2006 & 106 & 40 & 1998 & English & $58.6(7.3)$ & - & - & & & & & $\downarrow$ & & \\
\hline Rosen et al., 2002 & 10 & 8 & 1998 & English & $61.8[45-73]$ & $23.3(4.4)$ & - & & & $=*$ & & $=*$ & $=*$ & \\
\hline Rosen et al., 2004 & 22 & 22 & 1998 & English & $61.1(7.4)$ & $24.1(4.4)$ & - & & & & & $=$ & $=$ & \\
\hline Rosen et al., 2014 & 35 & 12 & 1998 & English & $59(7.1)$ & $27.1(2.7)$ & - & & & & & $\downarrow^{*}$ & $=*$ & \\
\hline Rousseaux et al., 2010 & 47 & 16 & 1998 & French & $61[51-78]$ & $27[14-30]$ & - & & & & & $=\downarrow$ & $=$ & \\
\hline
\end{tabular}




\begin{tabular}{|c|c|c|c|c|c|c|c|c|c|c|c|c|c|c|}
\hline Russo et al., 2014 & 40 & 27 & 1998 & Spanish & $66.5(9.6)$ & $25.2(6.3)$ & $3.3(2.2)$ & & & & & $\downarrow$ & & \\
\hline Salimi et al., 2019 & 54 & 51 & 2011 & English & $62(7.5)$ & - & $4.3(3.0)$ & $\downarrow$ & & & & & & \\
\hline Santamaría-García et al., 2017 & 20 & 20 & 2011 & Spanish & $58.9(6.4)$ & $21.6(4.5)$ & $3.1(2.2)$ & & & & & $=$ & & \\
\hline Scherling et al., 2014 & 47 & 45 & 1998 & English & $61(8)$ & $24.6(2.6)$ & $6.5(5.8)$ & & & & & $=$ & & \\
\hline Scherling et al., 2017 & 35 & 17 & 1998 & English & $62.1(8.2)$ & $25.5(2.3)$ & - & & & & & $\downarrow *$ & & \\
\hline Schubert et al., 2016 & 30 & 22 & 2011 & English & $62.7(8.6)$ & - & $4.3(3.0)$ & $\downarrow^{*}$ & & & & & & \\
\hline Semler et al., 2019 & 19 & 12 & 2011 & German & $64[50-81]$ & $26.5[24-30]$ & $2.6[0.9-10]$ & $=$ & & & & & & \\
\hline Shany-Ur et al., 2012 & 77 & 39 & 1998 & English & $61.6(7.3)$ & $25.7(3)$ & - & & & & & & & $\downarrow$ \\
\hline Smits et al., 2015 & 112 & 20 & 1998 & Dutch & $63(8)$ & $26(3)$ & - & & & & & $\downarrow$ & $\downarrow$ & \\
\hline Snowden et al., 2008 & 12 & 12 & 1998 & English & $65(8)$ & $25(3)$ & $5(3)$ & & & & $\downarrow$ & $=$ & & $\downarrow$ \\
\hline Spotorno et al., 2015a & 16 & 17 & 2011 & English & $63(2)$ & $24.9(1.0)$ & $3.5(0.6)$ & & & & & & $\downarrow$ & \\
\hline Spotorno et al., $2015 \mathrm{~b}$ & 12 & 13 & 2011 & English & $66(2)$ & $25.7(4.7)$ & $2.0(0.6)$ & & & & & & $\downarrow$ & \\
\hline Stopford et al., 2012 & 26 & 26 & 1998 & English & $64(6)$ & $23(6)$ & - & & & & & $\downarrow=$ & & \\
\hline Sturm et al., 2018 & 25 & 30 & 2011 & English & $63.5(8.4)$ & $23.7(4.4)$ & - & & & & & $\downarrow$ & & \\
\hline Tan et al., 2015 & 15 & 23 & 2011 & English & $62(10.1)$ & - & $4.0(2.4)$ & & & & & $\downarrow$ & & \\
\hline Torralva et al., 2007 & 10 & 20 & 1998 & Spanish & $67.2(8.1)$ & $27.9(1.6)$ & - & & & & & $\downarrow$ & $=$ & \\
\hline Van den Stock et al., 2015 & 20 & 20 & 2011 & Dutch & $65.7(8.7)$ & $26.7(1.5)$ & - & $\downarrow$ & & & & $\downarrow^{*}$ & & \\
\hline Van den Stock et al., 2017 & 19 & 13 & 2011 & Dutch & $66.6(7.2)$ & $26.6(1.6)$ & $2.1(1.0)$ & & & & & $\downarrow^{*}$ & $\downarrow^{*}$ & \\
\hline Van den Stock et al., 2019 & 19 & 15 & 2011 & Dutch & $67.3(6.7)$ & $26.4(1.6)$ & $2.1(1.0)$ & & & & & $\downarrow^{*}$ & $\downarrow^{*}$ & \\
\hline Vignando et al., 2020 & 21 & 7 & 1998 & Italian & $74.1(5.4)$ & $24.7(4.7)$ & $3.0(1.2)$ & & & & & $\downarrow$ & & \\
\hline Virani et al., 2013 & 18 & 28 & 2011 & French & $65.3(8.1)$ & $20.6(6.9)$ & $5.4(3.3)$ & & & & $\downarrow$ & $\downarrow$ & & \\
\hline Viskontas et al., 2011 & 21 & 12 & 1998 & English & $61.2(7.7)$ & $26.9(2.7)$ & - & & & $=$ & & $=*$ & & \\
\hline Vogel et al., 2017 & 24 & 24 & 2011 & English & $63.2(8.6)$ & - & $5.0(3.5)$ & & $\downarrow$ & $=$ & $\downarrow$ & $\downarrow$ & $=$ & $\downarrow$ \\
\hline Whitwell et al., 2009 & 30 & 66 & 1998 & English & 59 & 26.0 & 3 & & & & & $\downarrow$ & & \\
\hline Wicklund et al., 2004 & 20 & 16 & 1998 & English & $63.2(6.5)$ & $24.7(3.5)$ & - & & & & & $=*$ & & \\
\hline Wicklund et al., 2007 & 228 & 66 & 1998 & English & $62.3(1.4)$ & $22.0(0.8)$ & $3.4(0.3)$ & & & & & $\downarrow$ & & \\
\hline Wilson et al., 2010 & 10 & 10 & 1998 & English & $63.6(9.0)$ & $26.4(3.9)$ & $10.9(5.7)$ & & $=$ & & & $=$ & $=$ & \\
\hline Wilson et al., 2020 & 25 & 19 & 2011 & English & $62.5(8.3)$ & - & $5.7(2.8)$ & & & & & $\downarrow^{*}=*$ & & \\
\hline Yunusova et al., 2016 & 32 & 9 & 2011 & English & $68.4(8.4)$ & $26.4(2.5)$ & $5.2(2.0)$ & & & & $\downarrow$ & & & \\
\hline Zhou et al., 2010 & 12 & 12 & 1998 & English & $60.8(7.7)$ & $25.9(4.0)$ & $3.9(2.0)$ & & & & & $=*$ & & \\
\hline
\end{tabular}


Table 2. Summary of all included studies comparing bvFTD subgroups on at least one language measure

\begin{tabular}{|c|c|c|c|c|}
\hline Author, year & bvFTD subgroups (n) & Language results & Criteria & Language \\
\hline Bertoux et al., 2014 & $\begin{array}{l}\text {-Non-amnesic bvFTD (20) } \\
\text {-Amnesic bvFTD (24) }\end{array}$ & Picture naming did not differ between amnesic and non-amnesic bvFTD. & 2011 & French \\
\hline Bertoux et al., 2016 & $\begin{array}{l}\text {-Non-amnesic bvFTD (19) } \\
\text {-Amnesic bvFTD (19) }\end{array}$ & Picture naming did not differ between amnesic and non-amnesic bvFTD. & 2011 & French \\
\hline Cerami et al., 2016 & $\begin{array}{l}\text {-bvFTD frontal (25) } \\
\text {-bvFTD temporo-limbic (27) }\end{array}$ & Instruction comprehension was more impaired in bvFTD frontal than in temporo-limbic predominant. & 2011 & Italian \\
\hline Deutsch et al., 2015 & $\begin{array}{l}\text {-bvFTD without traumatic brain } \\
\text { injury (581), } \\
\text {-bvFTD with traumatic brain injury } \\
\text { (25) }\end{array}$ & Picture naming did not differ between bvFTD with or without traumatic brain injury & 1998 & English \\
\hline Downey et al., 2014 & $\begin{array}{l}\text {-bvFTD-sporadic (5) } \\
\text {-bvFTD-C9 (5) } \\
\text {-bvFTD-MAPT (7) }\end{array}$ & $\begin{array}{l}\text { Single word comprehension did not differ between the three bvFTD subgroups. Picture naming scores were higher in bvFTD-C } 9 \text { than in } \\
\text { bvFTD-MAPT and controls. }\end{array}$ & 2011 & English \\
\hline Fernández-Matarrubia et al., 2017 & $\begin{array}{l}\text {-Non-amnesic bvFTD (13) } \\
\text {-Amnesic bvFTD (13) } \\
\text { - CTRL (24) }\end{array}$ & Picture naming did not differ between amnesic and non-amnesic bvFTD. & 2011 & Spanish \\
\hline Gleichgerrcht et al., 2011 & $\begin{array}{l}\text {-Non-utilitarian bvFTD (13) } \\
\text {-Utilitarian bvFTD (9) }\end{array}$ & No difference in picture naming or comprehension of instructions between utilitarian and non-utilitarian bvFTD profiles. & 1998 & Spanish \\
\hline Hardy et al., 2016 & $\begin{array}{l}\text {-bvFTD-MAPT (6) } \\
\text {-bvFTD-C9 (4) } \\
\text {-CTRL (24) }\end{array}$ & $\begin{array}{l}\text { Word comprehension and picture naming were lower in bvFTD-MAPT than bvFTD-C9. Concrete and abstract synonyms as well as writing } \\
\text { scores were lower in bvFTD-MAPT than in bvFTD-C9. Verb naming, words and non-words reading, auditory processing, words repetition } \\
\text { and sentence-picture matching did not differ between bvFD-MAPT and bvFTD-C9. }\end{array}$ & 2011 & English \\
\hline Heuer et al., 2020 & $\begin{array}{l}\text {-bvFTD (135) } \\
\text {-bvFTD familial (99) } \\
\text {-bvFTD-C9 (43) } \\
\text {-bvFTD-GRN (14) } \\
\text {-bvFTD-MAPT (28) }\end{array}$ & Regular words, irregular words, sentence reading and sentence repetition did not differ between the bvFTD subgroups. & 2011 & English \\
\hline Kipps et al., 2009 & $\begin{array}{l}\text {-bvFTD MRI abnormal (15) } \\
\text {-bvFTD MRI normal (9) } \\
\text {-CTRL (10) }\end{array}$ & Picture naming did not differ between bvFTD with normal or abnormal MRI. & 1998 & English \\
\hline Kramer et al., 2018 & $\begin{array}{l}\text {-bvFTD with abnormal PET (20) } \\
\text {-bvFTD with normal PET(10) }\end{array}$ & Naming did not differ between bvFTD with a normal or abnormal FDG-PET & 2011 & German \\
\hline Manes et al., 2011 & $\begin{array}{l}\text {-bvFTD with impaired } \\
\text { neuropsychologic performance (30) } \\
\text {-bvFTD with normal } \\
\text { neuropsychologic performance (13) } \\
\text {-CTRL(14) }\end{array}$ & $\begin{array}{l}\text { Picture naming scores were lower in bvFTD with impaired neuropsychologic performance than in ones with normal neuropsychologic } \\
\text { performance. }\end{array}$ & 1998 & Spanish \\
\hline Massimo et al., 2019 & $\begin{array}{l}\text {-bvFTD professionals (50) } \\
\text {-bvFTD non professionals (13) }\end{array}$ & Picture naming performance did not differ between professionals and non professionals bvFTD. & 2011 & English \\
\hline Mendez et al., 2017 & $\begin{array}{l}- \text {-bvFTD PvSp + (9) } \\
\text {-bvFTD PvSp - (3) }\end{array}$ & $\begin{array}{l}\text { Pressure of speech, tangeantiality, derailment and clanging were more frequent in bvFTD with poverty of speech than without, but the } \\
\text { amount of neologisms, word approximations and perseverations, echolalia or blocking, the poverty of the content of speech, its incoherence, } \\
\text { illogicality and loss of goal did not differ between the two bvFTD subgroups }\end{array}$ & 2011 & English \\
\hline Mendez \& Shapira, 2013 & $\begin{array}{l}\text {-bvFTD-FTLD (74) } \\
\text {-bvFTD-AD (21) } \\
\text {-bvFTD-tau negative (51) }\end{array}$ & Picture naming did not differ between bvFTD-FTLD and bvFTD-AD, nor between bvFTD-tau positive and bvFTD-tau negative & 1998 & English \\
\hline
\end{tabular}


-bvFTD-tau positive (23)

\begin{tabular}{|c|c|c|c|c|}
\hline Moore et al., 2020 & $\begin{array}{l}\text {-bvFTD-MAPT (15) } \\
\text {-bvFTD-C9 }(56) \\
\text {-bvFTD-GRN (33) } \\
\text {-CTRL }(248)\end{array}$ & Semantic association scores did not differ between bvFTD due to a MAPT mutation and bvFTD-C9 or bvFTD-GRN. & 2011 & English \\
\hline Park et al., 2017 & $\begin{array}{l}\text {-bvFTD with parkinsonism (33) } \\
\text {-bvFTD without parkinsonism (38) }\end{array}$ & A global language score did not differ between bvFTD with or without parkinsonism. & 2011 & Korean \\
\hline Perry et al., 2017 & $\begin{array}{l}\text { - bvFTD-AD (7) } \\
\text { - bvFTD-FTLD (50) } \\
\text { - bvFTD-FTLD-tau (15) } \\
\text { - bvFTD-FTLD-TDP (31) } \\
\text { - bvFTD-FTLD-FUS (4) } \\
\text { - bvFTD-CBD (6) } \\
\text { - bvFTD-PSP (5) } \\
\text { - bvFTD-TDP-A (5) } \\
\text { - bvFTD-TDP-B (15) } \\
\text { - bvFTD-TDP-C (5) } \\
\text { - bvFTD-TDP-U (6) } \\
\text { - bvFD-aFTLDu (4) }\end{array}$ & $\begin{array}{l}\text { Repetition scores were lower in bvFTD-AD than in bvFTD-FTLD and did not differ between bvFTD-FTLD subgroups. Semantic association } \\
\text { scores were lower in bvFTD-TDP B than in bvFTD-TDP U. Picture naming scores were lower in bvFTD-TDP C than in bvFTD linked to } \\
\text { CBD, TDP U and aFTLD-U. Verbal agility did not differ between the bvFTD subgroups. }\end{array}$ & 2011 & English \\
\hline Ranasinghe et al., 2016 & $\begin{array}{l}\text {-bvFTD Salience Network Frontal- } \\
\text { Temporal (SN-FT) (21) } \\
\text {-bvFTD Semantic Appraisal } \\
\text { Network (SAN) (8) } \\
\text {-bvFTD Salience Network Frontal } \\
\text { (SN-F) (27) } \\
\text {-bvFTD subcortical (30) }\end{array}$ & $\begin{array}{l}\text { Syntax comprehension scores were lower in bvFTD SN-FT than in bvFTD SN-F and bvFTD subcortical. Picture naming scores were lower } \\
\text { in bvFTD SAN than in bvFTD SN-F and bvFTD subcortical. Verbal agility, affect naming, reading irregular words and repetition did not } \\
\text { differ between the bvFTD subgroups. }\end{array}$ & 2011 & English \\
\hline Roca et al., 2013 & $\begin{array}{l}\text {-Low-functioning bvFTD (19) } \\
\text {-High-functioning bvFTD (16) } \\
\text {-CTRL (14) }\end{array}$ & $\begin{array}{l}\text { Picture naming scores were lower in low-functioning bvFTD when compared to high-functioning bvFTD and controls. Semantic } \\
\text { associations were impaired in low-functioning bvFTD when compared to controls but the other subgroups. }\end{array}$ & 1998 & Spanish \\
\hline Sha et al., 2012 & $\begin{array}{l}\text {-bvFTD without C9 (48) } \\
\text {-bvFTD-C9 (15) }\end{array}$ & Syntax, naming, reading and repetition did not differ between bvFTD-C9 and bvFTD without C9 & 2011 & English \\
\hline Suhonen et al., 2017 & $\begin{array}{l}\text {-bvFTD without C9 (44) } \\
\text {-bvFTD-C9 (16) }\end{array}$ & Picture naming and semantic processing did not differ between bvFTD-C9 and bvFTD without C9 expansion. & 2011 & Finnish \\
\hline Torralva et al., 2009 & $\begin{array}{l}\text {-bvFTD with low score on } \\
\text { Addenbrooke Cognitive } \\
\text { Examination (19) } \\
\text {-bvFTD with high score on } \\
\text { Addenbrooke Cognitive } \\
\text { Examination (16) } \\
\text {-CTRL (14) }\end{array}$ & $\begin{array}{l}\text { Picture naming was lower in bvFTD with low score on Addenbroke Cognitive Examination than in bvFTD with high score on Addenbroke } \\
\text { Cognitive Examination. Instructions comprehension was lower bvFTD with low score on Addenbroke Cognitive Examinationthan in bvFTD } \\
\text { with high score on Addrenbroke Cognitive Assessment. }\end{array}$ & 1998 & Spanish \\
\hline Torralva et al., 2015 & $\begin{array}{l}\text {-Non-vascular bvFTD (66) } \\
\text {-Vascular bvFTD (23) }\end{array}$ & Picture naming did not differ between vascular and non-vascular bvFTD. & 1998 & Spanish \\
\hline Ye et al., 2015 & $\begin{array}{l}\text {-bvFTD early onset (47) } \\
\text {-bvFTD late onset (29) }\end{array}$ & Picture naming did not differ between early and late onset bvFTD. & 2011 & Korean \\
\hline
\end{tabular}




\section{Supplementary materials}

Appendix. Modified Newcastle-Ottawa Scale and scoring guide. http://www.ohri.ca/programs/clinical_epidemiology/oxford.asp

\section{(1) Representativeness of the sample (is the case definition adequate?)}

1 point: Requires some independent validation by a multidisciplinary team. The case was defined using multiple sources of information (neurology, neuropsychology, etc.)

0.5 point: No independent validation, but the case was defined using multiple sources of information (neurology, neuropsychology, etc.)

0 point: No description, not done

\section{(2) Sample size}

1 point: Sample size was greater than 30 participants.

0.5 point: Sample size was between 20 and 30 participants.

0 point: Sample size was less than 20 participants or a convenience sample.

\section{(3) Comparability of cases and controls based on the design or analysis}

1 point: Either cases and controls must be matched in the design or confounders (i.e., age, sex, education) must be adjusted for in the analysis.

0.5 point: Cases and controls are only partially matched in the design or confounders (i.e., age, sex, education).

0 point: Both cases and control are not matched in the design and confounders are not adjusted for in the analysis.

\section{(4) Ascertainment of language impairment}

1 point: Validated measurement tool.

0.5 point: Both validated and non-validated measurement tool.

0 point: no description.

\section{(5) Quality of descriptive statistics reporting}

1 point: Reported descriptive statistics to describe the population (e.g., language measures) with a proper measure of dispersion (e.g., standard deviation, standard error, effect size, range, distribution on the graph).

0 point: Descriptive statistics were not reported, were incomplete, or did not include proper measures of dispersion.

Legend: This scale, the scoring of which ranges from 0 to 5, assesses quality in several domains: sample representativeness and size, comparability between patients and controls, ascertainment of language impairment, and statistical quality. Studies were judged to be of low risk of bias ( $\geq 3$ points) or high risk of bias ( $<3$ points). 
Supplementary table 1: Risk of bias assessment for each study included in the systematic review

First Author \& Year

Agosta et al., 2015

Ash et al., 2006

Ash et al., 2009

Ash et al., 2013

Ash et al., 2016

Ash et al., 2019

Banks \& Weintraub, 2008

Bertoux et al., 2014

Bertoux et al., 2015

Brambati et al., 2006

Cerami et al., 2016

Chan et al., 2015

Charles et al., 2014

Chen et al., 2018

Chiong et al., 2013

Chow et al., 2010

Clague et al., 2005

Clark et al., 2015

Clark et al., 2016

Clark et al., 2017

Clark et al., 2018

Cohen et al., 2016

Cooke et al., 2003

Cosentino et al., 2006

Cotelli et al., 2006

Cotelli et al., 2007

Cousins et al., 2016

Couto et al., 2013

Dermody et al., 2016
Representativeness Size Comparability Outcome Statistics Total

$\begin{array}{cccccc}1 & 0 & 0.5 & 1 & 1 & 3.5 \\ 1 & 0 & 0.5 & 0.5 & 1 & 3 \\ 1 & 0 & 1 & 0.5 & 1 & 3.5 \\ 1 & 0 & 0 & 0.5 & 1 & 2.5 \\ 1 & 1 & 1 & 0.5 & 1 & 4.5 \\ 0.5 & 0 & 1 & 0.5 & 1 & 3 \\ 1 & 0 & 0 & 1 & 1 & 3 \\ 0.5 & 1 & 1 & 1 & 1 & 4.5 \\ 1 & 1 & 1 & 1 & 1 & 5 \\ 0.5 & 0.5 & 1 & 1 & 1 & 4 \\ 0.5 & 0.5 & 0.5 & 1 & 1 & 3.5 \\ 1 & 0 & 0.5 & 1 & 1 & 3.5 \\ 0.5 & 0.5 & 1 & 1 & 1 & 4 \\ 1 & 1 & 1 & 1 & 1 & 5 \\ 1 & 0 & 0.5 & 1 & 1 & 3.5 \\ 1 & 0 & 0.5 & 1 & 1 & 3.5 \\ 0.5 & 0 & 0.5 & 1 & 1 & 3 \\ 1 & 0.5 & 1 & 1 & 1 & 4.5 \\ 1 & 0 & 1 & 1 & 1 & 4 \\ 1 & 0 & 1 & 1 & 1 & 4 \\ 1 & 0 & 1 & 1 & 1 & 4 \\ 1 & 0 & 0.5 & 1 & 1 & 3.5 \\ 1 & 0 & 0.5 & 0.5 & 1 & 3 \\ 1 & 0 & 0.5 & 0.5 & 1 & 3 \\ 0.5 & 0 & 0.5 & 1 & 1 & 3 \\ 1 & 0 & 0.5 & 1 & 1 & 3.5 \\ 0.5 & 0 & 0.5 & 0.5 & 1 & 2.5 \\ 1 & 0.5 & 1 & 1 & 1 & 4.5 \\ 0.5 & 0.5 & 1 & 1 & 1 & 4\end{array}$


Dermody et al., 2016

Deutsch, 2015

DeWinter et al., 2016a

DeWinter et al., 2016b

Downey et al., 2013

Downey et al., 2014

Downey et al., 2015

Eckart et al., 2012

Farag et al., 2010

Fernandez-Duque et al., 2007

Fernandez-Matarrubia et al., 2017

Filippi et al., 2013

Filippi et al., 2017

Fletcher et al., 2015

Fletcher et al., 2016

Frings et al., 2010

Galton et al., 2001

Giovagnoli et al., 2008

Giovagnoli et al., 2019

Gleichgerrcht, 2011

Gleichgerrcht et al., 2012

Gola et al., 2015

Gregory et al., 2002

Grossman et al., 2004

Grossman et al., 2005

Gunawarderna et al., 2010

Hardy et al., 2016

Healey et al., 2015

Healey et al., 2019

Henley et al., 2014

Heuer et al., 2020

Hoefer et al., 2008

$\begin{array}{cccccc}1 & 0.5 & 1 & 1 & 1 & 4.5 \\ 0.5 & 1 & 0.5 & 1 & 1 & 4 \\ 1 & 0.5 & 1 & 1 & 1 & 4.5 \\ 1 & 0 & 0.5 & 1 & 1 & 3.5 \\ 1 & 0.5 & 0.5 & 1 & 1 & 4 \\ 1 & 0 & 1 & 1 & 1 & 4 \\ 1 & 0.5 & 0.5 & 1 & 1 & 4 \\ 1 & 0.5 & 0.5 & 1 & 0 & 3 \\ 1 & 0 & 0.5 & 0.5 & 1 & 3 \\ 0.5 & 0 & 1 & 0.5 & 1 & 3 \\ 1 & 0.5 & 1 & 1 & 1 & 4.5 \\ 0.5 & 0 & 1 & 1 & 1 & 3.5 \\ 1 & 1 & 1 & 1 & 1 & 5 \\ 1 & 0 & 1 & 0.5 & 1 & 3.5 \\ 1 & 0 & 1 & 0.5 & 1 & 3.5 \\ 1 & 0 & 0.5 & 0.5 & 1 & 3 \\ 1 & 0 & 0.5 & 1 & 1 & 3.5 \\ 0.5 & 1 & 0.5 & 1 & 1 & 4 \\ 0.5 & 0 & 1 & 1 & 1 & 3.5 \\ 0.5 & 0.5 & 0.5 & 1 & 1 & 3.5 \\ 1 & 1 & 1 & 0 & 0 & 3 \\ 0.5 & 0 & 1 & 0.5 & 1 & 3 \\ 1 & 0 & 0.5 & 1 & 1 & 3.5 \\ 0 & 0 & 0.5 & 0.5 & 1 & 2 \\ 0 & 0 & 0.5 & 0.5 & 1 & 2 \\ 1 & 0 & 1 & 0.5 & 1 & 3.5 \\ 0.5 & 0.5 & 1 & 0.5 & 1 & 3.5 \\ 1 & 0 & 1 & 1 & 1 & 4 \\ 1 & 0.5 & 1 & 1 & 1 & 4.5 \\ 1 & 0.5 & 0.5 & 1 & 1 & 4 \\ 0.5 & 1 & 1 & 1 & 1 & 4.5 \\ 0.5 & 0 & 0.5 & 0 & 0 & 1\end{array}$


Hou et al., 2005

Hsieh et al., 2012

Hsieh et al., 2013

Hua et al., 2018

Hughes et al., 2011

Hutchings et al., 2015

Hutchings et al., 2018

Irish et al., 2011

Irish et al., 2013

Irish et al., 2014a

Irish et al., 2014b

Irish et al., 2016

Jastorff et al., 2016

Jenner et al., 2006

Johnen et al., 2016a

Johnen et al., 2016b

Johnen et al., 2018

Johnson et al., 2011

Kamminga et al., 2014

Kamminga et al., 2015

Keane et al., 2002

Kipps et al., 2009

Koenig et al., 2006

Kramer et al., 2003

Kramer et al., 2018

Krawcyk et al., 2010

Kumfor et al., 2013a

Kumfor et al., 2013b

Kumfor et al., 2014

Kumfor et al., 2015

Kumfor et al., 2016

Kumfor et al., 2017

$\begin{array}{cccccc}1 & 0 & 0.5 & 1 & 1 & 3.5 \\ 0.5 & 0 & 0.5 & 0.5 & 1 & 2.5 \\ 0.5 & 0 & 0.5 & 1 & 1 & 3 \\ 1 & 0.5 & 0.5 & 1 & 1 & 4 \\ 0.5 & 0 & 0.5 & 1 & 1 & 3 \\ 0.5 & 0 & 1 & 1 & 1 & 3.5 \\ 0.5 & 0.5 & 0.5 & 1 & 1 & 3.5 \\ 1 & 0 & 1 & 1 & 1 & 4 \\ 1 & 0 & 1 & 1 & 1 & 4 \\ 1 & 0 & 0.5 & 1 & 1 & 3.5 \\ 1 & 0 & 0.5 & 1 & 1 & 3.5 \\ 1 & 0 & 1 & 0.5 & 1 & 3.5 \\ 1 & 0 & 0.5 & 1 & 1 & 3.5 \\ 1 & 0.5 & 0.5 & 1 & 1 & 4 \\ 1 & 0.5 & 0.5 & 1 & 1 & 4 \\ 1 & 0 & 1 & 1 & 1 & 4 \\ 1 & 1 & 0.5 & 1 & 1 & 4.5 \\ 0.5 & 0 & 1 & 0.5 & 1 & 3 \\ 1 & 0 & 1 & 1 & 1 & 4 \\ 1 & 0 & 1 & 1 & 1 & 4 \\ 0.5 & 0 & 0.5 & 1 & 1 & 3 \\ 1 & 0.5 & 0.5 & 1 & 1 & 4 \\ 1 & 0 & 0.5 & 0.5 & 1 & 3 \\ 0.5 & 0.5 & 0.5 & 1 & 1 & 3.5 \\ 0.5 & 0.5 & 0.5 & 1 & 1 & 3.5 \\ 0.5 & 0 & 0.5 & 1 & 0 & 2 \\ 1 & 0 & 1 & 1 & 1 & 4 \\ 1 & 0 & 1 & 1 & 1 & 4 \\ 1 & 0 & 0.5 & 1 & 1 & 3.5 \\ 1 & 0 & 1 & 1 & 0 & 3 \\ 1 & 0 & 1 & 1 & 1 & 4 \\ 1 & 0.5 & 0.5 & 1 & 1 & 4\end{array}$


Kumfor et al., 2018

Laisney et al., 2009

Lima-Silva et al., 2015

Lin et al., 2016

Luzzi et al., 2007

Luzzi et al., 2020

Magerova et al., 2014

Mahoney et al., 2014

Mahoney et al., 2015

Mandelli et al., 2016

Manes et al., 2011

Manuel et al., 2019

Marshall et al., 2017

Marshall et al., 2018a

Marshall et al., 2018b

Marshall et al., 2019

Massimo et al., 2019

Matuszewski et al., 2006

McKinnon et al., 2008

McMillan et al., 2013

Mendez et al., 2004

Mendez et al., 2013

Mendez et al., 2014

Mendez et al., 2017

Miller et al., 2012

Moore, 2020

Morrison et al., 2004

Murray et al., 2007

Nevler et al., 2017

Oliver et al., 2015

Omar et al., 2011

Omar et al., 2013

\begin{tabular}{|c|c|c|c|c|c|}
\hline 1 & 0 & 1 & 1 & 1 & 4 \\
\hline 0.5 & 0 & 1 & 1 & 1 & 3.5 \\
\hline 0.5 & 0.5 & 1 & 1 & 1 & 4 \\
\hline 0.5 & 0 & 1 & 1 & 1 & 3.5 \\
\hline 0.5 & 0 & 0.5 & 1 & 1 & 3 \\
\hline 0.5 & 0.5 & 1 & 0.5 & 1 & 3.5 \\
\hline 1 & 0 & 0.5 & 1 & 0 & 2.5 \\
\hline 1 & 0.5 & 1 & 1 & 1 & 4.5 \\
\hline 1 & 0.5 & 0.5 & 1 & 1 & 4 \\
\hline 1 & 0.5 & 1 & 1 & 1 & 4.5 \\
\hline 1 & 1 & 1 & 1 & 1 & 5 \\
\hline 1 & 1 & 0.5 & 1 & 1 & 4.5 \\
\hline 0.5 & 0 & 0.5 & 1 & 1 & 3 \\
\hline 0.5 & 0 & 0.5 & 1 & 1 & 3 \\
\hline 0.5 & 0 & 1 & 1 & 1 & 3.5 \\
\hline 0.5 & 0 & 1 & 1 & 1 & 3.5 \\
\hline 1 & 1 & 0.5 & 1 & 1 & 4.5 \\
\hline 0.5 & 0.5 & 0.5 & 0.5 & 1 & 3 \\
\hline 1 & 0 & 0.5 & 1 & 1 & 3.5 \\
\hline 0 & 0 & 0.5 & 0.5 & 1 & 2 \\
\hline 0.5 & 0 & 1 & 1 & 1 & 3.5 \\
\hline 0.5 & 0.5 & 1 & 1 & 1 & 4 \\
\hline 0.5 & 0 & 1 & 1 & 0 & 2.5 \\
\hline 0.5 & 0 & 0.5 & 1 & 1 & 3 \\
\hline 0.5 & 0 & 1 & 1 & 1 & 3.5 \\
\hline 0.5 & 1 & 0.5 & 1 & 1 & 4 \\
\hline 0.5 & 0 & 0.5 & 0.5 & 1 & 2.5 \\
\hline 0.5 & 0 & 0.5 & 1 & 1 & 3 \\
\hline 0.5 & 1 & 1 & 0.5 & 1 & 4 \\
\hline 0.5 & 0.5 & 1 & 1 & 1 & 4 \\
\hline 0.5 & 0 & 1 & 1 & 1 & 3.5 \\
\hline 0.5 & 0 & 1 & 1 & 1 & 3.5 \\
\hline
\end{tabular}


Orasji et al., 2016

Park et al., 2017

Peelle et al., 2007

Peelle et al., 2008

Perry et al., 2000

Perry, 2017

Piolino et al., 2017

Pressman et al., 2019

Ranasinghe et al., 2016

Rankin et al., 2007

Rankin et al., 2009

Reyes et al., 2018

Reyes et al., 2019

Rhee et al., 2001

Roca et al., 2013

Rogers et al., 2006

Rosen et al., 2002

Rosen et al., 2004

Rosen et al., 2014

Rousseaux et al., 2010

Russo et al., 2014

Salimi et al., 2019

Santamaria-Garcia et al., 2017

Scherling et al., 2014

Scherling et al., 2017

Schubert et al., 2016

Semler et al., 2019

Sha et al., 2012

Shany-Ur et al., 2012

Smits, 2015

Snowden et al., 2008

Spotorno et al., 2015a

\begin{tabular}{|c|c|c|c|c|c|}
\hline 1 & 0 & 1 & 0 & 0 & 2 \\
\hline 0.5 & 1 & 1 & 1 & 1 & 4.5 \\
\hline 0.5 & 0 & 0.5 & 0.5 & 1 & 2.5 \\
\hline 0.5 & 1 & 0.5 & 1 & 1 & 4 \\
\hline 0.5 & 0 & 0.5 & 1 & 1 & 3 \\
\hline 1 & 1 & 0.5 & 1 & 1 & 4.5 \\
\hline 0.5 & 0 & 0.5 & 1 & 1 & 3 \\
\hline 0.5 & 0 & 1 & 0.5 & 1 & 3 \\
\hline 1 & 1 & 0.5 & 1 & 1 & 4.5 \\
\hline 1 & 0 & 0.5 & 1 & 1 & 3.5 \\
\hline 1 & 0.5 & 1 & 1 & 1 & 4.5 \\
\hline 1 & 1 & 0.5 & 1 & 1 & 4.5 \\
\hline 1 & 0.5 & 0.5 & 1 & 1 & 4 \\
\hline 0.5 & 0 & 0.5 & 1 & 1 & 3 \\
\hline 0.5 & 1 & 0.5 & 1 & 1 & 4 \\
\hline 1 & 1 & 0.5 & 1 & 1 & 4.5 \\
\hline 0.5 & 0 & 0.5 & 1 & 1 & 3 \\
\hline 0.5 & 0.5 & 0.5 & 1 & 1 & 3.5 \\
\hline 1 & 0 & 0.5 & 1 & 1 & 3.5 \\
\hline 1 & 0 & 1 & 0.5 & 1 & 3.5 \\
\hline 0.5 & 0.5 & 1 & 1 & 1 & 4 \\
\hline 1 & 1 & 1 & 1 & 1 & 5 \\
\hline 1 & 0.5 & 1 & 1 & 1 & 4.5 \\
\hline 0.5 & 1 & 1 & 1 & 1 & 4.5 \\
\hline 1 & 0 & 1 & 1 & 1 & 4 \\
\hline 0.5 & 0.5 & 0.5 & 1 & 1 & 3.5 \\
\hline 0.5 & 0 & 1 & 1 & 1 & 3.5 \\
\hline 1 & 1 & 0.5 & 0.5 & 0 & 3 \\
\hline 1 & 1 & 0.5 & 0 & 0 & 2.5 \\
\hline 0.5 & 1 & 0.5 & 1 & 1 & 4 \\
\hline 0.5 & 0.5 & 0.5 & 1 & 1 & 3.5 \\
\hline 1 & 0 & 1 & 1 & 1 & 4 \\
\hline
\end{tabular}


Spotorno et al., 2015b

Stopford et al., 2012

Sturm et al., 2018

Suhonen et al., 2017

Tan et al., 2015

Torralva et al., 2007

Torralva et al., 2009

Torralva et al., 2015

VanDenStock et al., 2015

VanDenStock et al., 2017

VanDenStock et al., 2019

Vignando et al., 2019

Virani et al., 2013

Viskontas et al., 2011

Vogel et al., 2017

Whitwell et al., 2009

Wicklund et al., 2004

Wicklund et al., 2007

Wilson et al., 2010

Wilson et al., 2020

Ye et al., 2015

Yunusova et al., 2016

Zhou et al., 2010

$\begin{array}{cccccc}1 & 0 & 0.5 & 1 & 1 & 3.5 \\ 0.5 & 0.5 & 0.5 & 1 & 1 & 3.5 \\ 1 & 0.5 & 0.5 & 1 & 1 & 4 \\ 0.5 & 0.5 & 0.5 & 1 & 1 & 3.5 \\ 0.5 & 0.5 & 1 & 1 & 1 & 4 \\ 0.5 & 0.5 & 1 & 1 & 1 & 4 \\ 0.5 & 1 & 1 & 1 & 1 & 4.5 \\ 0.5 & 1 & 0.5 & 1 & 1 & 4 \\ 1 & 0.5 & 1 & 1 & 1 & 4.5 \\ 1 & 0 & 0.5 & 0.5 & 0 & 2 \\ 1 & 0 & 0.5 & 1 & 1 & 3.5 \\ 0.5 & 0 & 0.5 & 1 & 1 & 3 \\ 0.5 & 0.5 & 0.5 & 1 & 1 & 3.5 \\ 0.5 & 0 & 1 & 1 & 1 & 3.5 \\ 0.5 & 0.5 & 0.5 & 0.5 & 1 & 3 \\ 1 & 1 & 1 & 1 & 1 & 5 \\ 0.5 & 0 & 1 & 1 & 1 & 3.5 \\ 0.5 & 1 & 0.5 & 1 & 1 & 4 \\ 0.5 & 0 & 1 & 0.5 & 1 & 3 \\ 0.5 & 0 & 0.5 & 0.5 & 1 & 2.5 \\ 0.5 & 1 & 0.5 & 1 & 1 & 4 \\ 0.5 & 0 & 0.5 & 0.5 & 1 & 2.5 \\ 1 & 0 & 1 & 1 & 1 & 4\end{array}$


PRISMA 2020 Checklist

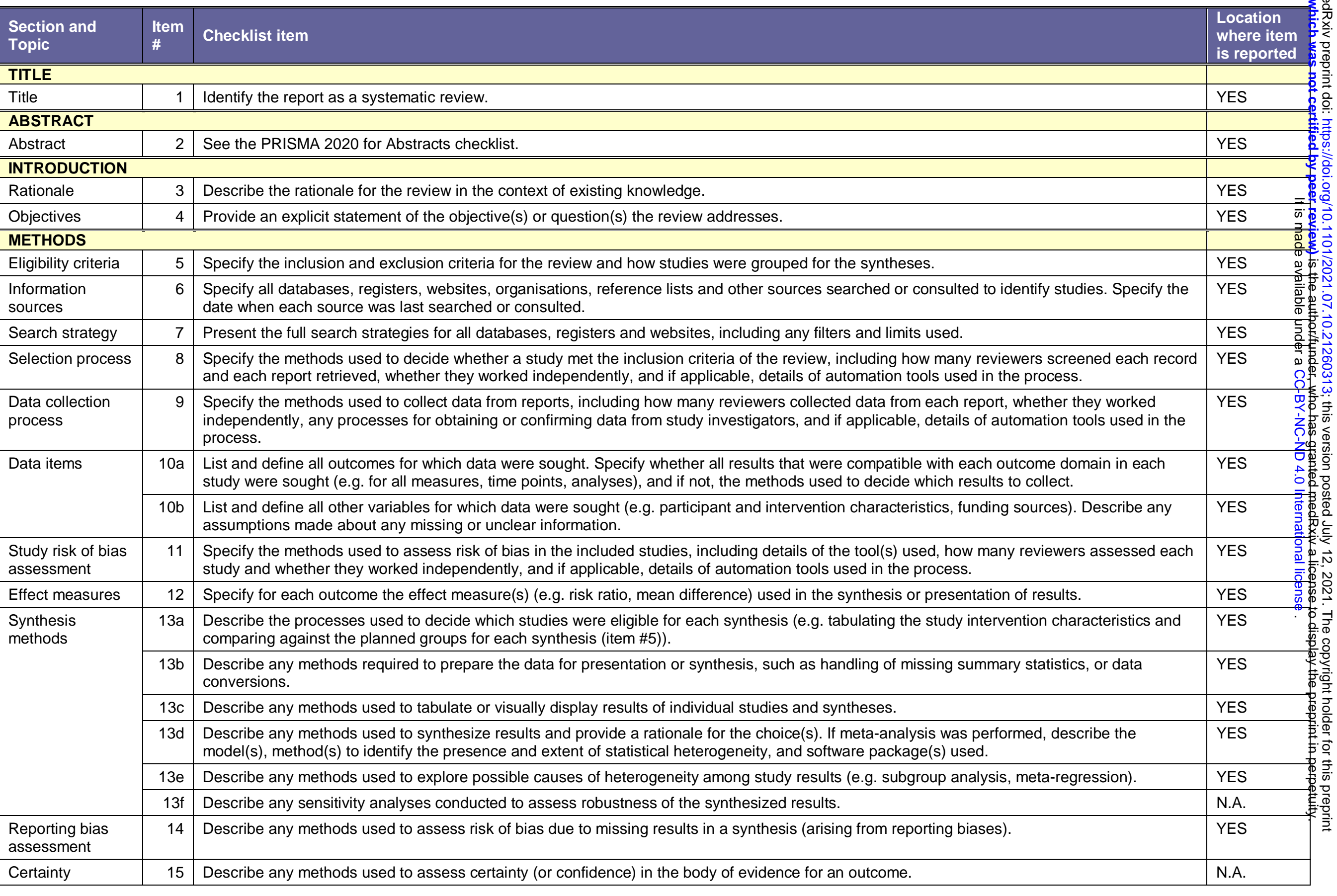


PRISMA 2020 Checklist

\begin{tabular}{|c|c|c|c|c|}
\hline $\begin{array}{l}\text { Section and } \\
\text { Topic }\end{array}$ & $\begin{array}{l}\text { Item } \\
\#\end{array}$ & Checklist item & $\begin{array}{l}\text { Location } \\
\text { where item } \\
\text { is reported }\end{array}$ & \\
\hline \multicolumn{4}{|l|}{ assessment } & \\
\hline \multicolumn{4}{|l|}{ RESULTS } & \\
\hline \multirow[t]{2}{*}{ Study selection } & $16 \mathrm{a}$ & $\begin{array}{l}\text { Describe the results of the search and selection process, from the number of records identified in the search to the number of studies included in } \\
\text { the review, ideally using a flow diagram. }\end{array}$ & YES & \\
\hline & $16 b$ & Cite studies that might appear to meet the inclusion criteria, but which were excluded, and explain why they were excluded. & YES & \\
\hline $\begin{array}{l}\text { Study } \\
\text { characteristics }\end{array}$ & 17 & Cite each included study and present its characteristics. & YES & \\
\hline $\begin{array}{l}\text { Risk of bias in } \\
\text { studies }\end{array}$ & 18 & Present assessments of risk of bias for each included study. & YES & \\
\hline $\begin{array}{l}\text { Results of } \\
\text { individual studies }\end{array}$ & 19 & $\begin{array}{l}\text { For all outcomes, present, for each study: (a) summary statistics for each group (where appropriate) and (b) an effect estimate and its precision } \\
\text { (e.g. confidence/credible interval), ideally using structured tables or plots. }\end{array}$ & YES & \\
\hline \multirow{4}{*}{$\begin{array}{l}\text { Results of } \\
\text { syntheses }\end{array}$} & $20 \mathrm{a}$ & For each synthesis, briefly summarise the characteristics and risk of bias among contributing studies. & YES & \\
\hline & 20b & $\begin{array}{l}\text { Present results of all statistical syntheses conducted. If meta-analysis was done, present for each the summary estimate and its precision (e.g. } \\
\text { confidence/credible interval) and measures of statistical heterogeneity. If comparing groups, describe the direction of the effect. }\end{array}$ & YES & \\
\hline & 20c & Present results of all investigations of possible causes of heterogeneity among study results. & YES & \\
\hline & 20d & Present results of all sensitivity analyses conducted to assess the robustness of the synthesized results. & N.A. & \\
\hline Reporting biases & 21 & Present assessments of risk of bias due to missing results (arising from reporting biases) for each synthesis assessed. & YES & \\
\hline $\begin{array}{l}\text { Certainty of } \\
\text { evidence }\end{array}$ & 22 & Present assessments of certainty (or confidence) in the body of evidence for each outcome assessed. & N.A. & \\
\hline \multicolumn{4}{|l|}{ DISCUSSION } & \\
\hline \multirow[t]{4}{*}{ Discussion } & $23 a$ & Provide a general interpretation of the results in the context of other evidence. & YES & \\
\hline & $23 b$ & Discuss any limitations of the evidence included in the review. & YES & \\
\hline & $23 c$ & Discuss any limitations of the review processes used. & YES & \\
\hline & $23 d$ & Discuss implications of the results for practice, policy, and future research. & YES & \\
\hline \multicolumn{4}{|c|}{ OTHER INFORMATION } & \\
\hline \multirow{3}{*}{$\begin{array}{l}\text { Registration and } \\
\text { protocol }\end{array}$} & $24 a$ & Provide registration information for the review, including register name and registration number, or state that the review was not registered. & N.A. & \\
\hline & $24 b$ & Indicate where the review protocol can be accessed, or state that a protocol was not prepared. & N.A. & \\
\hline & $24 c$ & Describe and explain any amendments to information provided at registration or in the protocol. & N.A. & \\
\hline Support & 25 & Describe sources of financial or non-financial support for the review, and the role of the funders or sponsors in the review. & YES & \\
\hline $\begin{array}{l}\text { Competing } \\
\text { interests }\end{array}$ & 26 & Declare any competing interests of review authors. & YES & \\
\hline $\begin{array}{l}\text { Availability of } \\
\text { data, code and } \\
\text { other materials }\end{array}$ & 27 & $\begin{array}{l}\text { Report which of the following are publicly available and where they can be found: template data collection forms; data extracted from included } \\
\text { studies; data used for all analyses; analytic code; any other materials used in the review. }\end{array}$ & YES & \\
\hline
\end{tabular}

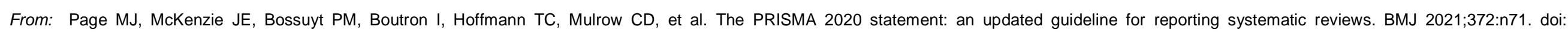


